\author{
UNIVERSIDADE DE SÃO PAULO \\ FACULDADE DE CIÊNCIAS FARMACÊUTICAS \\ Programa de Pós-Graduação em Toxicologia e Análises Toxicológicas
}

\title{
Mecanismos de modulação da anexina A1 sobre a função da proteína translocadora em células da glia
}

Lorena do Nascimento Pantaleão

Tese para obtenção do título de

DOUTOR

Orientador:

Profa. Dra. Sandra Helena Polisselli Farsky

São Paulo

2017 


\author{
UNIVERSIDADE DE SÃO PAULO \\ FACULDADE DE CIÊNCIAS FARMACÊUTICAS \\ Programa de Pós-Graduação em Toxicologia e Análises Toxicológicas
}

\title{
Mecanismos de modulação da anexina A1 sobre a função da proteína translocadora em células da glia
}

Versão corrigida conforme resolução CoPGr 6018

Versão Original encontra-se disponível no Serviço de Pós-Graduação da FCF/USP

Lorena do Nascimento Pantaleão

Orientador:

Profa. Dra. Sandra Helena Polisselli Farsky

São Paulo

2017 
Ficha Catalográfica

Elaborada pela Divisão de Biblioteca e Documentação do Conjunto das Químicas da USP

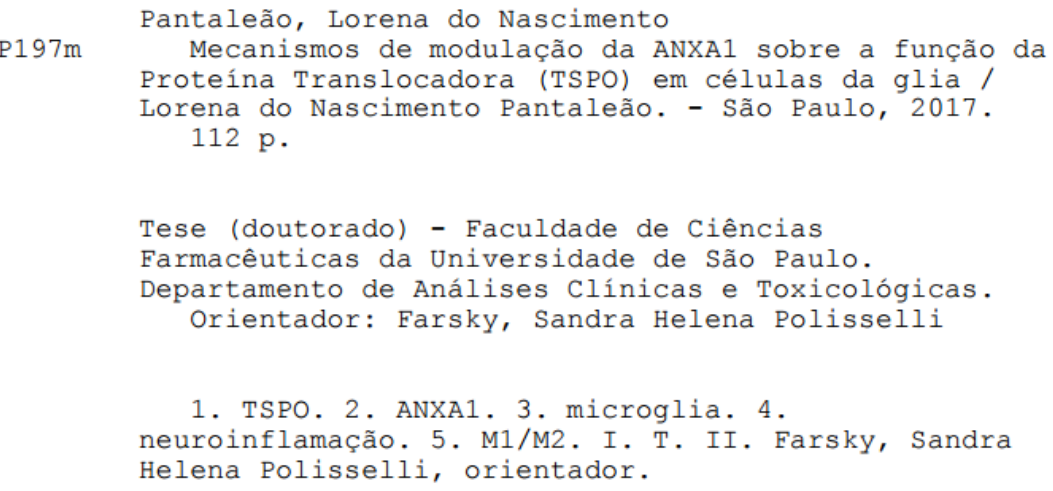


Lorena do Nascimento Pantaleão

\title{
Mecanismos de modulação da anexina A1 sobre a função da proteína translocadora em células da glia
}

\author{
Comissão Julgadora \\ da \\ Tese para obtenção do título de Doutor
}

Sandra Helena Poliselli Farsky

orientador/presidente

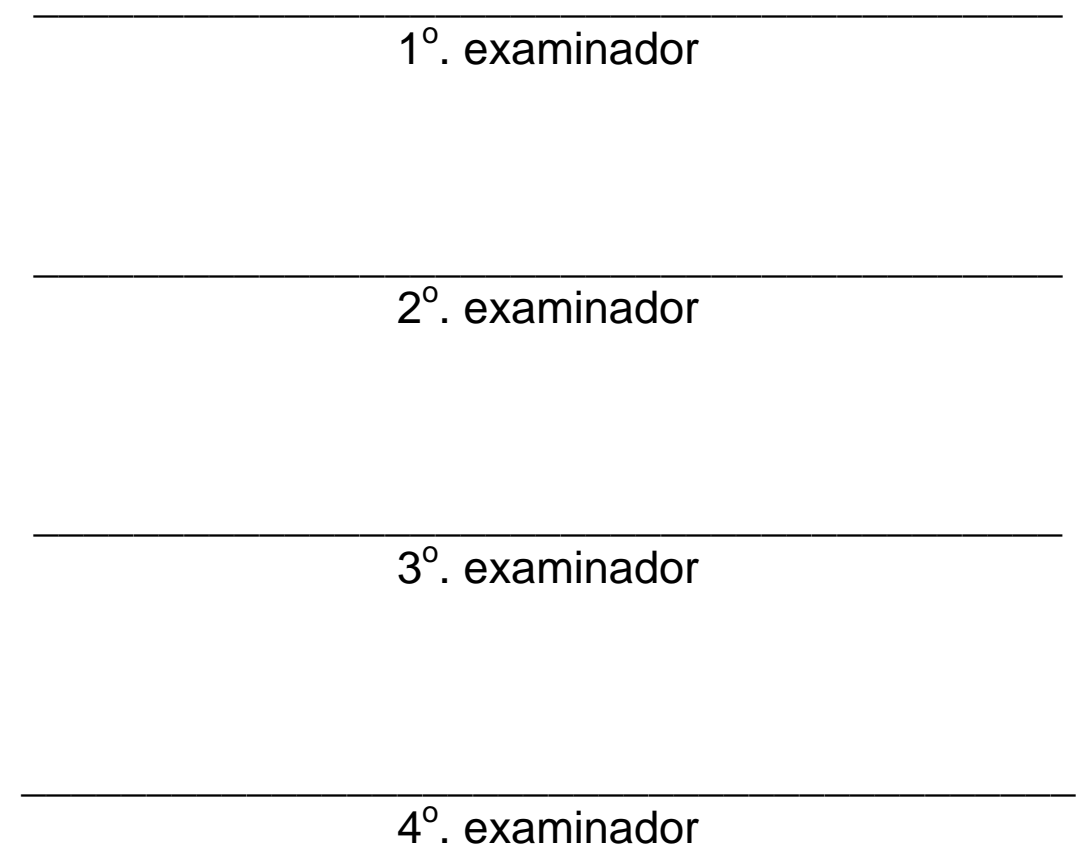

$4^{\circ}$. examinador

São Paulo, de de 2017. 
E ainda que eu conhecesse todos os mistérios e toda a ciência, (...), e não tivesse amor, nada seria (...) O amor é sofredor, é benigno; o amor não é invejoso; o amor não trata com leviandade, não se ensoberbece.

Não se porta com indecência, não busca os seus interesses, não se irrita, não suspeita mal (...) (...)tudo sofre, tudo crê, tudo espera, tudo suporta. O amor nunca falha. 
Aos meus pais Lourenço e Véra, e ao meu amor, amigo, esposo e companheiro Cristian, por serem meu porto seguro, meu ponto de apoio. Vocês me tornam mais forte a cada dia. 


\section{AGRADECIMENTOS}

À Profa Sandra Farsky que se dedica de forma intensa à arte do ensino e da pesquisa com muita competência, empenho e determinação. Sou muito grata por todos os ensinamentos que colhi, ter modelos como este é um privilégio.

Aos amigos do Laboratório de Toxicologia Experimental, Andre Fabris, Cintia Heluany, Cristina Hebeda, Eric Barioni, Gustavo Rocha, Marina de Paula, Silvana Sandri, por esse tempo de convivência, pela acolhida, companheirismo e por compartilharmos nossas vitórias e derrotas.

Aos colegas do Bloco 13B aos que já se foram e aos que ainda permanecem em especial à Ana Carolina Durão, Tiago e Sarah Franco de Oliveira, André Bairros, Marcelo Filonzi, Lívia Sanchez, Sayuri Udo, Mariah Ultramary, Natália Guimarães, Ariane Rivellis, Rapha Caio, Larissa Torres, Isabel Machado, José Roberto Santin, Rodrigo Loiola, Carla Baquedano e Fabiana dos Santos pela convivência, ouvidos e tudo mais.

Aos funcionários em especial à Paula, Beatriz, Stephany, Ângelo, Dona Luzia e Samantha por darem sempre aquela força em todos os momentos.

Ao meu irmão e minha sobrinha, $M^{a}$ Cecília. E toda a minha família sempre me dando força. Sem é claro esquecer os Azevedo Andrade, e nossos sobrinhos, Larissa, Cauã e Letícia. Por tornarem a vida mais leve.

Aos colaboradores deste trabalho, em especial à Profa Silvya Stuchi MariaEngler e à Dra Manoela Tiago pela imensa ajuda com as transfecções.

À Fundação de Amparo à Pesquisa do Estado de São Paulo (FAPESP), pela bolsa e auxílio financeiro sob Processo Número 2013/25903-3 que foram fundamentais para a realização deste trabalho.

E em especial a Deus, o autor da minha vida, que me sustenta e sem o qual eu nada sou e nada posso fazer! 


\section{RESUMO}

\section{Mecanismos de modulação da anexina A1 sobre a função da proteína translocadora em células da glia}

A inflamação no sistema nervoso central (SNC) está envolvida na gênese de uma série de doenças neurodegenerativas, sendo assim, compreender o processo inflamatório nessas circunstâncias se torna essencial para propor novas abordagens terapêuticas. Sabemos que a Anexina A1 (ANXA1) e o receptor TSPO são dois moduladores importantes da neuroinflamação. Enquanto se sabe que a ANXA1 possui propriedades antiinflamatórias, o papel do TSPO ainda não está esclarecido. Desta forma, este projeto avaliou a atuação da ANXA1 sobre a expressão do TSPO em linhagem de células da microglia (BV2), e sua conexão com o receptor Toll-like receptor-4 (TLR4) em BV2 ativada pelo lipopolisacarídeo de E.coli (LPS). Os resultados obtidos mostram que o tratamento de BV2 com LPS induz a expressão de TSPO, dependente de ativação de TLR4, através das vias da molécula adaptadora do fator de diferenciação mielóide 88 (MyD88) e do fator nuclear KB (NFkB). $O$ tratamento com ANXA1 recombinante induz um perfil antiinflamatório em células BV2 estimuladas com LPS, por reduzir a secreção de citocinas proinflamatórias e, ao mesmo tempo, aumentar secreção de citocinas antiinflamatórias. A exposição com ANXA1 ainda impede o aumento da expressão de TSPO induzida pelo LPS. Mostramos também que esta ação da ANXA1 é dependente da interação com o receptor de peptídeo formilado (FPR2). Adicionalmente, o silenciamento de TSPO em células BV2 predispõe essas células a um perfil ativado exacerbando a secreção do fator de necrose tumoral (TNFa) em resposta ao LPS, o que não pode ser revertido pelo tratamento com ANXA1 recombinante. Em conjunto, os resultados expõe a relação existente entre ANXA1 e TSPO em micróglia ativada pelo LPS, mostrando que a ANXA1 
modula negativamente a expressão do TSPO. Ademais, o silenciamento de TSPO inibiu a fagocitose de neurônios apoptóticos, o que ainda sugere a participação do TSPO na eferocitose.

Palavras Chave: TSPO, ANXA1, microglia, neuroinflamação, M1/M2. 


\section{ABSTRACT \\ Annexin A1 modulation mechanism on the expression of the Translocator Protein (TSPO) in BV2 cells}

Inflammation in the Central Nervous System (CNS) is involved in the genesis of a number of neurodegenerative diseases, so understanding the inflammatory process in these circumstances is essential to proposal new therapeutic approaches. We know that Annexin A1 (ANXA1) and the TSPO receptor are two important modulators of neuroinflammation. While it is known that ANXA1 has anti-inflammatory properties, the role of TSPO has not yet been clarified. Thus, this project evaluated the interference of ANXA1 on the expression of TSPO in microglia cell line (BV2), and its connection with the Toll-like receptor-4 receptor (TLR4) in BV2 activated by E. coli lipopolysaccharide LPS). The results show that the treatment of BV2 with LPS induces the expression of TSPO, dependent on activation of TLR4, through the pathways of the adapter molecule of myeloid differentiation factor 88 (MyD88) and nuclear factor KB (NFKB). Treatment with recombinant ANXA1 induces an anti-inflammatory profile in LPS-stimulated BV2 cells, by reducing the secretion of proinflammatory cytokines and, at the same time, increasing secretion of anti-inflammatory cytokines. Exposure with ANXA1 still prevents the increase of LPS-induced TSPO expression. We also show that this action of ANXA1 is dependent on the interaction with the formylated peptide receptor (FPR2). In addition, TSPO silencing in BV2 cells predisposes these cells to an activated profile exacerbating secretion of tumor necrosis factor (TNFa) in response to LPS, which can not be reversed by treatment with recombinant ANXA1. Together, the results show the relationship between ANXA1 and TSPO in LPS activated microglia, showing that ANXA1 negatively modulates TSPO 
expression. In addition, TSPO silencing inhibited the phagocytosis of apoptotic neurons, which still suggests the participation of TSPO in eferocytosis.

Key words: TSPO, ANXA1, microglia, neuroinflamation, M1/M2 


\section{LISTA DE ILUSTRAÇÕES}

Figura 1: Polarização das células da microglia 29

Figura 2: Representação esquemática do receptor de TSPO

Figura 3: Mapa dos plasmídeos $p R c / C M V$ utilizados para transfecção do gene de ANXA1. O fragmento contendo a sequência anti-senso para ANXA1. 47

Figura 4: Mapa dos plasmídeos $p R c / C M V$ utilizados para transfecção do gene de ANXA1. O fragmento contendo a sequência full lenght para ANXA1. 47

Figura 5: Mapa dos plas mídeos pLKO.1 contendo inserto shRNA. 48

Figura 6: Curva de crescimento para células BV2 em presença de concentrações crescentes de LPS 52

Figura 7: Secreção de IL-1ß (A) e IL-4 (B) por células BV2 frente a concentrações crescentes do LPS ao longo do tempo 53

Figura 8: Expressão proteica de TSPO, em função de diferentes concentrações do estímulo inflamatório (LPS) ao longo do tempo 54

Figura 9: Expressão proteica de TSPO avaliada por citometria de fluxo em células BV2 estimuladas com LPS.

Figura 10: Efeito do tratamento com ANXA1 e/ou LPS sobre a expressão de IL-1 $1 \beta$

Figura 11: Efeitos dos tratamentos com ANXA1 e/ou LPS sobre a expressão de TGF $\beta$

Figura 12: Efeitos dos tratamentos com ANXA1 e/ou LPS sobre a secreção de TNF- $\alpha$ 60

Figura 13: Efeitos do tratamento com ANXA1 e/ou LPS sobre a secreção de IL-6. 
Figura 14: Efeitos dos tratamentos com ANXA1 e/ou LPS sobre a secreção de IL-10 62

Figura 15: Efeito do silenciamento de ANXA1 em células BV2 sobre a secreção de IL-1 e TNF

Figura 16: Efeito do silenciamento de TSPO em células BV2 e a relação com a ANXA1 sobre a secreção de IL-1 65

Figura 17: Efeito do silenciamento de TSPO em células $B V 2$ e a relação com a ANXA1sobre a secreção de TNF. 65

Figura 18: Efeito do silenciamento de TSPO em células BV2 e a relação com a ANXA1 sobre a secreção de TGF 66

Figura 19: Efeito do silenciamento de TSPO em células BV2 e a relação do TSPO com a ANXA1 sobre a expressão de CD40

Figura 20: Efeito do silenciamento de TSPO em células BV2 e a relação do TSPO com a ANXA1 sobre a expressão de CD36

Figura 21: Expressão de TSPO em células BV2 normais (A); tratadas com RSLPS (B); ou silenciadas parao gene de TSPO (C)

Figura 22: Expressão de TSPO em células BV2 normais (A); tratadas com WRW4 (B); ou silenciadas parao gene de TSPO (C) 73

Figura 23: Expressão de TSPO em células BV2 tratadas com anti-NFkB e antiMyD88 por uma hora

Figura 24: Expressão de TSPO em células BV2 normais (A); tratadas com WRW4 (B); ou silenciadas parao gene de TSPO (C) incubadas com LPS por 4 horas

Figura 25: TSPO está envolvido na fagocitose em células BV2.

Figura 26: Mecanismo proposto para ação da ANXA1 sobre a expressão de TSPO. 
Figura 27: Curva de crescimento comparativa das células que receberam plasmídeo contendo a sequancia anti-senso para ANXA1 (ANXA -) e a sequência full leght (SUPER) após a transfecção

Figura 28: Níveis de ANXA1 intracelular utilizando a técnica de ELISA (A) e Western Blotting (B) .82

Figura 29: Resultados da caracterização de células BV2 transfectadas utilizando a técnica de citometria de fluxo 84

Figura 30: Curva de crescimento comparativa das células que receberam plasmídeo contendo a sequência anti-senso para TLR4 (TLR4-/-) e a sequência anti-senso para TSPO (TSPO-/-)

Figura 31: Resultados da caracterização de células BV2 transfectadas utilizando a técnica de citometria de fluxo 86

Figura 32: Curva de crescimento comparativa das células que receberam plasmídeo contendo a sequência anti-senso para TLR4 (TLR4-/-) e a sequência anti-senso para TSPO (TSPO-/-) .85

Figura 33: Níveis de TLR4 (A) e TSPO (B) intracelular utilizando a técnica de citometria de fluxo 86 


\section{LISTA DE TABELAS}

Tabela 1: Marcadores com expressão associada a um fenótipo específico de

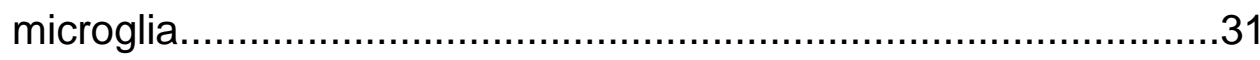




\section{LISTA DE ABREVIATURAS}

$A \beta$

placa beta amiloide

$A B C$

ATP-binding cassete

AD

Alzheimer disease

ANOVA Análise de Variância

ANXA1 Anexina A1

ATP

Adenosina Trifosfato

BHE

Barreira-hematoencefálica

CCL2 Quimiocina quimioatraeente para monócitos (MCP-1)

CD36 Cluster of Differentiation 36

CD206 Cluster of Differentiation 206

COX-2 Ciclo-oxigenase-2

EM Esclerose Múltipla

fMLP N-formylmethionyl-leucyl-phenylalanine peptide

FPR2 Formyl peptide receptor 2

IL-1 $\beta \quad$ Interleucina $1 \beta$

IL-1Ra receptor antagonista da IL-1

IL-4 Interleucina 4

IL-6 Interleucina 6

IL-10 Interleucina 10

IL-12 Interleucina 12

IL-13 Interleucina 13 
$\begin{array}{ll}\text { INFY } & \text { Interferon gama } \\ \text { iNOS } & \text { Óxido nítrico sintase induzida }\end{array}$

LPS Lipopolissacarídeo

MyD88 Myeloid differentiation primary response gene 88

NF-kB Factor Nuclear kappa B

NO Óxido nítrico

OGD/R Privação de oxigênio e glicose / reperfusão

PAMP Padrões moleculares associados a patógenos

PD Parkinson disease

PDTC Ammonium pyrrolidinedithiocarbamate

ROS Espécie reativa de oxigênio

RS-LPS Lipopolissacarídeo de Rhodobacter sphaeroides

SNC Sistema Nervoso Central

SOCS3 Suppressor of cytokine signaling 3

TLRs Receptores tipo Toll

TLR2 Toll-like receptor 2

TLR4 Toll-like receptor 4

TNF- $\alpha \quad$ Factor de necrose tumoral alfa

TRIF TIR-domain-containing adapter-inducing interferon- $\beta$

TSPO Translocator Protein 18kDA 


\section{SUMÁRIO}

1 - INTRODUÇÃO

1.1 - Inflamação. 21

1.2 - Neuroinflamação. .24

1.3 - Microglia. 26

1.3.1 - Polarização M1/M2 28

1.4 - Translocator Protein 18Kda (TSPO) 32

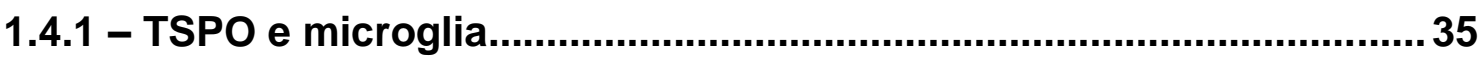

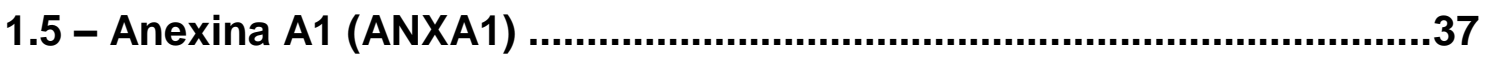

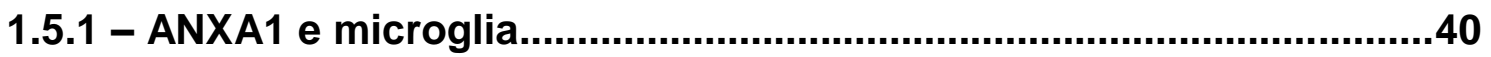

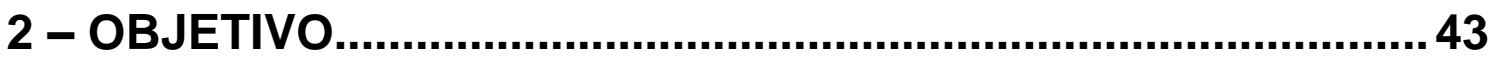

3 - MATERIAL E MÉTODOS........................................................ 44

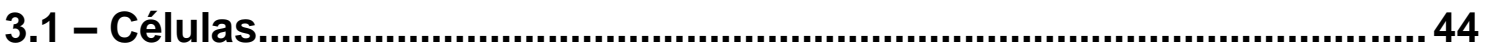

3.2 - Reagentes empregados no estudo....................................................... 44

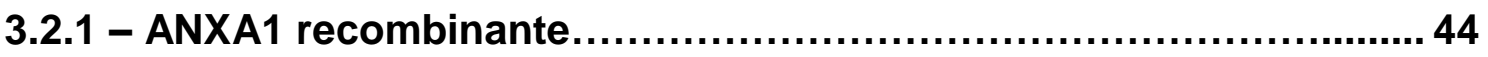

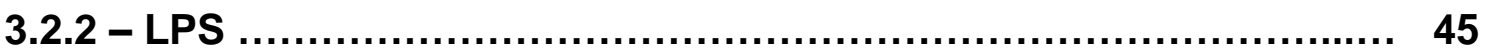

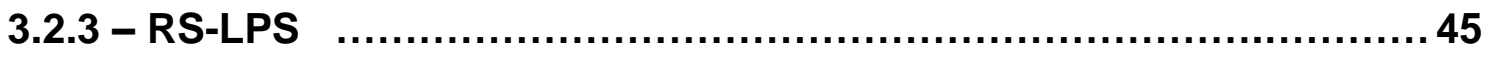

3.2.4 - WRW4 


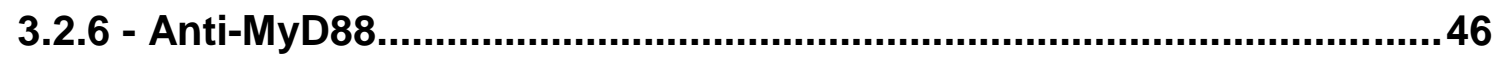

3.3 - Silenciamento e Superexpressão de ANXA1 ....................................... 46

3.4 - Silenciamento de TLR4 e TSPO...................................................... 48

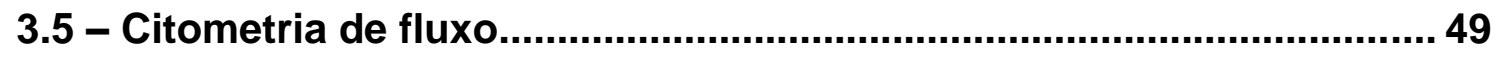

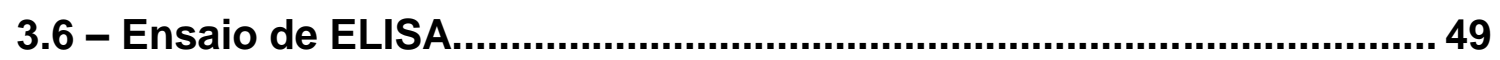

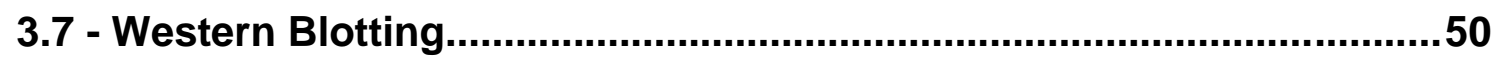

3.8 - Fagocitose de células PC-12 apoptóticas............................................51

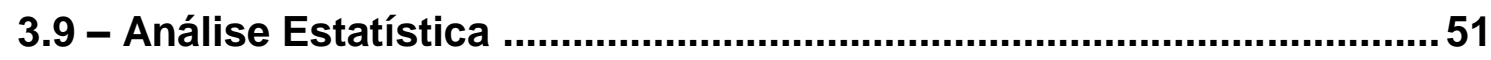

4 - RESULTADOS E DISCUSSÃO......................................... 52

4.1 - Responsividade de células BV2 frente ao LPS.............................. 52

4.2 - Influência do LPS na expressão do TSPO..........................................54

4.3 - Influência da ANXA1 na expressão de TSPO.......................................56

4.4 - Influência da ANXA1 sobre a secreção de mediadores inflamatórios

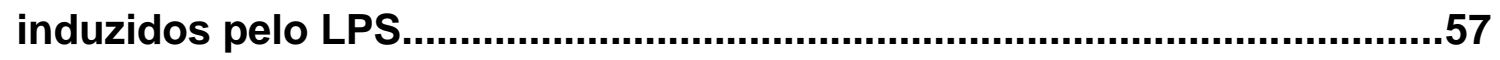

4.5 - Participação do receptor TSPO e sua correlação com a ANXA1 na secreção de mediadores inflamatórios induzidos pelo LPS........................ 65

4.6 - Participação do receptor de TLR4 na modulação da ANXA1 sobre TSPO

4.7 - Participação de proteínas intermediárias da via do TLR4 na modulação da ANXA1 sobre TSPO...................................................... 72 
4.8 - Participação do receptor FPR2 na modulação da ANXA1 sobre TSPO 75

4.9 - Participação do TSPO na fagocitose de células BV2 …….............. 76

4.10 - Resultados complementares....................................... 79

4.10.1 - Silenciamento e superexpressão de ANXA1 em células BV2... 79

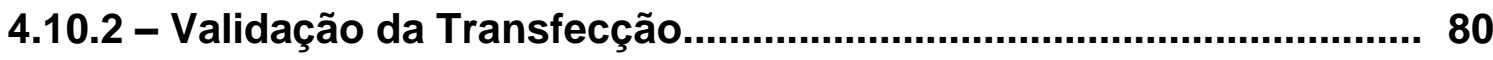

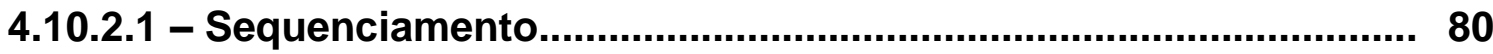

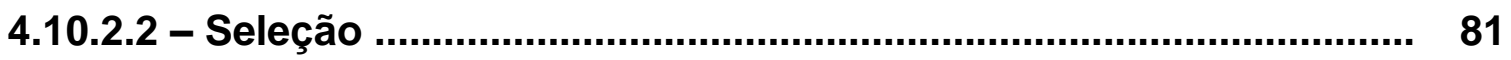

4.10.2.3 - Caracterização das células após a tranfecção........................... 82

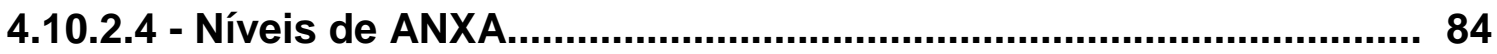

5- CONCLUSÕES ............................................................... 86

6- REFERÊNCIAS BIBLIOGRÁFICAS.................................... 87

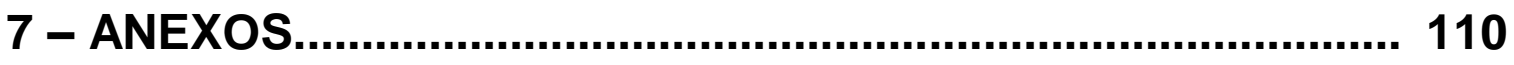




\section{1 - INTRODUÇÃO}

\section{1 - Inflamação}

Inflamação é a resposta do sistema imune com o objetivo de defender o organismo do dano celular. Esta resposta pode ser desencadeada por estímulos assépticos (como em cirurgias) ou não assépticos (como em infecções virais e bacterianas), químicos (toxinas) ou ainda fatores como necrose tecidual. A reação inflamatória aguda é caracterizada por uma série de eventos interrelacionados, que consiste em respostas vasculares, celulares e ativação de sistemas presentes no sangue circulante (LYMAN et al., 2014; ABBAS \& JANEWAY, 2000). De uma maneira generalizada, alterações hemodinâmicas (como modificações no fluxo sanguíneo da microcirculação) e ativações celulares (como dos leucócitos circulantes ou de células residentes) atuam para desencadear a inflamação. Este processo é complexo e regulado por substâncias químicas secretadas por diferentes células e também por ativação de sistemas plasmáticos (ROSEN, 2004).

Leucócitos, derivados do sistema de fagócitos mononucleares possuem a capacidade de penetrar o interstício para exercer suas funções fagocíticas e apresentadoras de antígenos. Substâncias sinalizadoras são outros importantes atores no processo inflamatório e incluem desde moléculas mais simples como o óxico nítrico (NO) quanto componentes lipídicos complexos como prostaglandinas, ou ainda proteínas como citocinas (LYMAN et al., 2014). Também ganham destaque os receptores tipo Toll (TLRs). Estes receptores detectam produtos de natureza microbiana desempenhando um papel central na imunidade inata e adaptativa (JANEWAY, 1989, LEHNARDT et al., 2003; SCARF \& KASSIOU, 2013). TLR2 e TLR4 são dois dos componentes mais bem conhecidos e caracterizados entre os TLRs e são capazes de responder a estímulos provenientes de antígenos de natureza bacteriana. O TLR2 é um receptor de superfície que reconhece padrões moleculares associados a patógenos (PAMPS) que são tipicamente associados a bactérias gram positivas como, por exemplo, lipoproteínas, peptideoglicanos, zymozan, porfirinas entre outros (ALIPRANTIS et al., 1999). 
Já o TLR4 é um receptor de superfície que também reconhece o lipopolissacarídeo (LPS) de bactérias gram negativas (HOSHINO et al., 1999; PARK \& LEE, 2013). A transdução de sinal que se segue após o reconhecimento de LPS pelo complexo do TLR4 é um componente essencial da imunidade do hospedeiro (PARK \& LEE, 2013). A sinalização de TLR4 através das vias dependentes de MyD88 e TRIF promovem produção de citocinas próinflamatorias ou IFN (TAKEDA \& AKIRA, 2006). Adicionalmente aos PAMPS, várias moleculas endógenas são capazes de ativar TLRs como, por exemplo, proteínas do tipo heat-shock, ácido hialurônico e lipoproteína de baixa densidade. $O$ desencadeamento do sinal de TLRs tem o objetivo inicial de eliminar o invasor, iniciar reparo de tecidos que sofreram dano além de iniciar respostas imunes adaptativas (JANEWAY, 1989, SCARF \& KASSIOU, 2013; AKIRA \& TAKEDA, 2006).

No contexto da inflamação, o organismo modula negativamente 0 processo, no sentido de limitar a intensidade da agressão para o retorno da homeostasia e reparo tecidual (ABBAS \& JANEWAY, 2000; WYSS-CORAY \& MUCKE, 2002). Quando bem controlada, a resposta inflamatória exibe um ajuste delicado a fim de promover clearance de patógenos sem causar dano ao indivíduo através de feedbacks e regulação negativa até a remoção do estímulo (LIEW et al., 2005). O clearance de patógenos é orquestrado através de uma combinação de peptídeos antimicrobianos, mediadores inflamatórios e processos como a fagocitose e a autofagia (BECKER \& O'NEIL, 2007).

A resposta inflamatória inicial é de essencial para a manutenção da homeostase do organismo, porém, quando mantida de forma extensiva pode, ela mesma, ser responsável por dano tecidual e doenças neurodegenerativas. A inflamação crônica ocorre quando existe uma falha na regulação do processo que prejudica a homeostasia corporal de forma local ou sistêmica como em caso de doenças auto-imunes (artrite, esclerose múltipla, Alzheimer, lúpus eritematoso sistêmico e aterosclerose) (KRAMER \& GENCO, 2017; WYSSCORAY \& MUCKE, 2002; FU et al., 2014). 
Já está documentado que existe uma conexão entre os sistemas imune da periferia do corpo e do sistema nervoso central (SNC) uma vez que estímulos inflamatórios induzidos na periferia podem induzir efeito central. Sendo assim, inflamações periféricas podem dar origem a respostas neuroinflamatórias envolvendo a barreira-hematoencefálica (BHE), células da glia e neurônios. (REUS et al., 2015; de VRIES et al., 1996).

Várias doenças no SNC são caracterizadas por deficiências na regulação de inflamações (NATHAN \& DING, 2010). Já está documentado que a presença de citocinas pró-inflamatórias como o TNF- $\alpha$ e IL-1 $\beta$ juntamente com PAMPs estão associados com indução de estados que incluem fadiga, febre, sonolência e hiperalgesia (DANTZER \& KELLEY, 2007). A ativação do sistema imune inato e a liberação de agentes pró-inflamatórios no foco da lesão podem até mesmo prejudicar a memória imunológica no SNC, contribuindo para diversas disfunções (SIMONE \& TAN, 2011). O papel desempenhado por citocinas pro-inflamatórias em condições neurodegenerativas possui uma grande importância podendo prejudicar até mesmo estados cognitivos do indivíduo (ECKENHOFF \& LAUDANSKY, 2013; FU et al., 2014).

Além disso, a literatura mostra que a inflamação está relacionada com o processo de envelhecimento, recentemente desenvolveu-se o conceito de inflammaging sugerindo haver uma casualidade entre a inflamação sistêmica e a progressão de várias doenças relacionadas ao envelhecimento (FORTI et al., 2017; FRANCESCHI et al., 2007). Como vários agentes infecciosos são conhecidos por causar inflamação através de resposta imune, sugeriu-se que um acúmulo de infecções persistentes ao longo da vida pode contribuir para um aumento de biomarcadores sistêmicos que são observados em idades mais avançadas (BRUUNSGAARD et al., 1999). Há evidências de uma correlação entre infecção, inflamação sistêmica e risco de doenças relacionadas ao envelhecimento em casos de infecções crônicas (WESTMAN et al., 2014). 


\section{2 - Neuroinflamação}

O sistema nervoso central é considerado um local imunologicamente privilegiado. Enquanto a Barreira Hematoencefálica (BHE) protege o SNC de agressões provenientes da periferia do corpo, o SNC também é capaz de induzir resposta imune inata frente à injúria como trauma, infecção, AVC e neurotoxinas a fim de neutralizar ameaças ao SNC minimizando dano (THOMSON et al., 2014; REUS et al., 2015, FONSECA et al., 2014).

Neuroinflamação é o termo utilizado para descrever a resposta inflamatória do SNC que, apesar de muito semelhante à resposta inflamatória periférica, possui algumas particularidades como as células envolvidas (por exemplo, microglia e astrócitos). A BHE também é um importante ator no processo de neuroinflamação sendo conhecida como uma forma extremamente especializada de endotélio com funções ativas no influxo de mediadores inflamatórios (THAL \& NEUHAUS, 2014; de VRIES et al., 1996; DEMEESTERE et al., 2015).

A neuroinflamação é um processo fisiológico complexo que inclui respostas do SNC a injúria e dano e envolve tanto degradação quanto remodelamento tecidual. A ativação de células da microglia está geralmente associada a stress oxidativo através da liberação de citocinas e quimiocinas, disfunção mitocondrial ou agregação de proteínas podendo levar à morte celular (DUPONT et al., 2017).

Estudos in vivo e in vitro tem demonstrado que algumas substâncias neurotóxicas e pró-inflamatórias como TNF-a, óxido nítrico (NO) e IL-6 são produzidas pela administração de ativadores microgliais como o LPS e podem induzir degeneração de neurônios dopaminérgicos (KIM et al. 2010; GAO et al. 2011; KNOTT et al. 2000; ORR et al. 2002; LIU et al. 2013; SLOWIK et al. 2012; HUMPEL, 2015).

Ainda, outros fatores podem disparar uma cascata inflamatória resultando em neurodegeneração. De fato, a ativação da microglia e o aumento da secreção de citocinas pro-inflamatórias (TNF- $\alpha$, IL-1 $\beta$, IL-6) já foram 
reportados no SNC de pacientes com doença de Parkinson (PD) (MOGl et al., 1994; McGEER et al., 2001; PAL et al., 2015).

Da mesma forma que para a $P D$, há uma correlação entre citocinas proinflamatórias e formação de placa beta amiloide $(A \beta)$, no caso de doença de Alzheimer $(A D)$. Uma combinação entre morte neuronal e acúmulo de placa $A \beta$ podem estimular as células da microglia criando um looping. Curiosamente a ativação da microglia pode não apenas contribuir para a progressão da doença, mas também são relatados efeitos benéficos. A microglia ativada possui a função de reduzir o acúmulo da placa $A \beta$ através de fagocitose, clearance e degradação (QIU et al., 1997) e ainda através da liberação de moléculas antiinflamatórias incluindo citocinas, fatores de crescimento, e a molécula ANXA1 (RIES et al., 2016).

Conforme mencionado anteriormente, apesar da proteção promovida pela $\mathrm{BHE}$, estudos recentes mostram que existe uma comunicação entre 0 sistema imune da periferia do corpo e o SNC. Foi demonstrado que pacientes com doenças inflamatórias crônicas, como artrite reumatóide, desordens inflamatórias intestinais ou até mesmo psoríase, podem apresentar sintomas que incluem depressão, ansiedade e fadiga (REUS et al., 2015). Apesar de haverem avanços recentes na compreensão das vias de comunicação do sistema imune, os efeitos específicos da ativação da imunidade periférica no SNC ainda não estão bem esclarecidos (THOMSON et al., 2014; AMANTEA et al., 2015).

De fato, a neuroinflamação persistente possui um papel central em desordens com doenças como Parkinson e Alzheimer ou esclerose múltipla visto que o quadro inflamatório é causa direta de morte celular. Em virtude do exposto, podemos perceber que o controle e prevenção da neuroinflamação tem uma grande importância em novas abordagens terapêuticas para doenças neurodegenerativas (LYMAN et al., 2014; KNOTT et al. 2000) já que existem evidências crescentes de que inflamação seja causa de neurodegenração em casos de doenças dessa natureza e não apenas uma consequência (CÔTÉ et al. 2015). 
A ação de mediadores em nível local tem sido alvo de estudo para intervenção farmacêutica. Em função disso, é de extrema importância compreender os mecanismos envolvidos na etiopatologia de doenças do SNC assim como o funcionamento normal da imunidade do sistema nervoso e a modulação de processos celulares para combater desordens neurodegenerativas (SHASTRI, 2013).

\section{3 - Microglia}

O termo microglia se refere a células do sistema immune residentes no Sistema Nervoso Central. Elas pertencem a um grupo de fagócitos mononucleares auto renováveis que possuem funções semelhantes às dos macrófagos (HOEFFEL \& GINHOUX, 2015; GIULIAN \& BAKER, 1986, PRINZ et al., 2011; GOMEZ et al., 2013; LAWSON et al., 1990). Essas células são importantes efetoras e reguladoras de alterações da homeostase no SNC tanto em situações fisiológicas quanto de injúria tecidual, sendo responsáveis por realizar o patrulhamento do parênquima cerebral (PRINZ \& PRILLER, 2014; NIMMERJAHN et al., 2005).

Assim como o nome sugere, as células da microglia são as menores células da glia. Em condições basais, em indivíduos adultos, essas células exibem uma morfologia característica com corpo celular alongado além de prolongamentos curtos e extremamente ramificados. Estímulos no SNC associados com morte celular podem induzir sua ativação (GEHRMANN, 1996).

Essas células tem a propriedade de aumentar muito em número em caso de dando cerebral atuando como a primeira linha de defesa na remoção de debris celulares de locais que sofreram dano ou ainda contribuindo com o turnover celular. A microglia também atua como célula apresentadora de antígenos, semelhantes a macrófagos (PURVES et al., 2001; MACK et al., 2003; LAWSON et al., 1990).

Sua distribuição no SNC não ocorre de maneira uniforme, substâncias branca e cinzenta e outras estruturas neuroanatomicamente definidas possuem 
densidades diferentes dessas células também existem diferenças entre espécies, por exemplo, o número dessas células em humanos é muito maior quando comparados a roedores (PERRY \& HOLMES, 2014).

A função dessas células não se limita à fagocitose e apresentação de antígenos. Elas também estão envolvidas na regulação da inflamação no SNC, neuroproteção e remodelamento do tecido neuronal (AARUM et al., 2003; KIPNIS et al., 2004; SHAKED et al., 2004; PONOMAREV, 2005), também possuem um importante papel em processos como a sinaptogênese bem como na manutenção da homeostase neuronal (TREMBLAY et al., 2011; EKDAHL, 2012).

A ativação clássica da microglia é seguida de modificação morfológica substancial caracterizada por retração de processos celulares e aumento dos corpos celulares até atingir um formato ameboide (SCHILLING et al., 2003; JUNG \& SCHWARTZ, 2012). A microglia ativada contribui na resposta inflamatória local produzindo citocinas como IL-1 $\beta$ e TNF- $\alpha$ (AMANTEA et al., 2015), espécies reativas de oxigênio (GREEN et al., 2001) e proteases (ZOPPO et al., 2007).

Ao mesmo tempo, outros estudos têm demonstrado efeitos protetores em doenças neuroinflamatórias (KITAMURA et al., 2004; LALANCETTEHEBERT et al., 2007). De fato, a microglia, além de sua função citotóxica, também atua na resolução do processo inflamatório e em mecanismos reparatórios envolvendo recuperação tecidual pela produção de citocinas como IL-10 e TGF- $\beta$ (LALANCETTE-HEBERT et al., 2007, NEUMAN et al., 2008).

A razão dessa aparente discrepância nos resultados encontrados em diferentes estudos se dá pela capacidade que a microglia possui em se diferenciar em fenótipos distintos dependendo da evolução do dano tecidual (PEREGO et al., 2011). Sendo assim, a microglia pode assumir estados de polarização que estão discutidos mais adiante.

Alternativamente, a microglia também pode alterar dramaticamente seu padrão de expressão gênica em certas regiões do cérebro durante o processo de envelhecimento podendo se tornar reativa e inflamada como resultado de 
disfunção nas suas propriedades fagocíticas e de homeostase proteica. A microglia disfuncional pode reduzir a sua capacidade de degradar a placa $A \beta$ podendo promover ou mesmo iniciar a doença de Alzheimer. Atualmente estão sendo testados anticorpos que se ligam à placa beta amilóide a fim de facilitar seu clearance pela microglia (SPENCER \& MASLIAH, 2014).

Qualquer disfunção na microglia pode levar a um quadro de neuroinflamação que prejudica a homeostase e contribui para o agravamento de quadros inflamatórios. Estes eventos podem gerar um mecanismo que se retroalimenta aumentando o dano às membranas bem como a agregação de proteínas. Se de fato a inflamação pode efetivamente disparar ou acelerar a progressão de doenças neurodegenerativas, a compreensão das vias envolvidas na ativação da microglia pode fornecer importantes alternativas para combater a neuroinflamação (GROOT et al., 2015; REYNOLDS et al., 2011).

\subsection{1 - Polarização M1/M2}

É importante lembrar que a microglia é fundamental no processo de neuroinflamação podendo tanto desempenhar papéis na toxicidade celular quanto reparo, regeneração e imunossupressão tecidual, vale ressaltar que estudos recentes têm ajudado a compreender as funções de células imunes cerebrais nos estágios de desenvolvimento, homeostase, envelhecimento ou resposta a injúria (FUMAGALI et al., 2015; SALINA et al., 2014).

Distúrbios no microambiente do SNC podem desencadear a ativação da microglia, levando a mudanças morfológicas nessas células além de sobrerregulação de um espectro de moléculas intracelulares e antígenos de

superfície. A microglia ativada apresenta perfis de polarização, com a capacidade de sintetizar um amplo espectro de citocinas pró ou antiinflamatórias e outros mediadores moleculares. Da mesma forma que foram propostas distinções entre subpopulações de macrófagos definidas como "citotóxicas" ou "reparo", a microglia ativada no SNC é comumente chamada como M1 (próinflamatória) ou M2 (anti-inflamatória) (Figura 1). Entretanto, esta distinção é 
com frequência simplista: em vários estados de doença, o espectro de citocinas e antígenos expressos pela microglia vai além de simplesmente uma categoria M1 ou M2 (CHHOR et al., 2013; DURAFOURT et al., 2012; HANISCH \& KETTENMMANN, 2007; BISWAS, S. \& MANTOVANI, 2010; PERRY \& HOLMES, 2014).

A polarização dessas células para o fenótipo M1 ocorre por PAMPs como o lipopolissacarídeo (LPS) associado, ou não com interferon y (IFN Y) (MILLS et al., 2014, ROCA et al., 2009; MOSSER \& EDWARDS, 2008), ou ainda estímulos como a placa $A \beta$ em pacientes com $A D$ (LIU et al., 2005; HAYHOE et al., 2006) ou aumento no influxo de cálcio e liberação de adenosina trifosfato (ATP) por células da circunvizinhança (DAVALOS et al., 2005; SIEGER et al., 2012). Nessas condições, observamos uma intensa migração de células para o local da infecção na tentativa de conter a proliferação bacteriana levando à produção de espécies reativas de oxigênio (ROS) e citocinas pró-inflamatórias como IL-1 $\beta$, IL-23 e TNF a com o objetivo de incrementar a capacidade de apresentação de antígenos aumentando a atividade microbicida (BISWAS, S. \& MANTOVANI, 2010; HESSE et al., 2001).

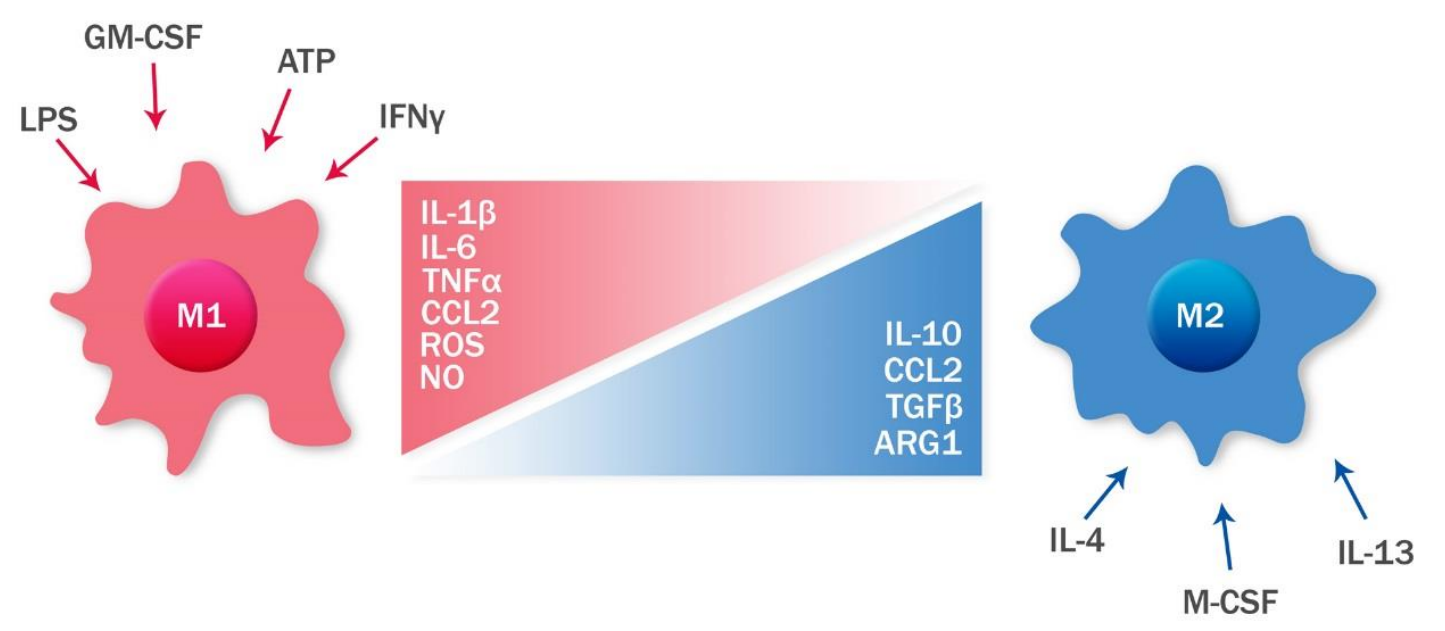

Figura 1: Polarização das células da microglia. As células da microglia consistem em um grupo heterogêneo que pode ser dividido em duas classes principais denominadas M1 e M2 (FONTE: Adaptado de CHHOR et al., 2013 e PRINZ \& PRILLER, 2014). 
Por outro lado, a ativação M2 pode ser induzida por citocinas expressas por células Th2 como IL-4 e IL-13 (MILLS et al., 2000; MILLS \& LEY, 2014). Durante a resolução do processo inflamatório, o equilíbrio de células M1 e M2 ocorre a fim de promover o clearance de debris, inibir a produção descontrolada de mediadores inflamatórios e restauração da homeostase tecidual (MILLS et al., 2014; MILLS et al., 2000; DEY et al., 2014; GORDON \& MARTINEZ, 2010).

A maior parte dos autores menciona as alterações fenotípicas apenas em M1/M2 embora já sejam conhecidos três diferentes fenótipos para as células caracterizadas como M2 denominados M2a, M2b e M2c com alterações discretas em seu espectro de ação (TABELA 1) (PRINZ \& PRILLER, 2014; CHHOR et al., 2013).

A eficiência da alteração do fenótipo dessas células é geralmente avaliada por marcadores específicos. Na polarização das células para o estágio M1 observa-se incremento de citocinas e mediadores pro-inflamatórios como interleucina $1 \beta$ (IL-1 $\beta$ ), interleucina 6 (IL-6), fator de necrose tumoral $\alpha$ (TNF- $\alpha$ ), interleucina 12 (IL-12), espécies reativas de oxigênio (ROS), oxido nítrico (NO) e óxido nítrico sintase (iNOS), o objetivo deste estágio de polarização é atuar na defesa do hospedeiro contra infecções virais e bacterianas (GORDON \& MARTINEZ, 2010), neste perfil também podemos observar a perda de marcadores M2a. Marcadores utilizados para quantificar M2-b (microglia imunorregulatória) incluem desde aumento na expressão de IL-1RA e SOCS3 e para M2a (reparo e regeneração) podemos perceber incremento de arginase 1, CD 36, CD206 e citocinas anti-inflamatórias como IL-10 além de perda de marcadores M1 e M2b (CHLORR et al., 2013; GORDON \& MARTINEZ, 2010). 
TABELA 1: Marcadores com expressão associada a um fenótipo específico de microglia (FONTE: CHHOR et al., 2013; PRINZ \& PRILLER, 2014; PAOLI et al., 2014).

\begin{tabular}{|c|c|c|c|c|c|c|}
\hline & & & & l na inflamaç & & \\
\hline & $\begin{array}{l}\text { Sinal para } \\
\text { polarização }\end{array}$ & Inflamotóxico & Pro-inflamatório & $\begin{array}{l}\text { Anti- } \\
\text { Inflamatório }\end{array}$ & Reparo & Imunorregulação \\
\hline 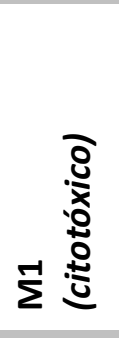 & $\begin{array}{l}\text { IFNY } \\
\text { LPS } \\
\text { TNF } \alpha \\
\text { GM-CSF }\end{array}$ & $\begin{array}{l}\text { TNF- } \alpha \\
\text { iNOS }\end{array}$ & $\begin{array}{l}\text { IL-1 } 1 \beta \\
\text { IL-6 } \\
\text { IL-12 } \\
\text { IFN- } \gamma \\
\text { CXCL1 } \\
\text { IL-1 } \alpha \\
\text { CCL5 (RANTES) }\end{array}$ & Cox-2 & & \\
\hline 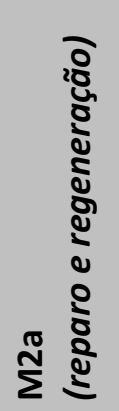 & $\begin{array}{l}\text { Citocinas } \\
\text { Th-2: } \\
\text { IL4 e IL13 } \\
\text { M-CSF }\end{array}$ & & & $\begin{array}{l}\text { IL-4 } \\
\text { IL-1RA } \\
\text { CXCR1 } \\
\text { TGF- } \beta\end{array}$ & $\begin{array}{l}\text { YM1 } \\
\text { FIZZ1 } \\
\text { IGF-1 } \\
\text { Arg1 } \\
\text { G-CSF } \\
\text { GM-CSF }\end{array}$ & $\begin{array}{l}\text { CD206 } \\
\text { Gal-3 } \\
\text { CCL2 (MCP-1) } \\
\text { CCR2 (CD192) }\end{array}$ \\
\hline 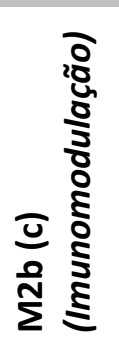 & $\begin{array}{l}\text { LPS +IL-1 } \beta \\
M-C S F\end{array}$ & TNF $\alpha$ & IL-6 & $\begin{array}{l}\text { IL-10 } \\
\text { Cox-2 } \\
\text { SphK1/2 } \\
\text { SOCS3 } \\
\text { IL-4R } \alpha\end{array}$ & VEGF & \\
\hline 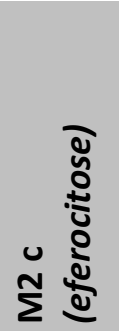 & $\begin{array}{l}\text { IL-10 } \\
\text { TGF } \beta \\
\text { GC } \\
\text { M-CSF }\end{array}$ & iNOS & & IL-10 & & \\
\hline
\end{tabular}

Células M1 e M2 podem ser convertidas umas nas outras em seu microambiente, os fatores envolvidos na polarização da microglia podem interagir uns com os outros regulando essas células para fenótipos específicos em diversas doenças de natureza inflamatória (WYNN et al., 2013; LAWRENCE \& NATOLI, 2011). Consequentemente, M1 e M2 representam dois extremos de todo o espectro possível de ativação de microglia. A polarização dessas células 
regula tanto o início do processo inflamatório, como seu desenvolvimento e sua resolução (NAKAGAWA \& CHIBA, 2014).

\section{4 - Translocator Protein 18KDa (TSPO)}

A proteína translocadora de $18 \mathrm{kDa}$ (TSPO), é uma proteína transmembrana que está localizada primariamente na membrana mitocondrial externa (PAPADOPOULOS et al., 2015; PAPADOPOULOS et al., 2009; PAPADOPOULOS et al., 2007) e é expressa de forma mais intensa em tecidos cuja produção de esteroides e neuroesteróides é elevada (JORDA et al., 2005, LACAREPE \& PAPADOPOULOS, 2003; CHEN, M. K. \& GUILARTE, 2008).

Esta proteína foi inicialmente estudada no contexto da farmacologia dos benzodiazepínicos sendo considerada, durante um período, como um receptor para substâncias desta classe distinto do seu receptor central ligado ao GABA (GAVISH et al., 1999). O nome TSPO foi adotado posteriormente em face de novos insights quanto à sua estrutura e funções moleculares quando ficou evidenciado que substâncias específicas não benzodiazepínicas como o PK11195 (uma isoquinolina carboxamida) e o Ro5-4864 se ligam ao receptor TSPO com alta afinidade, mas não ao receptor $\mathrm{GABA}_{\mathrm{A}}$. Assim é possível explorar ações celulares específicas deste receptor (SCARF et al., 2012; PAPADOPOULOS et al., 2006; SELVARAJ \& STOCCO, 2015).

Estruturalmente, sugere-se um complexo multimérico com $32 \mathrm{kDa}$ formado uma hélice transmembrana de 5 domínios associado ao canal de ânion voltagem dependente (VDAC) (Figura 2) (LACAREPE \& PAPADOPOULOS, 2003; PAPADOPOULOS et al., 2006; McENERY et al., 1992). 


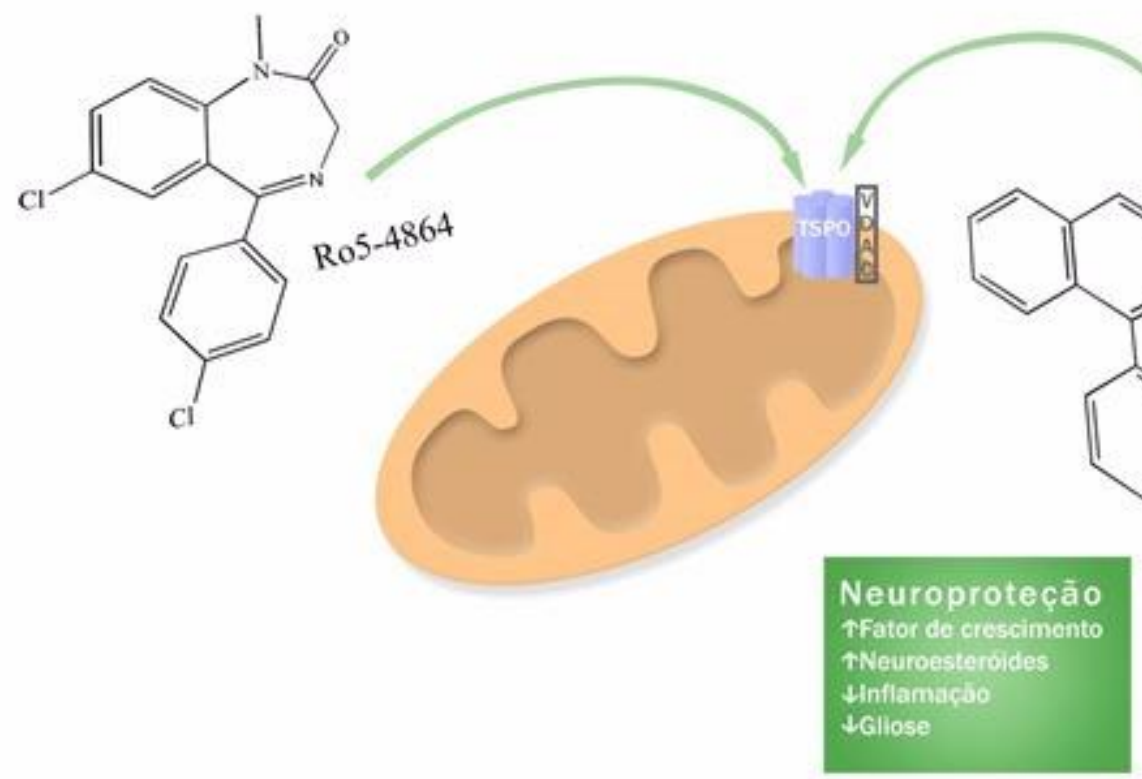

Figura 2: Representação esquemática do receptor de TSPO com cinco domínios transmembrana sendo alvo de ligantes específicos que exercem suas funções de neuroproteção (FONTE: Adaptado de RUPPRECHT et al. 2010).

Embora o TSPO já tenha sido isolado, clonado e sequenciado, sua estrutura tridimensional, seus sítios de ligação e a atividade agonista/antagonista ainda não estão bem estabelecidos. Aliás, o aumento da expressão de TSPO de forma crescente e prolongada em células neurais após injúria ou desordem do sistema nervoso sugere que este receptor pode estar envolvido em mecanismos de resposta dessas células a processos degenerativos ou outros tipos de dano (SELVARAJ \& STOCCO, 2015; RUPPRECHT et al. 2010).

Algumas funções do TSPO já estão bem descritas. Sabemos que o receptor está envolvido na translocação do colesterol do exterior para a parte interna da membrana mitocondrial, o qual é um passo essencial na síntese de esteroides e neuroesteróides (PAPADOPOULOS et al., 2006; PAPADOPOULOS et al., 2007). 
TSPO tem sido relacionado com a gênese de diversas doenças. A expressão de TSPO está aumentada em doenças neuroinflamatórias, neurodegenerativas e até mesmo no câncer, sendo que neste último caso sua expressão tem sido correlacionada com o prognóstico de doenças, embora os dados ainda sejam controversos (CHEN \& GUILARTE, 2008; RUPPRECHT et al., 2010; HARBERTS et al., 2013). Processos como proliferação da glia, migração e fagocitose ou ainda secreção de citocinas pró-inflamatorias são fatores que desencadeiam aumento da expressão de TSPO. Apesar disso, é difícil precisar a partir de que ponto a expressão desse receptor pode ser considerada como resposta a um estado patológico em função de variações individuais apesar da já conhecida relação do aumento da expressão desse receptor em quadros como doença de Alzheimer, por exemplo (VARRONE et al., 2015; GHADERY et al., 2017).

Muito do que se sabe sobre esta proteína foi elucidado através do estudo de ligação ao receptor. Ligantes específicos de TSPO apresentam atividade neuroprotetora modulando a resposta inflamatória e a gliose (RUPPRECHT et al. 2010). Além disso, ligantes de TSPO possuem eficácia in vivo substancial em modelos animais e humanos de neurodegeneração e ansiedade. Esses estudos contribuem para a compreensão do potencial desse receptor em limitar a neuroinflamação além de promover regeneração melhorando disfunções do sistema nervoso (GIRARD et al., 2008; da SETTIMO et al., 2008, RUPPRECHT et al., 2009).

Neste sentido, vários trabalhos utilizando ligantes específicos do receptor relatam o seu papel imunomodulador e o envolvimento com a secreção de citocinas e imunoglobulinas (PAPADOPOULOS et al., 2006; ZHENG et al., 2011; LAZZARINI et al., 2010). Os ligantes deste receptor mais estudados são o Ro5-4864 e o PK11195. Já foi demonstrado que a ligação deles ao TSPO induz neuroproteção por reduzir a ativação de microglia e astrócitos frente a aminoácidos excitatórios ou pela redução da inflamação induzida pelo LPS, eles também se mostraram efetivos na redução de edema de pata provocado pela carragenina além de reduzir a secreção de citocinas inflamatórias (JORDA et al., 2005; CHOl et al., 2011). 
Além destes, outros ligantes também tem sido estudados, por exemplo, o SSR180575 melhorou a restauração funcional em nervos faciais lesionados em modelo murino (CHAVEAU et al., 2011). Estes autores mostraram que além de promover regeneração essas moléculas parecem ser úteis no tratamento de disfunções no sistema nervoso (GIRARD et al., 2008).

Nosso grupo de pesquisa mostrou que o tratamento de ratos Wistar com Ro5-4864, diminuiu a interação de leucócitos circulantes ao endotélio de vênulas pós-capilares da microcirculação mesentérica induzidas pelo fMLP (Nformylmethionyl-leucyl-phenylalanine peptide) e que, além disso, testes realizados in vitro demonstraram que o Ro5-4864 preveniram a internalização da molécula de adesão CD62L (L-selectina), a superexpressão de PECAM-1, a quimiotaxia, e o aumento do cálcio intracelular $\left({ }_{i} \mathrm{Ca}^{+2}\right)$ em neutrófilos inflamados pelo fMLP via receptor de glicocorticóides (LIMA et al., 2012). Corroborando com estes dados, Costa e colaboradores (2012) também demonstraram que o ligante XBD173 modula negativamente estados de pânico e ansiedade com envolvimento da via dos glicocorticóides.

Células do SNC como microglia e astrócitos parecem ser alvos de ligantes de TSPO enquanto que outras células neurais são alcançadas indiretamente pelos seus efeitos provavelmente mediados por citocinas, hormônios e fatores neurotróficos (RUPPRECHT et al. 2010). A compreensão do funcionamento do TSPO permitirá a descoberta de novas formas de integração de sinal entre órgãos centrais e periféricos além de ser um pré-requisito para efetivamente delinear novas estratégias terapêuticas para tratamento de doenças neurodegenerativas (BAE et al., 2014).

\subsection{1 - TSPO e microglia}

Conforme já mencionado, existe uma forte correlação entre os níveis de TSPO e a neuroinflamação sugerindo o envolvimento do receptor em várias doenças inflamatórias. Vale lembrar da influência de ligantes de TSPO em modular negativamente a neuroinflamação e neurotoxicidade (ZHAO et al. 2011; 
BARRON et al. 2013; RUPPRECHT et al., 2010). Mas os mecanismos pelos quais o TSPO regula a neuroinflamação ainda não estão plenamente esclarecidos.

Os níveis de TSPO no SNC em condições basais são baixos. A expressão do receptor aumenta dramaticamente frente a injúria e neurodegeneração principalmente nas células da microglia (evento já evidenciado em estudo em modelos animais e estudos post mortem em humanos). Aliás, várias desordens de natureza neurodegenerativa estão acompanhadas por aumento na ativação da microglia que parece ter relação com a progressão dessas doenças (BARRON et al. 2013; BAE et al., 2014).

Vale ressaltar que já está documentado que o TSPO modula negativamente a neuroinflamação por ação sobre as células da microglia tanto em ensaios in vitro quanto in vivo. O aumento da expressão do TSPO desencadeado por ligantes atenua a ativação do fator nuclear-kappaB (NF-kB) reduzindo a produção de citocinas pró-inflamatórias pela polarização dessas células para o fenótipo M2 mesmo na vigência de estímulo inflamatório como o LPS. Por outro lado, a redução da proteína translocadora eleva o nível de citocinas pró inflamatórias (BAE et al., 2014).

Dados da literatura demonstraram que a expressão constitutiva de TSPO é fortemente induzida em células de linhagem de microglia murina (BV2) quando estas são desafiadas com estímulo inflamatório como o LPS. Da mesma forma, o ligante XBD173 suprimiu a transcrição de genes para marcadores proinflamatórios como CCL-2, IL-6 e a óxido nítrico sintase induzida (iNOS). Também é importante mencionar que o tratamento com o ligante XBD173 reduziu a capacidade migratória e a proliferação da microglia como também os níveis de secreção de NO, sua atividade neurotóxica além de um incremento da capacidade fagocítica (KARLSTETTER et al., 2014).

A expressão de TSPO in vivo pode ser avaliada utilizando modelos de PET scan. Imagens desse tipo em pacientes em estágios iniciais de doenças neurodegenerativas como a $P D$ são capazes de mostrar a polarização da microglia mesmo em fases iniciais da doença (TERADA et al., 2016). Isso 
corrobora com o reportado em modelos animais de $P D$, nos quais a ativação da microglia aparenta preceder perda neuronal dopaminérgica. Dado o fato de que a proteína alfa-sinucleína está diretamente envolvida na promoção de ativação da microglia, a tendência é que exista um aumento de sinal de TSPO durante a ativação desta célula ao longo do tempo (ZHANG et al., 2016).

Da mesma forma como acontece para $P D$, imagens de TSPO utilizando PET scan mostram uma ativação microglial mais intensa em várias regiões corticais conhecidas por serem depósitos de placa $\beta$-amilóide em $A D$ (SURIDJAN et al., 2015) quando comparados a indivíduos saudáveis.

O aumento da expressão de TSPO em diversas células do corpo (incluindo fagócitos e microglia) também pode ocorrer em resposta a citocinas. Esse aumento pode servir como uma estratégia protetora contra citotoxicidade, uma vez que a microglia ativada é, em si mesma, fonte de citocinas e, desta forma, a sobre-regulação da proteína translocadora pode ser interpretada como um fenômeno auto-parácrino (BANATI et al., 2014). Sendo assim, o TSPO parece atuar como um regulador negativo da ativação da microglia na neuroinflamação (BAE et al., 2014; VENNETI et al., 2006).

Em conjunto, os dados da literatura mostram que o TSPO é receptor importante na inflamação do SNC, sendo um marcador do processo, no entanto o papel deste na indução e evolução da inflamação não é conhecido. Desta forma, estudos que investiguem os mecanismos de ação do TSPO, bem como a interelação do mesmo com demais mediadores da inflamação, contribuirão para elucidar a gênese das doenças inflamatórias do SNC.

\section{5 - Anexina A1 (ANXA1)}

O processo inflamatório normal é, por si só, autolimitante. Para evitar a progressão para a cronicidade, o próprio organismo ativa mecanismos que reduzem a produção de mediadores inflamatórios de forma ativa promovendo o clearance de leucócitos e debris celulares do sítio inflamatório. Nesse contexto, 
várias famílias de moléculas, incluindo mediadores de pró-resolvinas, mediadores gasosos como o monóxido de carbono e proteínas foram descritos por regular aspectos no processo de resolução da inflamação (PERRETTI E D'ACQUISTO, 2009). Entre as proteinas que possuem um papel central na resolução do processo inflamatório encontra-se a ANXA1.

A proteína ANXA1 é um membro da superfamília das anexinas que se liga com alta afinidade a fosfolipídeos em presença de cálcio. Foram identificadas 13 dessas proteínas em mamíferos, cada uma com funções biológicas específicas. De forma semelhante ao que ocorre com outras anexinas, a ANXA1 é expressa de maneira constitutiva nas células (GERKE et al., 2005). Esta proteína está envolvida em vários processos moleculares e celulares, incluindo agregação de membrana, sinalização anti-inflamatória, apoptose, manutenção do citoesqueleto e integridade da matriz extracelular, crescimento tecidual, apoptose e diferenciação celular (BIZZARRO et al., 2012; GUO et al., 2013).

A ANXA1 age via receptor acoplado à proteína G conhecido como FPR2 (formyl peptide receptor 2) (PERRETTI et al., 2002). Em condições basais, a proteína é expressa, tanto em humanos quanto em murinos, em diversos tipos celulares como neutrófilos, monócitos, macrófagos e microglia (MORAND et al., 1995; PERRETTI et al., 2000; MULLA et al., 2005).

Em células ativadas, a ANXA1 é prontamente mobilizada do citoplasma para a superfície celular até ser secretada (PERRETTI et al., 1996; PERRETTI E D'ACQUISTO, 2009). Vários mecanismos celulares atuam nessa mobilização. Em macrófagos, o sistema de transporte conhecido como ATP-binding cassete (ABC) parece ser responsável pela secreção da proteína (WEIN et al., 2004). Em células pituitárias, a secreção ocorre devido à fosforilação do resíduo de serina localizado na porção amino terminal da anexina (SOLITO et al., 2006). Em neutrófilos humanos, a ANXA1 é armazenada de forma predominante em grânulos do citoplasma. Isso permite uma mobilização rápida da proteína mesmo com estímulos fracos ou em baixas concentrações de quimioatraentes (PERRETTI et al., 2000; PERRETTI et al., 1996; LOMINADZE et al., 2005; VONG et al., 2007). 
A ativação celular geralmente leva à realocação da anexina $A 1$ para o exterior da membrana plasmática, adicionalmente, concentrações extracelulares de cálcio maiores que $1 \mathrm{mM}$ levam a uma mudança de conformação na proteína, sobremaneira em sua região N-terminal, levando-a à sua forma ativa (GERKE et al., 2005; ROSENGARTH et al., 2003, PERRETTI \& D'ACQUISTO, 2009).

É importante ressaltar que a ANXA1 é produzida e secretada por ação hormonal. A administração de glicocorticóides em voluntários saudáveis leva a um aumento dos níveis de expressão de anexina A1 por monócitos circulantes e neutrófilos (WALTHER et al., 2000).

Sabemos ainda que os glicocorticoides controlam as interações de leucócitos com o epitélio vascular interferindo na responsividade tanto das células quanto do endotélio durante o recrutamento de leucócitos (principalmente neutrófilos e monócitos). O aumento da expressão de ANXA1 por GC pode explicar, ainda que parcialmente, a forma como os glicocorticóides inibem a resposta de leucócitos. Por exemplo, a administração de anexina A1 interfere no rolling e na migração de neutrófilos provavelmente via expressão de L-selectina (GOULDING et al., 1990; GAVINS et al., 2012). A anexina A1 também está envolvida na fagocitose de neutrófilos apoptóticos promovendo o clearance de corpos celulares que ocorre na resolução do processo inflamatório levando a transdução de sinais antiinflamatórios, incluindo aqueles mediados por TGF- $\beta$ (PERRETTI \& D'ACQUISTO, 2009), a ANXA1 também interfere na migração de neutrófilos do compartimento medular para o sangue (MACHADO et al., 2014).

Muito do que se sabe sobre a conexão entre a proteína ANXA1 e os glicocorticóides foi avaliado através de estudos utilizando animais knockouts. Partindo desse modelo, ficou evidenciado que os efeitos antiinflamatórios dos glicocorticoides na imunidade inata são mediados pela liberação de anexina $A 1$ atuando sobre seu receptor (FPR2) em neutrófilos e macrófagos. Por outro lado, vários efeitos imunossupressores dos GC na resposta imune adaptativa se dão através da inibição da expressão de anexina $A 1$ em células T (BARRIONUEVO et al., 2007). 
Em outras palavras, a ANXA1 possui a função de limitar a inflamação em processos patológicos possuindo um papel de proteção tecidual. Estudos utilizando ANXA1 recombinante mostraram uma redução da ativação da microglia após estimulação com LPS. Também já foi demonstrado que existe um aumento de expressão de ANXA1 em torno da placa $A \beta$ (McARTHUR et al., 2010). Ries et al. (2016) também mostraram o potencial desta proteína sobre a degradação e clearance da placa beta amiloide reduzindo a neuroinflamação o que sugere que a ANXA1 possui um papel protetor na progressão de doenças neurodegenerativas como $A D$ propondo uma nova abordagem terapeutica para estudos desta doença.

O uso de animais tratados com RU 38486 ou geneticamente depletados de ANXA1, ou ainda sistemas celulares que super ou sub expressam a proteína, tem sido muito empregados para demonstrar o papel fundamental da ANXA1, na granulopoese (CAVALCANTI et al., 2006; 2007; MACHADO et al., 2014); na migração de neurófilos do compartimento medular para o sangue (CAVALCANTI et al., 2007; DALLI et al., 2012; MACHADO et al., 2014); na migração de neutrófilos do sangue para os tecidos inflamados via inibição da interação leucócito-endotélio (FARSKY et al., 1995; NADKARNI et al., 2014). Esses dados tornam esta proteína um alvo interessante na resolução da resposta inflamatória permitindo um melhor controle da resposta imune (PERRETTI \& D'ACQUISTO, 2009).

\subsection{1 - ANXA1 e microglia}

O microambiente do cérebro é constantemente monitorado pela microglia, célula conhecida por atuar como "macrófagos residentes" no SNC, que identifica e fagocita células apoptóticas ou patógenos a fim de prevenir respostas inflamatórias exacerbadas. A ANXA1 exerce papel importante no clearance de neurônios apoptóticos tanto em condições inflamatórias quanto não inflamatórias e sua expressão é sobreregulada em casos de patologias. Além disso, ela está envolvida na resolução de processos inflamatórios previamente 
instalados (PARENTE \& SOLITO, 2004; SOLITO \& SASTRE, 2012; McARTHUR et al., 2010). A ANXA1 também está envolvida na inibição de enzimas inflamatórias como a Óxido Nítrico Sintase induzida (iNOS) em macrófagos e ciclooxigenase-2 induzida (COX-2) em células do sistema imune no SNC como a microglia (LIU et al., 2005; HAYHOE et al., 2006).

Estudos em camundongos utilizando $O G D / R$ (privação de oxigênio e glicose / reperfusão) exploram o mecanismo pelos quais a ANXA1 exerce seu papel de neuroproteção em casos como infarto e isquemia por induzirem a ativação da microglia e, ao mesmo tempo, a secreção de ANXA1 (YOUNG et al., 1999).

A ANXA1 também tem se mostrado um mediador importante na fagocitose e no processo de englobamento de células apoptóticas (ARUR et al., 2003). Recentemente, foi descrita mais uma função da ANXA1 no sentido de induzir a microglia para o estado "resting" através de sua ação sobre o receptor FPR. Liu e colaboradores (2016) mostraram esse efeito da ANXA1 também sobre a migração de células BV2 (linhagem de microglia murina).

Já foi ressaltado que o processo inflamatório tem um papel importante na progressão de diversas doenças degenerativas do SNC, que pode apresentar consequências para a manutenção das funções de neurônios e outras células (SOLITO \& SASTRE, 2012). É importante lembrar que estímulos inflamatórios (como, por exemplo, LPS ou placa beta amiloide) induzem um aumento da expressão da ANXA1 no SNC (McARTHUR et al., 2010; HAYHOE et al., 2006). Além disso, foi demonstrado que, na ausência da ANXA1, a microglia perde a habilidade de discriminar células apoptóticas e não apoptóticas confirmando mais uma vez a sua importância na resolução da inflamação o que traz esta proteína para o centro dos estudos das doenças neurodegenerativas (McARTHUR et al., 2010; SOLITO \& SASTRE, 2012).

Do exposto, fica evidente que existe uma importante modulação da ANXA1 em respostas inflamatórias, entre as quais as doenças do SNC. Uma vez que a incidência das doenças neurodegenerativas são crescentes com 0 envelhecimento da população, e que a gênese destas doenças é complexa e 
não totalmente conhecida, o conhecimento dos mecanismos que regem os processos inflamatórios no SNC contribuirá para o mapeamento dos processos envolvidos na doença e para o desenvolvimento de terapias mais efetivas. 


\section{2 - OBJETIVO}

Este trabalho investigou a interação da proteína antiinflamatória ANXA1 sobre a expressão e função do TSPO em células BV2 em cultura após ativação da via do TLR-4. 


\section{MATERIAL E MÉTODOS}

\section{1 - Células}

Os experimentos foram realizados em células imortalizadas da linhagem BV2 (microglia de origem murina transfectada com o vírus J2), adquiridas do Banco de Células do Rio de Janeiro (BCRJ), foram empregadas pelas suas características morfológicas e funcionais similares às células da glia, e pelo fato da expressão de ANXA1 nesta linhagem celular estar bem estabelecida (McARTHUR et al., 2010).

As células foram cultivadas em meio RPMI 1640 (Vitrocell Embriolife, Campinas, SP, Brasil) com 10\% de soro fetal bovino (Vitrocell Embriolife, Campinas, SP, Brasil), a $37^{\circ} \mathrm{C}$ sob atmosfera de $5 \%$ de $\mathrm{CO}_{2}$ (HENKEL, 2009).

Para os experimentos envolvendo fagocitose utilizamos células imortalizadas de feocromocitomas da linhagem PC12 também adquiridas do BCRJ. Da mesma forma que para as células BV2, as células PC12 foram cultivadas em meio RPMI 1640 (Vitrocell Embriolife, Campinas, SP, Brasil) com $10 \%$ de soro fetal bovino (Vitrocell Embriolife, Campinas, SP, Brasil), a $37^{\circ} \mathrm{C}$ sob atmosfera de $5 \%$ de $\mathrm{CO}_{2}$. Imediatamente antes de iniciar os experimentos relativos à fagocitose propriamente dita, as células foram semeadas em garrafas ou placas previamente tratadas com colágeno tipo I (Corning, NY, USA) e induzidas à apoptose utilizando meio carenciado de soro.

\section{2 - Reagentes empregados no estudo}

\subsubsection{ANXA1 recombinante}

A ANXA1 recombinante foi gentilmente fornecida pelo $\mathrm{Dr}$. Cris Reutelingsperger, da Universidade de Maastrich, Holanda. A proteína foi utilizada nas concentrações de 10 ou $100 \mathrm{nM}$, em diferentes períodos de incubação. Os protocolos experimentais foram baseados nos descritos por McArthur et al., 2010. 


\subsubsection{LPS}

O lipopolissacarídeo (LPS 055:B5, Sigma-Aldrich, St.Louis, MO, USA) foi diluído em solução de BSA $3 \%$, como agente estimulador das células, empregado em diferentes concentrações (10 e $100 \mathrm{ng} / \mathrm{mL}$ ) e tempos de exposição (4h e 12h). O perfil temporal e as concentrações do lipopolissacarídeo foram avaliados em diferentes efeitos em células BV2, como a expressão de TSPO, secreção de citocinas e expressão de anticorpos de membrana (DUAN et al., 2013; PYO, et al., 2013; JEONG et al., 2014; LEE et al., 2013).

\subsubsection{RS-LPS}

O LPS proveniente da bactéria fotossintética Rhodobacter sphaeroides (RS-LPS) é um potente antagonista de LPS, tanto em humanos quanto em murinos, como também previne choque séptico induzido por LPS em camundongos pelo bloqueio da ligação ao sítio principal de MD-2 (QURESHI et al., 1999).

O RS-LPS (InVivoGen, San Diego, CA, USA) foi solubilizado em água para injetáveis até a concentração de $5 \mathrm{mg} / \mathrm{mL}$ e diluído em meio de cultura e utilizado na concentração final de $500 \mathrm{ng} / \mathrm{mL}$.

\subsubsection{WRW4}

O WRW4 é um conhecido antagonista seletivo da sinalização do receptor FPR-2. Esse peptídeo inibe a sinalização mediada por FPR2 (BAE et al., 2014).

O WRW4 (Tocris Bioscience, Bristol, UK) foi solubilizado em etanol $25 \%$ na concentração de $1 \mathrm{mM}$ e diluído em meio de cultura e utilizado na concentração de $10 \mu \mathrm{M}$. 


\subsubsection{Ammonium pyrrolidinedithiocarbamate (PDTC)}

O PDTC é conhecido por reduzir o desenvolvimento de inflamação aguda ou crônica, funcionando também como um inibidor de ROS através da prevenção da ativação de NFKB (CUZZOCREA et al., 2002).

O PDTC (Sigma-Aldrich, Darmstadt, Alemanha) foi solubilizado em água até a concentração de $1000 \mu \mathrm{M}$ e utilizado na concentração final de $50 \mu \mathrm{M}$, em meio de cultura.

\subsubsection{Anti-MyD88}

MyD88 é uma proteína adaptadora que possui um papel importante na sinalização família de receptores tipo Toll/IL-1, levando à ativação de NFKB, secreção de citocinas e resposta inflamatória (KAWAl et al., 1999).

O inibidor da dimerização de MyD88 (ST 2825) (Apexbio, Houston, TX, USA) foi solubilizado em DMSO até a concentração de $1700 \mu \mathrm{M}$ e utilizado em uma concentração final de $20 \mu \mathrm{M}$, em meio de cultura.

\section{3 - Silenciamento e Superexpressão de ANXA1}

As células BV2 foram manipuladas a fim de sub ou superexpressar a proteína Anexina A1 conforme descrito por MCARTHUR e colaboradores (2010). Brevemente, as células foram transfectadas de forma transiente, utilizando plasmideos pRc/CMV contendo: 1) full-lenght cDNA para ANXA1 contendo 1040 pb denominado pRc/CMV ANXA1 FL, ou 2) uma sequência anti-senso contendo 476 pb denominado ANXA1 AS (SOLITO et al., 1998) (Figuras 3 e 4) e controle negativo pRc/CMV (Invitrogen, CA, EUA). Inicialmente, as células foram transformadas por bactérias competentes (E. Coli - DH5a, gentilmente cedida pelo laboratório da Pra Dra Sylvia Stucchi). 


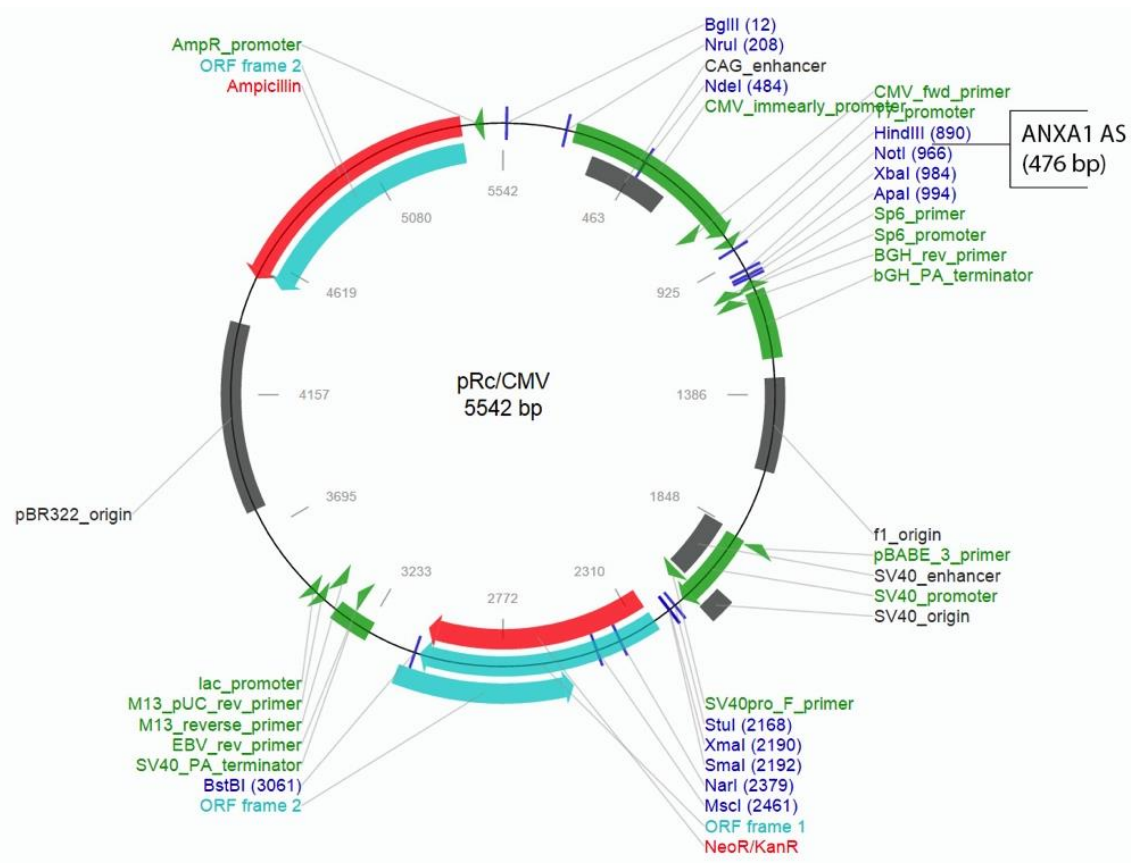

Figura 3: Mapa dos plasmídeos pRc/CMV utilizados para transfecção do gene de ANXA1. O fragmento contendo a sequência anti-senso para ANXA1 utilizado com a finalidade de silenciar a expressão do gene da ANXA1 foi inserido em plasmídeo $\mathrm{pRc/CMV}$ entre os sítio de restrição para as enzimas Hindlll e Notl. FONTE: www.addgene.org/vector-database/ com alterações

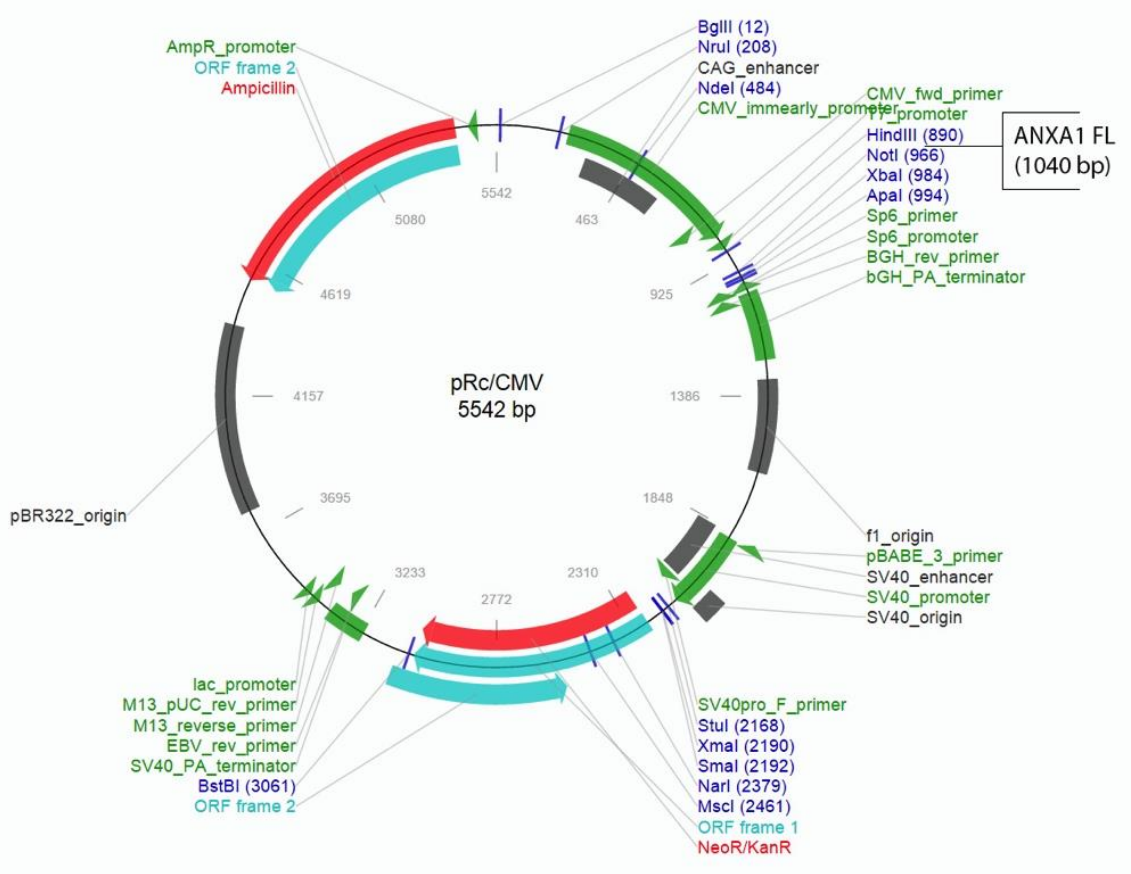

Figura 4: Mapa dos plasmídeos pRc/CMV utilizados para transfecção do gene de ANXA1. O fragmento contendo a sequência full lenght para ANXA1 utilizada com finalidade de super expressar a proteína ANXA1 foi inserida em plasmídeo pRc/CMV entre os sítio de restrição para as enzimas HindllI e Notl. FONTE: www.addgene.org/vector-database/ com alterações 
Os plasmídeos utilizados para manipular a expressão de ANXA foram gentilmente cedidos pela Dra Egle Solito (New Harvey Institute, London UK). Todos os experimentos relativos à transfecção e manipulação gênica foram realizados em colaboração com o laboratório da $\operatorname{Pr}^{\mathrm{a}} \operatorname{Dr}^{\mathrm{a}}$ Silvya Stuchi MariaEngler.

\section{4 - Silenciamento de TLR4 e TSPO}

Da mesma forma como para o gene da ANXA1, as células BV2 foram transfectadas com plasmídeos provenientes de lentivírus (shRNA) obtidos da biblioteca Mission TRC shRNA (Sigma-Aldrich) com o objetivo de silenciar o gene para os receptores TSPO (shRNA-TSPO TRCN 102106) bem como TLR4 (shRNA-TLR4 TRCN 21297).

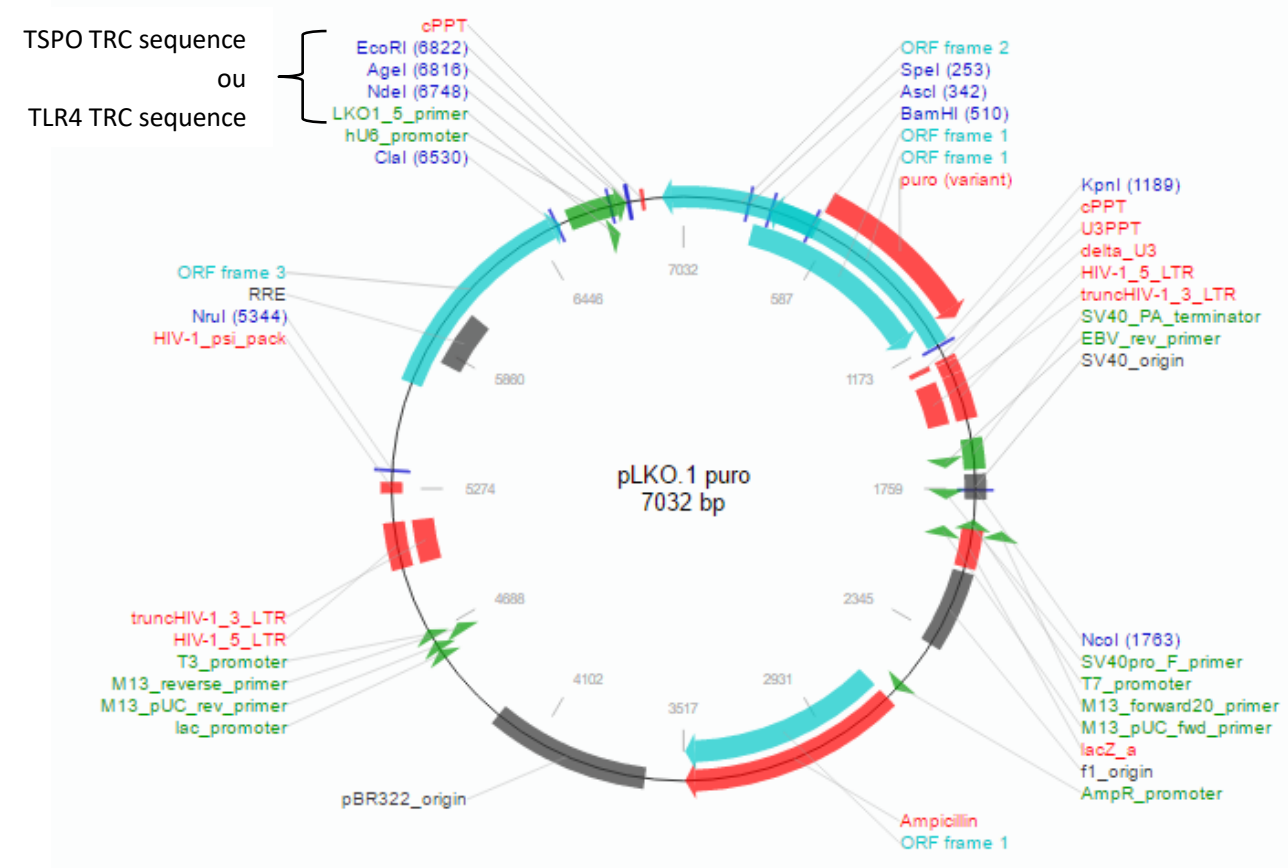

Figura 5: Mapa dos plas mídeos pLKO.1 contendo inserto shRNA. Os fragmentos contendo sequência antisenso para TSPO (shRNA-TSPO TRCN 102106) ou TLR4 (shRNA-TLR4 TRCN 21297)foram inseridos neste plasmídeos entre os sítios do promotor U6 e cPPT (central polypurine tract). FONTE: www.addgene.org/vector-database/ com alterações 
A seguir, os vetores (TLR4 e TSPO) foram purificados e adicionados ao reagente FuGENE HD (Promega Biotecnologia do Brasil, Ltda) para transfecção utilizado meio de cultura conforme indicado pelo fabricante.

A eficiência das transfecções foi avaliada por seleção de células transfectadas utilizando puromicina para os plasmídeos targeting TSPO ou TLR4. O processo de transfecção foi considerado satisfatório quando as células que receberam o plasmídeo puderam proliferar em concentrações crescentes do antibiótico (observando-se, ao mesmo tempo, a morte dos controles).

\section{5 - Citometria de fluxo}

A citometria de fluxo foi utilizada para avaliar a expressão de TSPO e de proteínas de membrana de células BV2. Para tanto, foi utilizado o anticorpo primário policlonal rabbit, anti-TSPO (Abcam Products, San Francisco, CA, USA) e o anticorpo secundário donkey anti-rabbit IgG (Abcam Products, San Francisco, CA, USA) após permeabilização da célula utilizando kit Fixation/Permeabilization (BD - Becton Dickinson, Mountain View, CA, USA) conforme a instrução do fabricante. Adicionalmente, avaliamos os marcadores de membrana para caracterização da microglia, bem como suas características pro ou antiinflamatórias como os anticorpos hamster, anti-mouse CD36 e CD40 (BD Biosciences, Franklin Lakes, NJ, Estados Unidos). Os ensaios foram realizados no citômetro $B D$ Accuri $^{\mathrm{TM}}$ CSampler personal flow cytometer (BD Becton Dickinson, Mountain View, CA, USA) e analisados usando o software próprio. Os dados de 10.000 eventos (considerando apenas células viáveis) foram utilizados para os ensaios.

\section{6 - Ensaio de ELISA}

As citocinas IL-1 $\beta, I L-4, I L-10$, TNF e TGF foram quantificadas por ensaio imunoenzimático (ELISA) em sobrenadantes de culturas de células. Para tanto, foram utilizados Kits Duo Set disponíveis comercialmente (R \& D System, 
Minneapolis, USA). Os ensaios foram conduzidos conforme indicado pelo fabricante.

A proteína ANXA1 secretada no meio de cultura também foi quantificada por ensaio imunoenzimático (ELISA) (MyBiosourece, San Diego, Ca, USA) conforme indicado pelo fabricante. Da mesma forma, a expressão de NFKB (Cayman Chemical Company, Ann Arbor, MI, USA) foi detectada por ensaio imunoenzimático.

\section{7 - Western Blotting}

A expressão de ANXA1 e MyD88 foi avaliada utilizando a técnica de Western Blotting padronizada no laboratório. Brevemente, o material proteico produzido por células BV2 após tratamentos foi obtido por sonicação da massa de células imersa em tampão de lise $(100 \mathrm{mM} \mathrm{KCl}, 3 \mathrm{mM} \mathrm{NaCl}, 3,5 \mathrm{mM} \mathrm{MgCl}$,

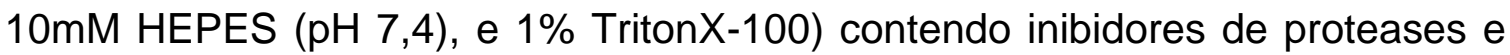
fosfatases. Os lisados foram centrifugados e digeridos em ultra-som e a concentração de proteínas foi quantificada pelo método de Bradford. As proteínas foram desnaturadas pelo tampão de laemmli (Tris-HCl 50mM, pH 6.8, SDS 1\%, 2-mercaptoetanol 5\%, glicerol 10\%, azul de bromofenol 0,001\%) e aquecidas por 5 minutos. Alíquotas correspondentes a $60 \mu \mathrm{g}$ de proteína foram separadas em gel de poliacrilamida a $12 \%$ e transferidas para membrana de nitrocelulose (Hybond ECL, Amersham Pharmacia Biotech) que, posteriormente, foi bloqueada com tampão PBS-T contendo $0,1 \%$ de Tween $20(\mathrm{v} / \mathrm{v})$ e $5 \%$ de leite desnatado. Posteriormente, a membrana foi incubada overnight com anticorpo monoclonal rabbit, anti-ANXA1 (AbCam, Cambridge, UK) a $4^{\circ} \mathrm{C}$ e, posteriormente, utilizando anticorpo secundário anti-rabbit HRP-conjugado (AbCam, Cambridge, UK). As bandas imunorreativas foram reveladas utilizando sistema quimioluminescente (ECL). 


\subsection{Fagocitose de células PC-12 apoptóticas}

Células BV2 foram colocadas em co-cultura com células PC-12 apoptóticas (48 h em cultura em deprivação completa de soro) para realização de teste de fagocitose. Inicialmente, um total de $2 \times 10^{5}$ células BV2 foram plaqueadas por poço e mantidas em meio de cultura como descrito anteriormente. Em seguida, células PC-12 apoptóticas previamente marcadas com carboxifluoresceína succinimidil-éster (Cell Trace CFSE Cell Proliferation Kit®) (Thermo Fisher Scientific, Waltham, MA, Estados Unidos) e CFSE $5 \mu \mathrm{M}$, foram adicionadas a placas de cultura contendo células BV2 já tratadas. As células foram mantidas em co-cultura por 30 minutos. Após o tempo de cocultura, o sobrenadante foi descartado (para que quaisquer células PC-12 não fagocitadas fossem removidas) e as células BV2 foram coletadas mediante tripsinização, lavadas com PBS e marcadas com anti-corpo rat anti-F4/80 PeCy5 por 30 minutos (1/100) (eBiosciences, San Diego, CA, Estados Unidos). As células BV2 foram então ensaiadas em citômetro Accuri CSampler ${ }^{\circledR}$ (BD Biosciences, Franklin Lakes, NJ, Estados Unidos) para análise de fagocitose. Os dados de 10.000 eventos (considerando apenas células viáveis) foram utilizados para os ensaios.

\subsection{Análise Estatística}

Os resultados obtidos nos experimentos foram expressos em média \pm erro padrão da média (e.p.m.) e analisados estatisticamente pela análise de variância com comparações múltiplas (ANOVA), quando necessário, foi utilizado como pós-teste o Teste de Tukey-Kramer (SOKAL \& ROHLF, 1995). Os resultados obtidos estão representados como média \pm erro-padrão da média. Os dados foram analisados no programa GraphPad Prism®, admitindo como significativamente estatístico o $\mathrm{p}<0,05$. 


\section{RESULTADOS e DISCUSSÃO}

\section{1 - Responsividade de células BV2 frente ao LPS}

Inicialmente avaliamos o comportamento das células BV2 frente ao LPS, estímulo inflamatório escolhido para nossos estudos, com base na extensa literatura sobre a ativação de microglia com LPS e expressão de TSPO (WANG et al., 2016; ZHANG et al., 2016; MA et al., 2016). Os dados obtidos estão demonstrados nas Figuras 6 e 7.

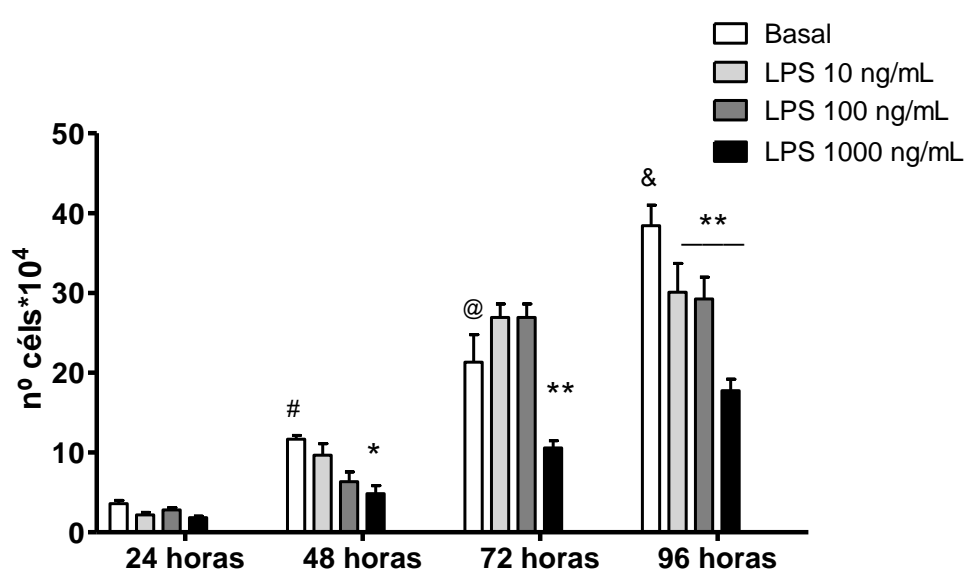

Figura 6: Curva de crescimento para células BV2 em presença de concentrações crescentes de LPS. Os dados foram obtidos em ensaios de citometria de fluxo e representam a média \pm e.p.m de 6 amostras de células em cada grupo. Os resultados foram avaliados por ANOVA de duas vias.

* $p<0,05{ }^{* *} p<0,01$ vs basal e \# $p<0,05$ Basal 48 horas vs basal 24 horas; $@ p<0,01$ Basal 72 horas vs 48 horas, \& Basal 96 vs 72 horas. .

A curva de crescimento mostra que as células incubadas com meio de cultura apresentaram crescimento de população a cada 24 horas; mostra também que houve redução significativa no crescimento celular a partir de 48 horas de incubação com $1000 \mathrm{ng} / \mathrm{mL}$ de LPS; e que todas as concentrações empregadas foram tóxicas em 96 horas de incubação (Figura 6). A literatura mostra que a incubação de LPS com células BV2 causa efeito citotóxico com as concentrações de $1000 \mathrm{ng} / \mathrm{mL}$ em 48 horas e exposição (SHINSMON et al., 2014), assim como demonstrado neste estudo. No entanto, outros autores também utilizam as mesmas concentrações de LPS, mas com incubações de, no máximo, 24 horas de exposição, a fim de observar os efeitos in vitro do agente flogístico em células BV2 (CHEN et al., 2015). Assim, os dados obtidos neste 
trabalho, associados aos da literatura, mostram que em até 24 hs de incubação, as concentrações de LPS aqui empregadas não causam alterações no crescimento de células BV2.

Dando continuidade, investigamos a funcionalidade das células BV2 frente ao LPS, quantificando a secreção das citocinas IL-1 e IL-4. A literatura mostra secreção de citocinas, principalmente IL-1ß, por células BV2 em diferentes intervalos de tempo após estimulação pelo LPS. Assim, MartínezZamudio e colaboradores (2014) encontraram aumento significativo de IL-1 $\beta$ e TNF- $\alpha$ após incubação por apenas 1 hora com LPS, enquanto outros autores utilizaram incubação por intervalos de 6 a 24 horas, e observaram aumento na secreção de IL-1 $\beta$, TNFa, MCP-1 e, ainda, da expressão do fator de transcrição NFkB (ZHU et al., 2014; RANKINE et al., 2006; JEONG et al., 2015). Desta forma, escolhemos estudar os efeitos da incubação com LPS no intervalo de 4 a 36 horas. Os resultados obtidos mostram elevação significativa da secreção de IL-1ß, 12 horas após a incubação com $100 \mathrm{ng} / \mathrm{mL}$ de LPS, e de IL-4 após 4 ou 12 horas com a concentração de $10 \mathrm{ng} / \mathrm{mL}$.

A partir destes resultados, continuamos os ensaios com as concentrações de 10 ou $100 \mathrm{ng} / \mathrm{mL}$ de LPS e com os tempos máximos de 48 horas.

A

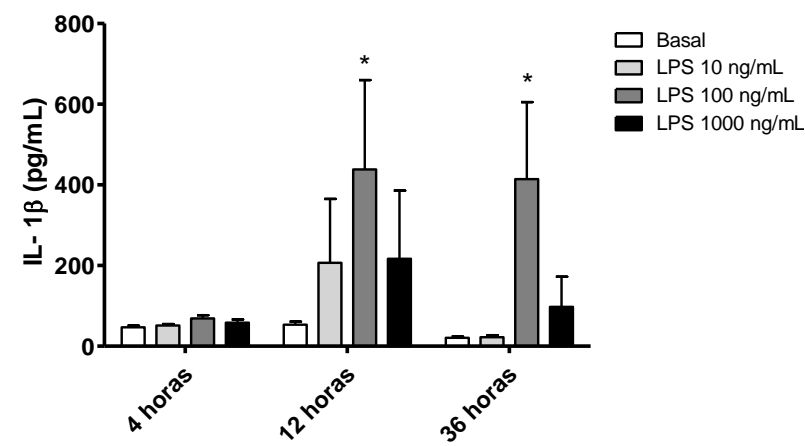

B

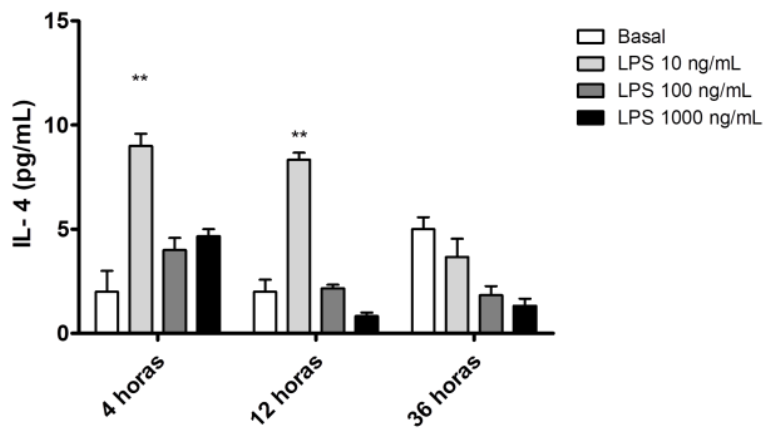

Figura 7: Secreção de IL-1 $\beta$ (A) e IL-4 (B) por células BV2 frente a concentrações crescentes do LPS ao longo do tempo. Os dados foram obtidos em ensaios de ELISA e representam a média \pm e.p.m de 4 amostras de células em cada grupo. Os resultados foram avaliados por ANOVA de duas vias. ${ }^{*} p<0,05{ }^{* *} p<0,01$ vs basal. 


\subsection{Influência do LPS na expressão do TSPO}

Uma vez padronizadas as condições de estímulo pelo LPS, avaliamos se estas induziam a expressão de TSPO em células BV2. Utilizamos a técnica de citometria de fluxo para avaliar possíveis alterações na resposta da expressão proteica de TSPO frente ao estímulo com LPS. Os dados obtidos mostram que o tratamento com LPS aumentou a expressão do receptor a partir de 4 horas de incubação.

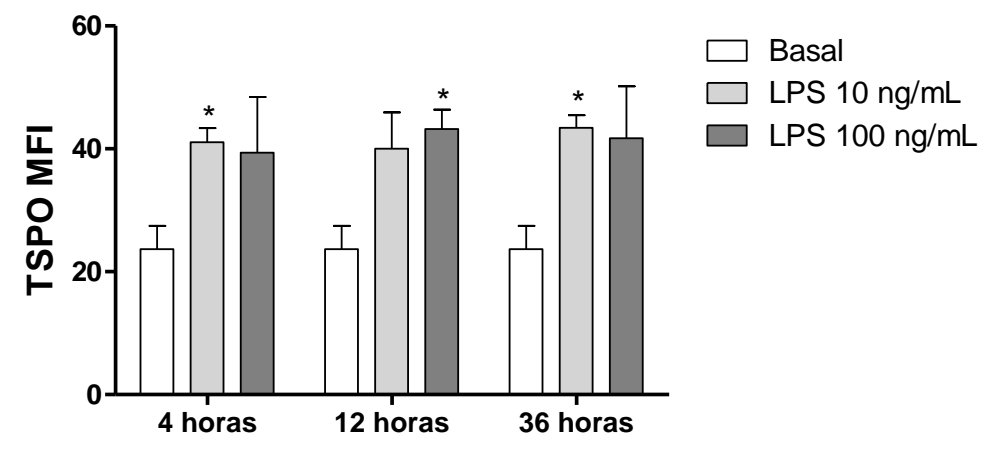

Figura 8: Expressão proteica de TSPO, em função de diferentes concentrações do estímulo inflamatório (LPS) ao longo do tempo. Os dados foram obtidos em ensaios de citometria de fluxo e representam a média \pm e.p.m de 6 amostras de células em cada grupo. Os resultados foram avaliados por ANOVA de uma via.

${ }^{*} p<0,05$ vs basal

Os resultados da Figura 8 confirmam que estas condições experimentais são adequadas para estimulação das células BV2 pelo LPS, pois causaram aumento da secreção de citocinas e da expressão de TSPO. O aumento da expressão de TSPO frente a estímulo com LPS corrobora com os dados encontrados por outros autores tanto in vivo (DICKENS et al., 2014), quanto em células BV2 ou primárias de microglia (KARLSTETTER et al., 2014; ZHAO et al., 2011).

A relação entre LPS e TSPO em microglia já está descrita, como aqui confirmado, no entanto os mecanismos envolvidos entre ambos e seus efeitos 
durante a ativação celular ainda não são conhecidos. Não há uma evidência clara da ação direta do LPS sobre a expressão de TSPO via receptor TLR4, mas dados da literatura indicam que o LPS possa estimular a expressão de TSPO de forma indireta, provavelmente por modulação do TNFa (LI et al., 2008, REY et al., 2000). Estes autores mostraram que a elevação da concentração de TNFa aumentou a expressão gênica de TSPO mas, ao mesmo tempo, o aumento da expressão do TSPO protegeu a microglia dos efeitos tóxicos provocados pela citocina. Corroborando esta última informação, foi mostrado que a ação de ligantes de TSPO são capazes de reduzir a expressão de TNFa (LEAVER et al., 2012), o que pode sugerir uma retroalimentação neste sistema ou ações antiinflamatórias do receptor. Ademais, a elevação na expressão de TSPO por iRNA protegeu a célula BV2 da ação do LPS (BAE et al., 2014; BATARSEH \& PAPADOPOULOS, 2010) e ligantes específicos de TSPO (Ro5-4864, PK11195, F-GE-180 e XBD173) reduziram o potencial neurotóxico do LPS no microambiente inflamatório por reduzir secreção de citocinas como IL-1 $\beta$, IL-6 e TNFa em BV2 (ZHAO et al., 2011; KARLSTETTER et al., 2014). Estes resultados sugerem que o receptor TSPO é expresso em microglia por a ação de agentes inflamatórios (TNFa ou LPS) e que pode atuar como inibidor do processo.

Até recentemente, alguns autores mostravam o aumento na expressão de TSPO como indutor de ativação da microglia pelo LPS (DICKENS et al., 2014; ZIPP et al., 2006). No entanto, em animais nocautes para TSPO foi demonstrado que a microglia é capaz de se ativar normalmente na vigência de estímulo inflamatório por LPS, mesmo na ausência da proteína translocadora (BANATI et al., 2014).

Os dados obtidos até aqui mostram que a proteína translocadora é expressa em células BV2 sob estimulação pelo LPS, confirmando o TSPO como um biomarcador de neuroinflamação induzida pela via do TLR4 (DUPONT et al., 2017; BANATI et al., 2014; CHEN et al., 2008; CERAMI et al., 2017). 


\subsection{Influência da ANXA1 na expressão de TSPO}

O objetivo central deste trabalho foi determinar se a proteína ANXA1 possui algum controle sobre a expressão de TSPO na inflamação mediada pelo LPS. Assim, este foi o passo seguinte de nossas investigações.

Os resultados apresentados na Figura 9 confirmam que a incubação com LPS por 4 horas, de fato, aumenta a expressão de TSPO pelas células BV2. A incubação com ANXA1 recombinante pelo mesmo período (4 horas) não altera a expressão do receptor. No entanto, quando a ANXA1 foi incubada simultaneamente com célula estimulada pelo LPS, observou-se redução marcada na expressão de TSPO, mostrando que a ANXA1 reverte o efeito do LPS (Figura 9A). Em 12 horas de incubação com LPS e ANXA1 o efeito foi semelhante, embora o tratamento com ANXA1 recombinante tenha inibido 0 aumento da expressão de TSPO induzida por $10 \mathrm{ng} / \mathrm{mL}$ de LPS (Figura 9B). É importante salientar que os dados obtidos são inéditos, portanto de difícil comparação com a literatura. Pela primeira vez mostramos a interferência da ANXA1 na via de ativação dos TLRs, que resulta na inibição da expressão de TSPO. Dados da literatura sugerem que a ANXA1 pode estar envolvida na ativação da via de TLR4 em macrófagos e células dendrítcas (BIST et al., 2013), neste trabalho foi demonstrado que ao estimular a via da MyD88 por ligantes específicos, observou-se maior produção de TNF $\alpha$ em animais ANXA1-/- quando comparados com os WT. Neste estudo, não se observou o mesmo efeito quando outras vias foram estimuladas, como TRIF, o que sugere uma modulação da ANXA1 sobre a MyD88. 
A

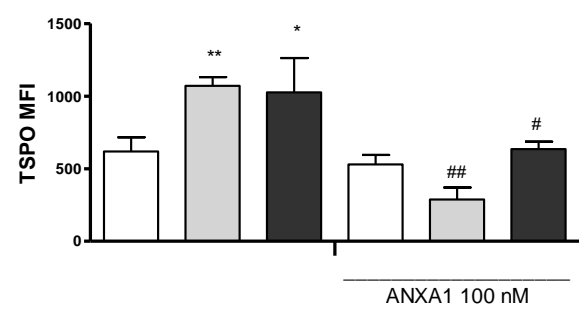

B

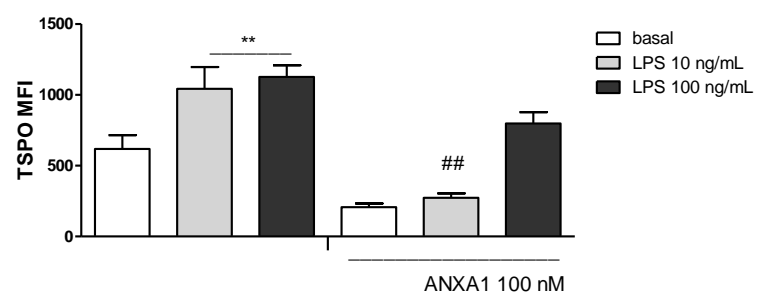

Figura 9. Expressão proteica de TSPO avaliada por citometria de fluxo em células BV2 estimuladas com LPS e tratadas com ANXA1 por 4 (A) ou 12 (B) horas. Os dados foram obtidos em ensaios de citometria de fluxo e representam a média \pm e.p.m de 6 amostras de células em cada grupo. Os resultados foram avaliados por ANOVA de duas vias.

${ }^{\star} p<0,05,{ }^{* *} p<0,01$ vs veículo ${ }^{\#} p<0,05,{ }^{\# \#} p<0,01$ ANXA + LPS vs respectivos LPS

\section{4- Influência da ANXA1 sobre a secreção de mediadores inflamatórios induzidos pelo LPS}

A microglia é considerada a principal célula do sistema imune inato presente no cérebro em função de sua capacidade de fagocitose e apresentação de antígenos além de expressar uma diversidade de receptores envolvidos na inflamação, como os TLRs, GPCR, quimiocinas e prostanoides (GHADERY et al., 2017; FONSECA et al., 2014; BIST et al., 2013; MARTIN \& TRACEY, 1992). A microglia secreta uma série de citocinas pro-inflamatóriasvem resposta ao LPS como, por exemplo, TNFa, IL-1 $\beta$, IL-6, MCP-1, IL-12 (LEHNARDT et al., 2003; REGEN et al., 2011, RUBIO-PEREZ \& MORILLAS-RUIZ, 2012).

A proteína anti-inflamatória ANXA1 inibe a liberação de fosfolípedes de membrana importantes para a secreção de mediadores inflamatórios (BIZZARRO et al., 2012; GUO et al., 2013). Desta forma, a ação da ANXA1 inibe a secreção de derivados da enzima ciclooxigenase, óxido nítrico sintase e de citocinas (PARENTE \& SOLITO, 2004). Apesar desta ação primordial da ANXA sobre fosfolípedes, há relatos de algumas ações específicas da ANXA1 na secreção de mediadores inflamatório como, IFNy, IL-4, IL-10, IL-12, IL-13, TGF $\beta$ (DURAFOURT et al., 2012, CHHOR et al., 2013, BIST et al., 2013). 
Baseados nessas informações, nós caracterizamos a secreção de citocinas por células BV2 após exposição ao LPS, bem como a influência da ANXA1 nesse processo.

Os dados apresentados na Figura 10 mostram que as células BV2 secretam IL-1 $\beta$ após 4 ou 12 horas de estímulo com LPS, e que o tratamento com a ANXA1 inibe a secreção da citocinas em ambos os tempos de estimulação.

A

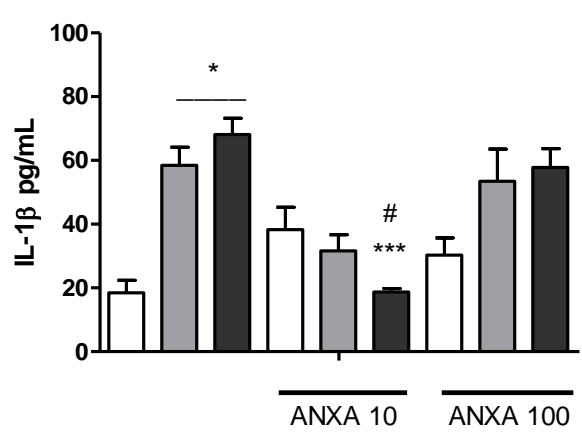

B

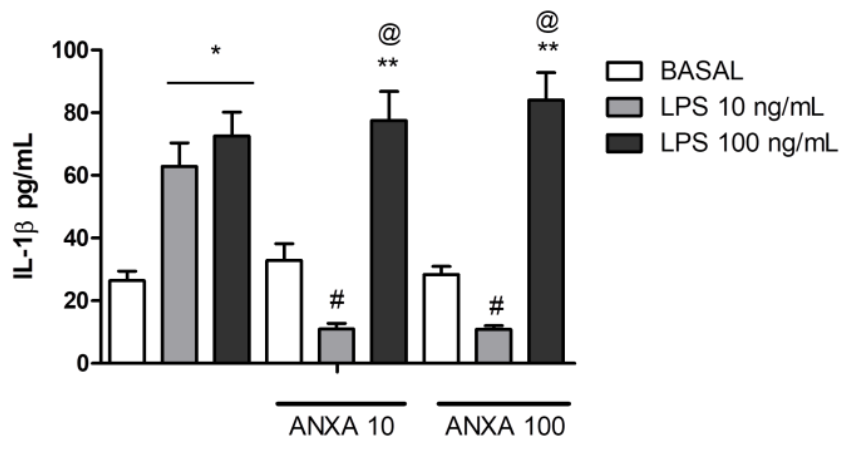

Figura 10: Efeito do tratamento com ANXA1 e/ou LPS sobre a expressão de IL-1 $\beta$ em 4 (A) ou 12 (B) horas de incubação. Os dados foram obtidos por ELISA e representam a média \pm e.p.m de 4 amostras de células em cada grupo. Os resultados foram avaliados por ANOVA de duas vias.

${ }^{*} p<0,05 ;{ }^{* *} p<0,01 ;{ }^{* * *} p<0,001$ vs basal

$\# p<0,05$ vs LPS respectivo; @ $p<0,05$ vs LPS $10 \mathrm{ng} / \mathrm{mL}$

O TGFß é uma citocina anti-inflamatória que atua na proliferação, diferenciação, transformação, sinalização e apoptose de diversos tipos de células que vão desde células do sistema imune, como macrófagos e microglia, e células epiteliais, hematopoiéticas e tecidos neurais (MACIAS et al., 2015). $O$ TGF $\beta$ é um citocina importante na polarização de neutrófilos e macrófagos, induzindo a via alternativa (M2) de ativação em macrófagos (ZHOU et al., 2012). Ademais, a ANXA1 é considerada uma proteína de fase de resolução da inflamação e induz a polarização de macrófagos (ZHOU et al., 2012; MACIAS et al., 2015). Alguns autores sugerem que a ANXA1 possa induzir a secreção de TGF $\beta$ como um mediador antiinflamatório em condições de inflamação (SCANNELL et al., 2007; GRAAUW et al., 2010). No entanto, no modelo de 
fibrose pulmonar induzida por bleomicina os níveis de TGF $\beta$ foram aumentados em animais nocautes para ANXA1 (GRAAUW et al., 2010).

Assim, aqui investigamos se o LPS ou ANXA1 poderiam induzir a secreção de TGF $\beta$ e o possível efeito da ANXA1 sobre as ações do LPS. Os resultados obtidos mostram que o LPS não induz a secreção deste mediador (Figura 11). Por outro lado, o tratamento com ANXA1 recombinante induz a secreção de TGF $\beta$ por células BV2 em 4 ou 12 horas de incubação com a proteína. Na vigência do LPS, o efeito da ANXA1 sobre a secreção de TGF $\beta$ foi revertido com a concentração de $100 \mathrm{ng} / \mathrm{mL}$ do agente flogístico (Figura 11).
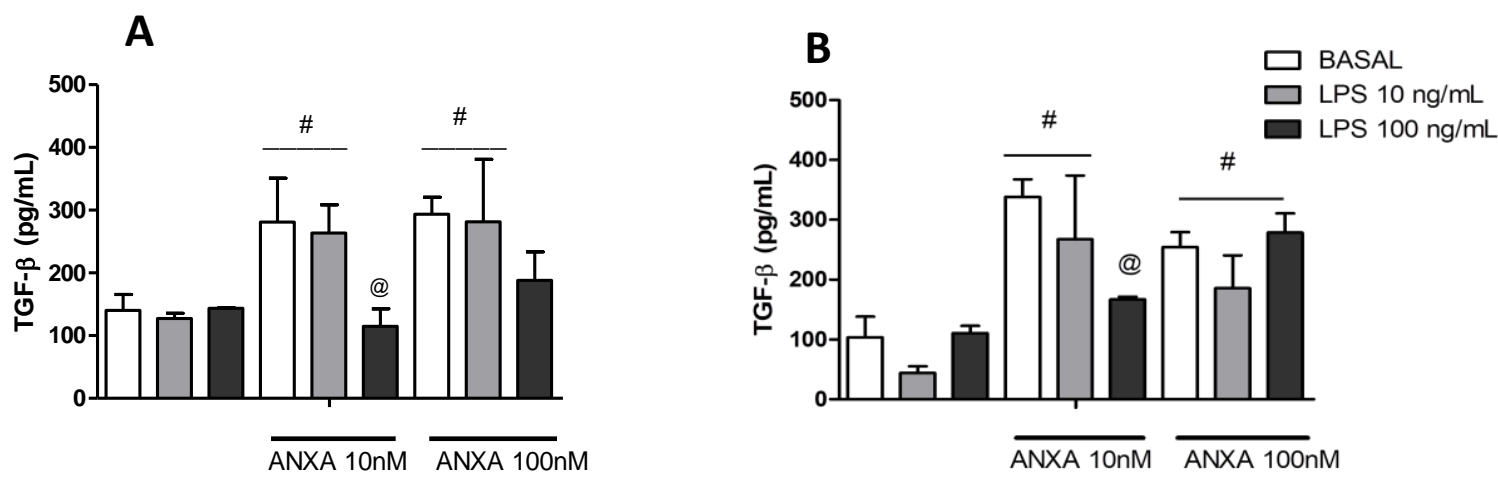

Figura 11: Efeitos dos tratamentos com ANXA1 e/ou LPS sobre a expressão de TGF $\beta$ após 4 (A) ou 12 (B) horas de incubação. Os dados foram obtidos por ELISA e representam a média \pm e.p.m de 4 amostras de células em cada grupo. Os resultados foram avaliados por ANOVA de duas vias. \# $p<0,05$ vs basal não tratado @ $p<0,05$ vs respectivo LPS10 ng/mL

Assim, mostramos também pela primeira vez que a ANXA1 tem um efeito direto na secreção do TGF $\beta$ por células da microglia e este pode representar um mecanismo importante anti-inflamatório da ANXA1 no SNC. Ademais, este mecanismo pode ser sobresposto em concentrações elevadas de LPS, e o mecanismo deste efeito deve ser investigado futuramente.

Os dados apresentados na Figura 12 mostram que a secreção de TNFa aumenta em células BV2 frente a estimulação com LPS, quando comparado com células em condições basais, tanto em 4 ou 12 horas de incubação. No entanto, o tratamento com ANXA1 recombinante inibe o efeito do LPS. O aumento da concentração de TNFa é parcialmente revertido pela co-incubação com a proteína ANXA1, sobremaneira nas menores concentrações de LPS, em especial no período de 4 horas de incubação. Podemos observar também que a 
ANXA1 per se não alterou as concentrações de TNF- $\alpha$ secretados pela microglia.
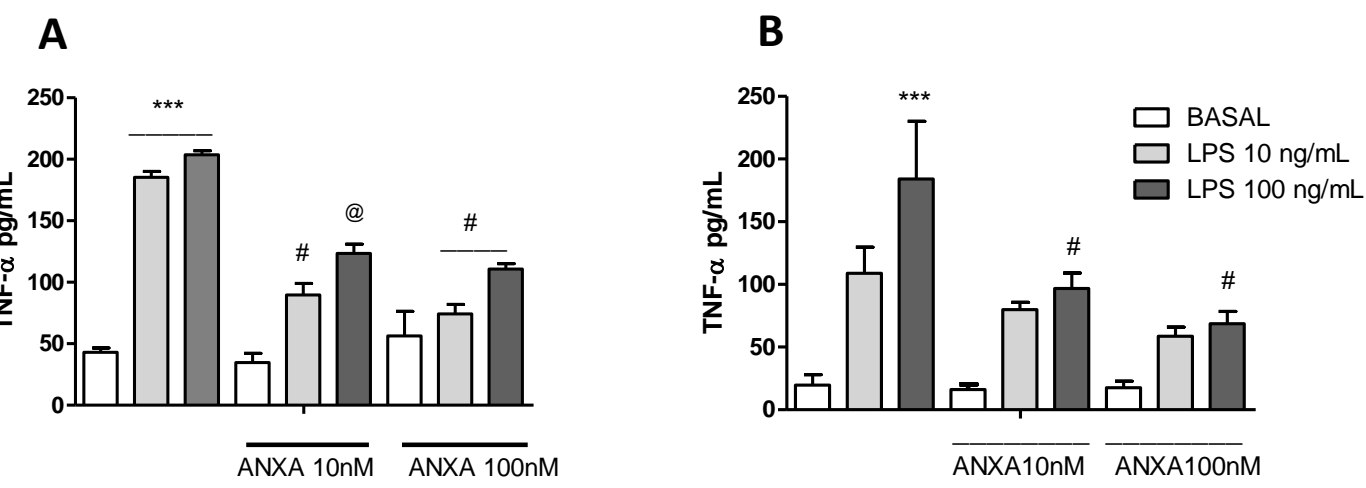

Figura 12: Efeitos dos tratamentos com ANXA1 e/ou LPS sobre a secreção de TNF- $\alpha$ após 4 (A) ou 12 (B) horas de tratamentos. Os dados foram obtidos por ELISA e representam a média \pm e.p.m de 6 amostras de células em cada grupo. Os resultados foram avaliados por ANOVA de duas vias. ${ }^{* * *} p<0,001$ vs respectivos valores basais; \# vs respectivos valores de LPS não tratado com ANXA1; @ vs respectivo LPS 10ng $/ \mathrm{mL}$

O TNFa é uma citocina pró-inflamatória central na defesa do organismo e na resposta inflamatória, porém, em certas circunstâncias, também pode ser responsável por morte celular e lesão tecidual, sendo que suas ações são detectadas no desenvolvimento de doenças autoimunes particularmente aquelas que afetam o SNC (PROBERT et al., 2015; MICHEAU \& TSCHOPP, 2003; VASSALLI et al., 1992). TNF- $\alpha$ e IL-1ß são citocinas pro-inflamatórias clássicas agindo na resposta inflamatória aguda, além disso, são importantes para a produção de IL-6 (RUBIO-PEREZ \& MORILLAS-RUIZ, 2012; WANG et al., 2015). A IL-6 também é produzida por microglia e astrócitos e possui um papel central na neuroinflamação persistente e doenças neurodegenerativas (LYMAN et al., 2014; MARTIN \& TRACEY, 1992).

Assim, consideramos importante avaliar a secreção desta citocina nas nossas condições experimentais. Os dados obtidos mostram que o tratamento com LPS foi capaz de aumentar a secreção de IL-6, relacionada à concentração, após 4 ou 12 horas de incubação com o estímulo (Figura 13). Diferentemente do observado para as demais citocinas estudadas, o tratamento com ANXA1 recombinante não alterou a secreção de IL-6 após a estimulação com LPS em 
nenhum dos tempos estudados (Figura 13), a incubação com ANXA1 na concentração de 100 nM foi capaz de reduzir a secreção de IL-6 produzida pelo LPS apenas após 12 horas de incubação na concentração de 100 nM (Figura 13B)

A

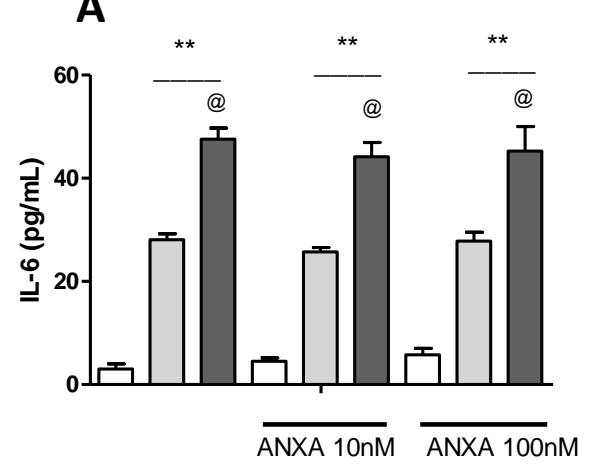

B

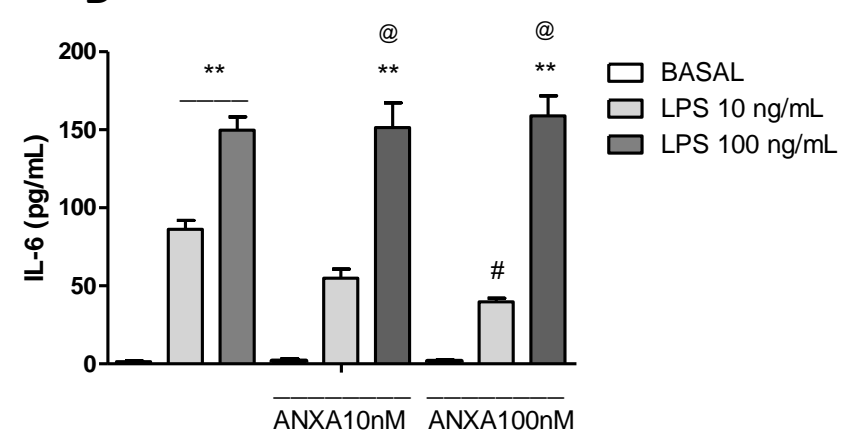

Figura 13: Efeitos do tratamento com ANXA1 e/ou LPS sobre a secreção de IL-6 em 4 (A) ou 12 (B) horas de exposição. Os dados foram obtidos por ELISA e representam a média \pm e.p.m de 6 amostras de células em cada grupo. Os resultados foram avaliados por ANOVA de duas vias. ${ }^{* *} \mathrm{p}<0,01$ vs respectivos valores basais; @ vs respectivo LPS $10 \mathrm{ng} / \mathrm{mL}$

Os dados da literatura mostram, em diferentes estratégias experimentais, que a ANXA 1 inibe a secreção de IL-6, por inibir a transcrição de NFKB e a ativação de ERK e JNK MAP/ERK (PUPJALIS et al., 2011). No entanto, não há dados sobre a ação da ANXA1 sobre a secreção de IL-6 em células do SNC. Desta forma, é importante que os mecanismos moleculares da modulação da ANXA1 sobre a secreção de IL-6 na célula da microglia sejam investigados futuramente.

Continuamos a investigação do perfil de citocinas secretadas pela ação do LPS avaliando a secreção de IL-10 (Figura 14). A IL-10, é uma citocina antiinflamatória, secretada por células do sistema imune, entre as quais a microglia (ZHU et al., 2016), no sentido de limitar a evolução do processo. O aumento da produção de IL-10, por sua vez, possui um efeito inbitório sobre a produção de citocinas pró-inflamatórias como IL-6 e TNF- $\alpha$ em função da ação desta citocina sobre NFKB (DRIESSLER et al., 2004).

Nossos dados corroboram que o LPS estimula a secreção de IL-10 pelas células BV2 (McARTHUR et al., 2010; HUANG et al., 2008). Ainda, o tratamento 
com ANXA1 per se, na ausência de estimulação celular, não alterou a concentração desse mediador, porém, houve uma tendência de aumento ainda maior de IL-10 quando as células BV2 foram co-incubadas com ANXA1 e LPS principalmente no período de 4 horas (Figura 14). Dados semelhantes foram observados para macrófagos (KIM et al., 2010; PARENTE \& SOLITO, 2004).

A

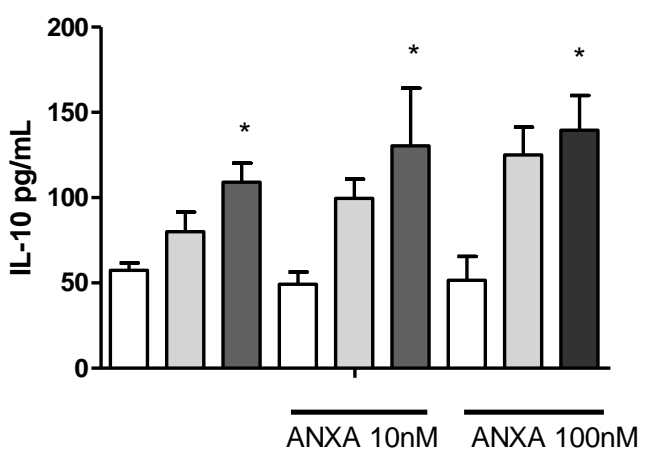

B

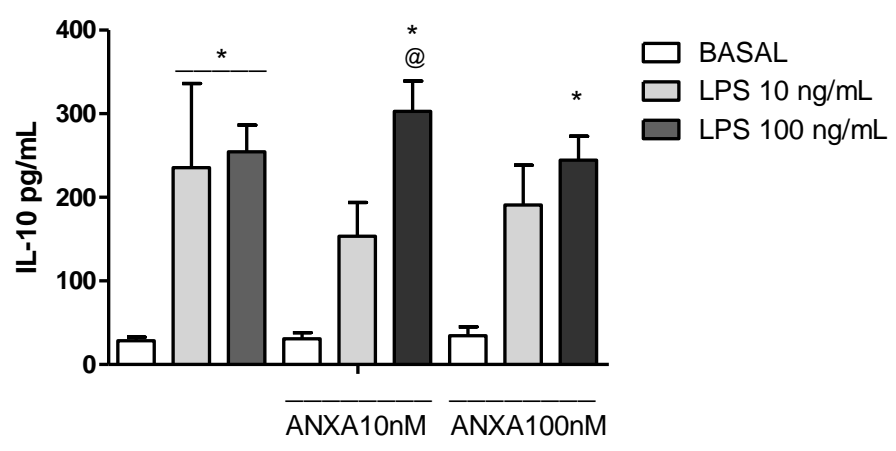

Figura 14: Efeitos dos tratamentos com ANXA1 e/ou LPS sobre a secreção de IL-10 em 4 (A) ou 12 (B) horas de tratamento. Os dados foram obtidos por ELISA e representam a média \pm e.p.m de 6 amostras de células em cada grupo. Os resultados foram avaliados por ANOVA de duas vias. ${ }^{*} p<0,05$ vs respectivos valores basais; @ $p<0,05$ vs respectivo LPS $10 \mathrm{ng} / \mathrm{mL}$

Dependendo do estado de ativação, a microglia pode exercer diversas funções tanto neurotóxicas quanto neuroprotetoras. A microglia ativada por LPS apresenta um perfil de polarização conhecido como "M1" (ativação clássica). Sob este fenótipo, as células possuem um papel vital na defesa do organismo contra patógenos e células tumorais pela produção de citocinas pró-inflamatórias como IL-1 $\beta$, TNF- $\alpha$, IL-12, IL-6 etc., sendo que este estado de ativação também está associado com perda neuronal. Por outro lado, o fenótipo alternativo "M2" considerado anti-inflamatório está associado com reparo tecidual e angiogênese devido a concentrações elevadas de citocinas anti-inflamatórias como IL-10, IL-4 e TGF- $\beta$ (NAKAGAWA \& CHIBA, 2014; VEREMEYKO et al., 2013; FREILIC et al., 2013; SALINA et al., 2014; WYSS-CORAY et al., 2002; CHHOR et al., 2013; MILLS et al., 2014).

Os dados aqui mostram a propriedade da proteína ANXA1 em alterar o padrão de citocinas envolvidas no fenótipo celular, com tendência a um perfil antiinflamatório uma vez que induziu a secreção de TGF $\beta$, associado a fase de 
resolução da inflamação, e inibiu a secreção de $\mathrm{IL}-1 \beta$ e TNFa, associadas a quadros pro-inflamatórios em resposta ao LPS.

Estes resultados confirmam a importância da proteína ANXA1 na modulação da neuroinflamação. Já está descrito que a ANXA1 está envolvida na resolução da neuroinflamação (SOLITO \& SASTRE, 2012) e na fagocitose de células apoptóticas (neurônios e linfócitos) (McARTHUR et al., 2010).

Ademais, os dados obtidos neste projeto mostram que a ANXA1 inibe a expressão de TSPO em células com características antiinflamatórias, ou seja, a expressão de TSPO é reduzida na resolução da inflamação, implicando que o TSPO seja expresso primordialmente no desenvolvimento da neuroinflamação a fim de regular a resposta inflamatória, porém o aumento dessa expressão está relacionado à proteção tecidual.

A fim de confirmar a importância da proteína ANXA1 no estabelecimento de um perfil antiinflamatório em microglia, nós avaliamos se o silenciamento de ANXA1 poderia interferir na secreção de citocinas. A Figura 15 mostra que a incubação de células BV2 com LPS causa um aumento intenso na secreção de TNF $\alpha$ observado em células BV2 após a transfecção com o plasmídeo contendo a sequência anti-senso para a proteína ANXA1 (BV2 ANXA). Surpreendentemente, não hove alteração significativa quando comparamos a secreção de IL1 $\beta$ entre as células controle e com deficiência de ANXA1. Esse resultado pode ocorrer porque, enquanto a secreção de TNF $\alpha$ está mais intimamente ligada à via do receptor TLR4 e sua ativação por PAMPs como 0 LPS (HOAREAU et al., 2010; PARAMESWARAN and PATIAL et al., 2010), podemos observar que a secreção de IL1 $\beta$ pode ocorrer em função de diferentes estímulos além destes como ATP, inflamassoma ou ainda presença de citocinas pro-inflamatórias que agem de forma orquestrada em sua secreção (LOPEZCASTEJON AND BROUGH, 2011; NASI et al., 2017). 

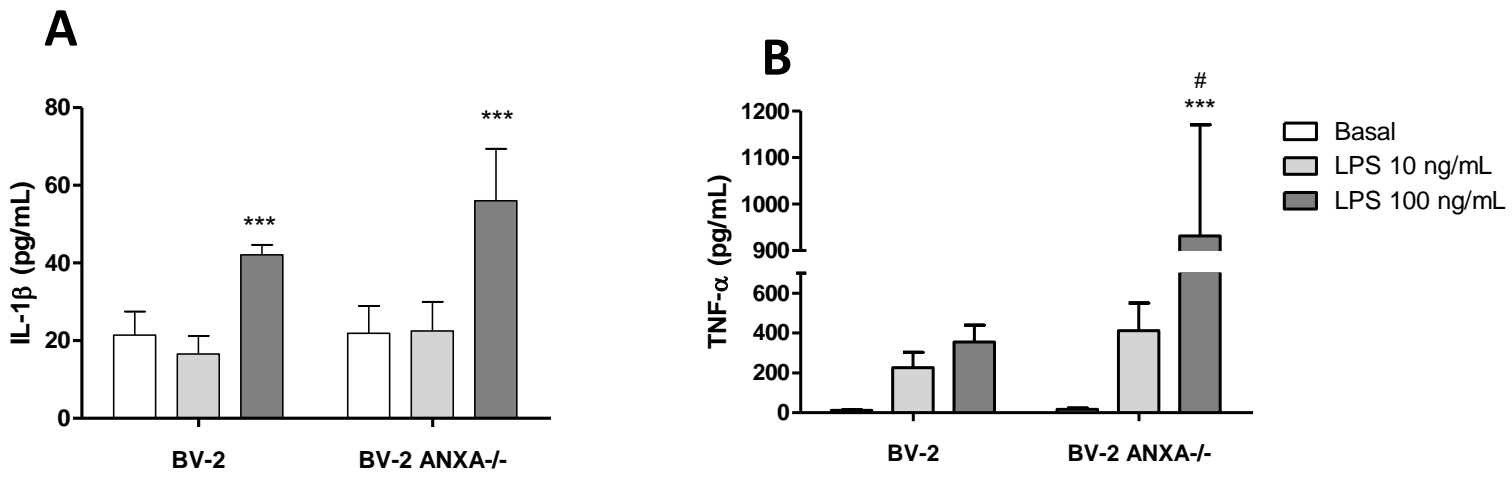

Figura 15: Efeito do silenciamento de ANXA1 em células BV2 sobre a secreção de IL-1 $\beta$ (A) e TNF- $\alpha$ (B) induzida pela incubação com 4 horas de LPS. Os dados foram obtidos por ELISA e representam a média \pm e.p.m de 6 amostras de células em cada grupo. Os resultados foram avaliados por ANOVA de duas vias. ${ }^{* *} p<0,001$ vs respectivo basal; $\# p<0,05$ vs BV2 LPS $100 \mathrm{ng} / \mathrm{mL}$

\subsection{Participação do receptor TSPO e sua correlação com a ANXA1 na secreção de mediadores inflamatórios induzidos pelo LPS}

Nossos dados mostram que a ANXA1 recombinante inibe a expressão de TSPO em células BV2. Desta forma, nos propusemos a compreender qual é o papel do TSPO na secreção de mediadores inflamatórios e qual sua correlação com a ANXA1 recombinante. Desta forma, passamos a empregar BV2 silenciadas para TSPO e tratadas com LPS e/ou ANXA1.

Os dados apresentados na Figura 16 mostram que o silenciamento de TSPO não alterou a secreção IL-1 $\beta$ basal ou aquela secretada após estímulo pelo LPS. Os dados aqui obtidos confirmaram que o tratamento com ANXA1 recombinante reduziu a secreção de IL-1 $\beta$ após incubação com LPS, e que este efeito se manteve em células deletadas de TSPO. Os dados obtidos mostram que o TSPO não é modulador da secreção de IL-1 $\beta$ por células BV2 e também não interfere com a ação inibitória da ANXA1 exógena. 
A

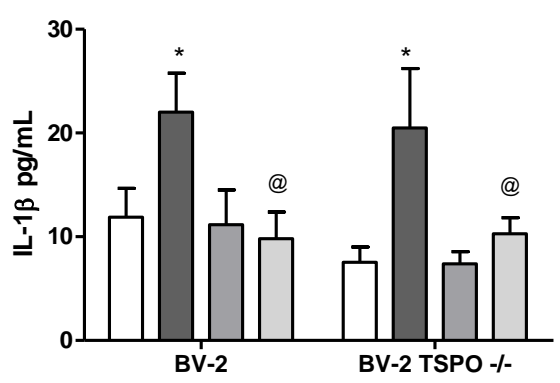

B

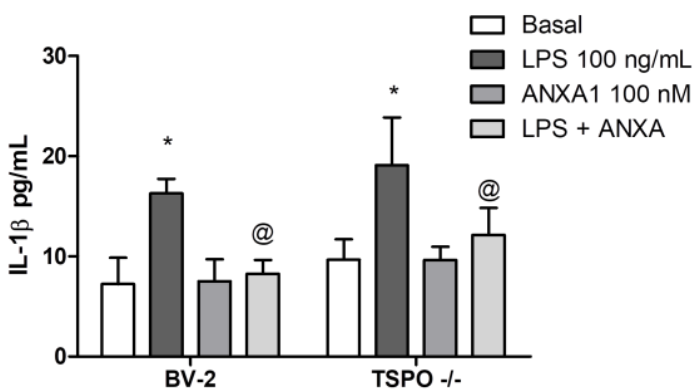

Figura 16: Efeito do silenciamento de TSPO em células BV2 e a relação com a ANXA1 sobre a secreção de IL-1 $\beta$ por células BV2 incubadas com LPS por 4 (A) ou 12 (B) horas. Os dados foram obtidos por ELISA e representam a média \pm e.p.m de 6 amostras de células em cada grupo. Os resultados foram avaliados por ANOVA de duas vias. ${ }^{* * *} p<0,001$ vs respectivos valores basais

* $p<0,05$ vs respectivo basal; @ $p<0,05$ vs valor no respectivo grupo LPS.

Diferente do observado para IL-1 $\beta$, o TSPO é um receptor que modula negativamente a secreção de TNF- $\alpha$, uma vez que as concentrações desta citocina são muito mais elevadas em células BV2 silenciadas para o TSPO e estimuladas pelo LPS do que em células normais. Ademais, o TSPO é um receptor importante para ação inibitória da ANXA1 sobre a secreção de TNF- $\alpha$. Em células silenciadas para o TSPO, a redução da secreção de TNF- $\alpha$ causada pela ANXA1 é revertida (Figura 17).

A

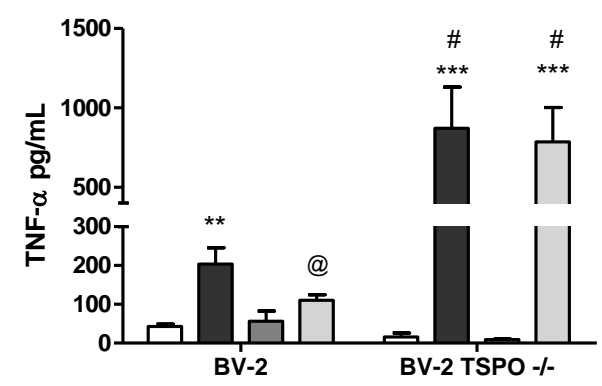

B

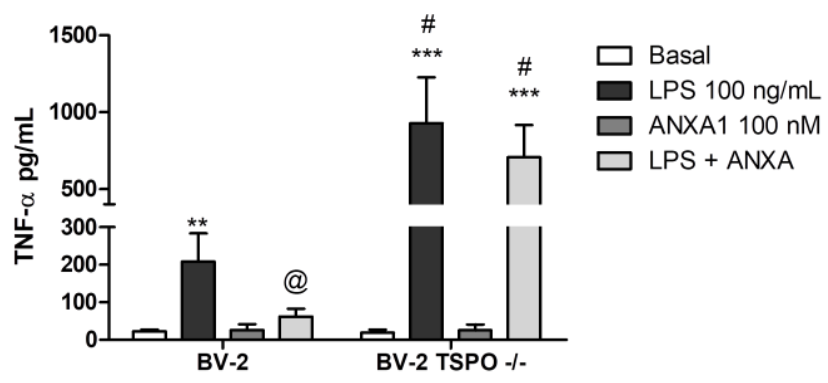

Figura 17: Efeito do silenciamento de TSPO em células BV2 e a relação com a ANXA1sobre a secreção de TNF $\alpha$ por células BV2 incubadas com LPS por 4 (A) ou 12 (B) horas. Os dados foram obtidos por ELISA e representam a média \pm e.p.m de 6 amostras de células em cada grupo. Os resultados foram avaliados por ANOVA de duas vias. ${ }^{* * *} p<0,001$ vs respectivos valores basais

${ }^{*} p<0,05,{ }^{* *} p<0,01 ;{ }^{* * *} p<0,001$ vs respectivo basal; @p $<0,05$ vs valor no respectivo grupo LPS; @ $p<0,05$ vs LPS em células BV2 \# $p<0,05$ vs BV2 LPS 
A literatura demonstra que ligantes de TSPO reduzem a secreção de TNF $\alpha$ e de IL-1 $\beta$ em células do sistem imune, entre os quais a microglia (WANG et al., 2014; 2016; ISSOP et al., 2016). Nossos resultados confirmam que o TSPO modula a secreção de TNF $\alpha$, mas não de IL-1 $\beta$.

O TGF $\beta$ foi a citocina antiinflamatória escolhida para o estudo pelas suas propriedades no desenvolvimento da inflamação e no reparo, como já salientado, e pelo fato da ANXA1 per se induzir a sua secreção. Os resultados obtidos mostraram que o TSPO não é relevante no controle da secreção de TGF $\beta$, mas interfere com a ação da ANXA1. Em células TSPO ${ }^{-1}$ houve inibição da secreção de TGF $\beta$ induzida pela ANXA1 (Figura 18).
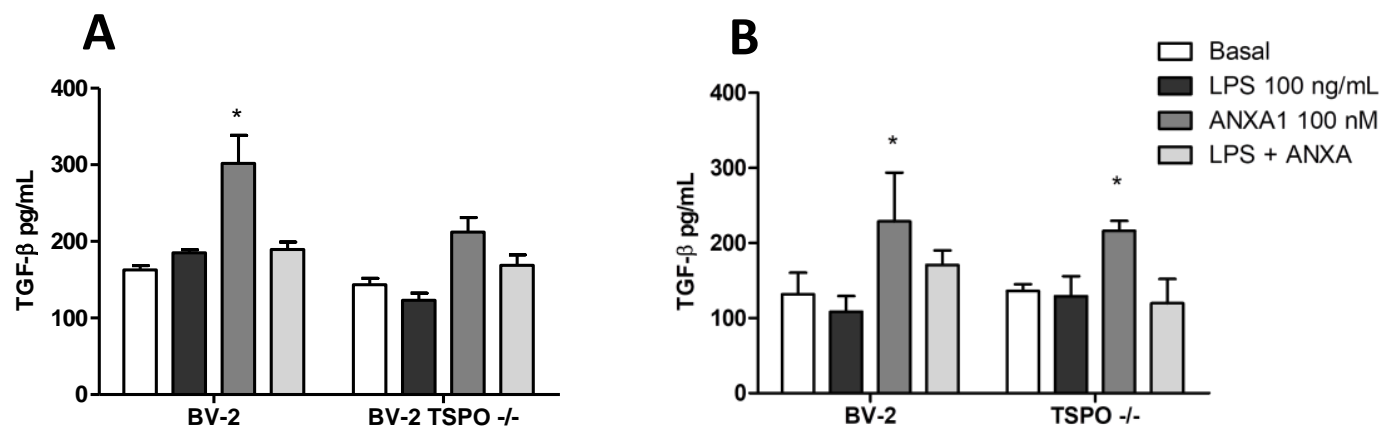

Figura 18: Efeito do silenciamento de TSPO em células BV2 e a relação com a ANXA1 sobre a secreção de TGF $\beta$ por células BV2 incubadas com LPS por 4 (A) ou 12 (B) horas. Os dados foram obtidos por ELISA e representam a média \pm e.p.m de 6 amostras de células em cada grupo. Os resultados foram avaliados por ANOVA de duas vias. ${ }^{* * *} p<0,001$ vs respectivos valores basais

${ }^{*} p<0,05$ vs respectivo basal.

Em conjunto, nossos resultados mostram, pela primeira vez, que o TSPO modula preferencialmente a secreção de TNFa após estímulo por LPS, e que reverte as ações antiinflamatórias da ANXA1. Assim, pode-se supor que o TSPO age sobre a via de TLR4 e ainda, a ausência deste receptor predispõe as células da microglia a um estado ativado.

Após avaliarmos o perfil de secreção de citocinas dessas células, nós investigamos marcadores de membrana relacionados com ativação celular uma 
vez que a marcação de receptores de membrana tem sido empregada, entre outras razões, para a caracterização do fenótipo celular (CHHOR et al., 2013).

O CD40 é um importante receptor envolvido na sinalização e ativação celular, induzindo a inflamação e mediando a apresentação de antígenos (KARMANN et al., 1995), além de estar associado à polarização para o estado de ativação M1. O aumento da expressão de CD40 no microambiente cerebral indica ativação da microglia, que é evidenciado pelo aumento de citocinas próinflamatórias como TNFa em resposta à injúria neuronal, além disso a ativação de TLR4 aumenta a expressão desse receptor (TAN et al., 1999; GAIKWAD et al., 2016).

Os resultados obtidos mostraram que o tratamento com LPS aumentou a expressão da proteína em células BV2 normais (Figura 19). As mesmas condições aplicadas às células nocautes para TSPO provocaram uma alteração no perfil de expressão do mediador prejudicando a sua resposta o que sugere que o TSPO seja importante na resposta das células BV2 a estímulo inflamatório. Podemos notar uma tendência de aumento na expressão de CD40 mesmo em condições basais após 12 horas de incubação (Figura 19 B). A estratégia de gate utilizada para avaliar os resultados obtidos encontra-se no Anexo 2.

A

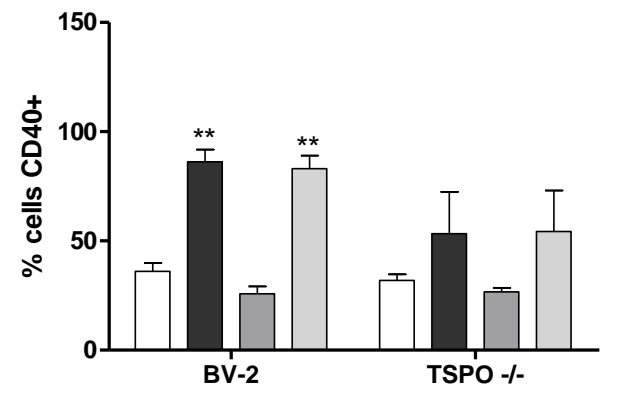

B

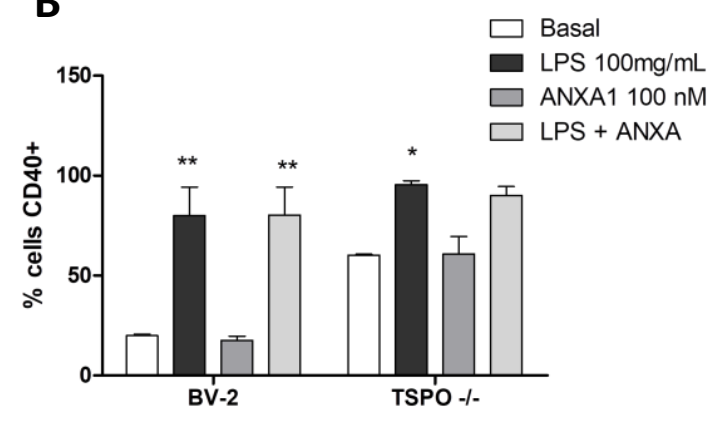

Figura 19: Efeito do silenciamento de TSPO em células BV2 e a relação do TSPO com a ANXA1 sobre a expressão de CD40 por células BV2 incubadas com LPS por 4 (A) ou 12 (B) horas. Os dados foram obtidos por citometria de fluxo e representam a média \pm e.p.m de 6 amostras de células em cada grupo. Os resultados foram avaliados por ANOVA de uma via. ${ }^{*} p<0,05,{ }^{* *} p<$ 0,01 vs respectivos valores basais 
O receptor CD36 é uma glicoproteína transmembrana de $88 \mathrm{kDa}$ que é expresso em diversos tipos celulares incluindo monócitos, macrófagos, plaquetas, células endoteliais e adipócios e pertence a uma família de receptores do tipo scavengers (PARK et al., 2014). Ele está envolvido na adesão celular, transporte de lipídeos e ácidos graxos, apresentação de antígenos e fagocitose. O CD36 coopera com o receptor TLR4 como mediador de fagócitos após estimulação por bactérias (CAO et al., 2016). A expressão deste receptor está correlacionada com a resolução do processo inflamatório.

Nossos resultados mostram que os tratamentos com LPS, ANXA1 ou LPS + ANXA1 não modificarm a expressão de CD36 em BV2 ou BV2 silenciadas para TSPO. No entanto, é importante salientar que, houve aumento pronunciado na expressão de CD36 em células silenciadas para o gene do TSPO, mesmo em condições basais (Figura 20). Este resultado é muito interessante, embora ainda não seja possível descrever sua importância biológica. Mas o fato do TSPO regular negativamente a expressão de CD36, de forma muito expressiva, sugere implicações deste receptor em doenças metabólicas, já que o CD36 é um scavenger de colesterol em células espumosas, além de ser expresso associadamente com o receptor ativado por peroxissosomo $\gamma$ (PPAR $\gamma$ ) e, desta forma, participar da resolução da inflamação na fagocitose de células apoptóticas (HE et al., 2011; MANIO et al., 2017). Como o TSPO está expresso na membrana da mitocôndria e envolvido no transporte de colesterol para esta organela, estudos adicionais devem ser realizados para investigar a relação do TSPO e CD36 em doenças metabólicas e na resolução da inflamação. A estratégia de gate utilizada para avaliar os resultados obtidos encontra-se no Anexo 2. 

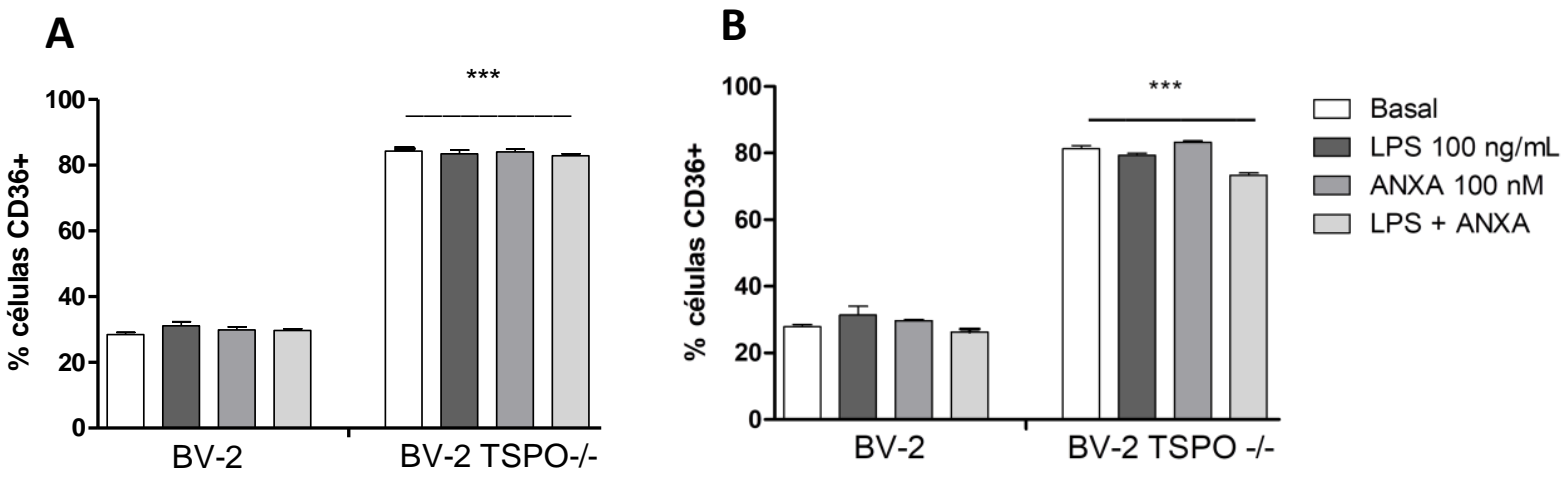

Figura 20: Efeito do silenciamento de TSPO em células BV2 e a relação do TSPO com a ANXA1 sobre a expressão de CD36 por células BV2 incubadas com LPS por 4 (A) ou 12 (B) horas. Os dados foram obtidos por citometria de fluxo e representam a média \pm e.p.m de 6 amostras de células em cada grupo. Os resultados foram avaliados por ANOVA de uma via. ${ }^{* * *} p<0,001$ vs respectrivos valores em células BV2

Em conjunto, nossos resultados utilizando células depletadas de TSPO confirmam um possível efeito protetor da proteína translocadora em relação a processo inflamatório em células BV2. Pudemos observar que, o silenciamento do receptor tornou as células pre-dispostas a exacerbação de um quadro inflamatório quando estimuladas por LPS, o que ficou bastante evidente quando avaliamos a resposta de TNFa, o que também pode ser observado quando avaliamos marcadores de membrana. Nossos dados corroboram com o que diz a literatura uma vez que Choi e colaboradores (2011), demonstraram que ligantes de TSPO podem modular a ativação da microglia, reduzindo a expressão de genes pró-inflamatórios e a secreção de citocinas.

Outro dado interessante, foi que a resposta mais pronunciada observada para células depletadas de ANXA1 ou TSPO se deu sobre a secreção do TNFa. Isso nos leva a crer que a ação desses dois moduladores do processo inflamatório, ANXA1 e TSPO, podem estar inter-relacionadas e, ao mesmo tempo, que esta conexão deve ocorrer através da via do receptor de TLR4.

Assim, decidimos investigar com mais detalhes a relação do TSPO e ANXA1 na via de ativação do TLR4. 


\section{6 - Participação do receptor de TLR4 na modulação da ANXA1 sobre TSPO}

O objetivo desta etapa foi avaliar o efeito da ANXA1 in vitro sobre a expressão e função do TSPO na vigência de estímulo inflamatório (LPS) e as vias envolvidas nesse processo. Nossos resultados confirmam dados experimentais sobre o papel antiinflamatório da ANXA1 na vigência de estímulo inflamatório pelo LPS, e mostramos que existe correlação com o TSPO em alguns eventos. Em função disso, nós avaliamos a relação entre estas duas proteínas (ANXA1 e TSPO), bloqueando o receptor TLR4. Para tanto nós utilizamos LPS proveniente da bactéria fotossintética Rhodobacter Sphaeroides (RS-LPS) ou células silenciadas para o receptor a fim de avaliar a importância do receptor Toll like 4 nos efeitos observados até aqui.

Mostramos que o receptor TLR4 está envolvido na expressão da proteína translocadora induzida pelo LPS. Após o bloqueio de TLR4 utilizando RS-LPS (Figura 21A) não houve variação significante da expressão do TSPO entre os grupos testados. Da mesma forma, o silenciamento do receptor TLR4 impediu o aumento da expressão de TSPO frente ao estímulo com LPS (Figura 21B). Podemos observar também que as células incubadas com RS-LPS tiveram um aumento na expressão de TSPO mesmo em níveis basais (Figura 21A). É possível que este aumento seja decorrente da ativação do TLR2, já que o RS-LPS se liga a este receptor ativando-o. Desta forma, embora investigações adicionais ainda sejam necessárias, é possível supor que a ativação de TLR2 cause superexpressão de TSPO. O bloqueio do receptor TLR4 aboliu o efeito inibitório da ANXA1 sobre a expressão de TSPO, mostrando, de fato, que a ação da ANXA1 depende da ativação de TLR4. Estes dados foram confirmados em células silenciadas para TLR4. 


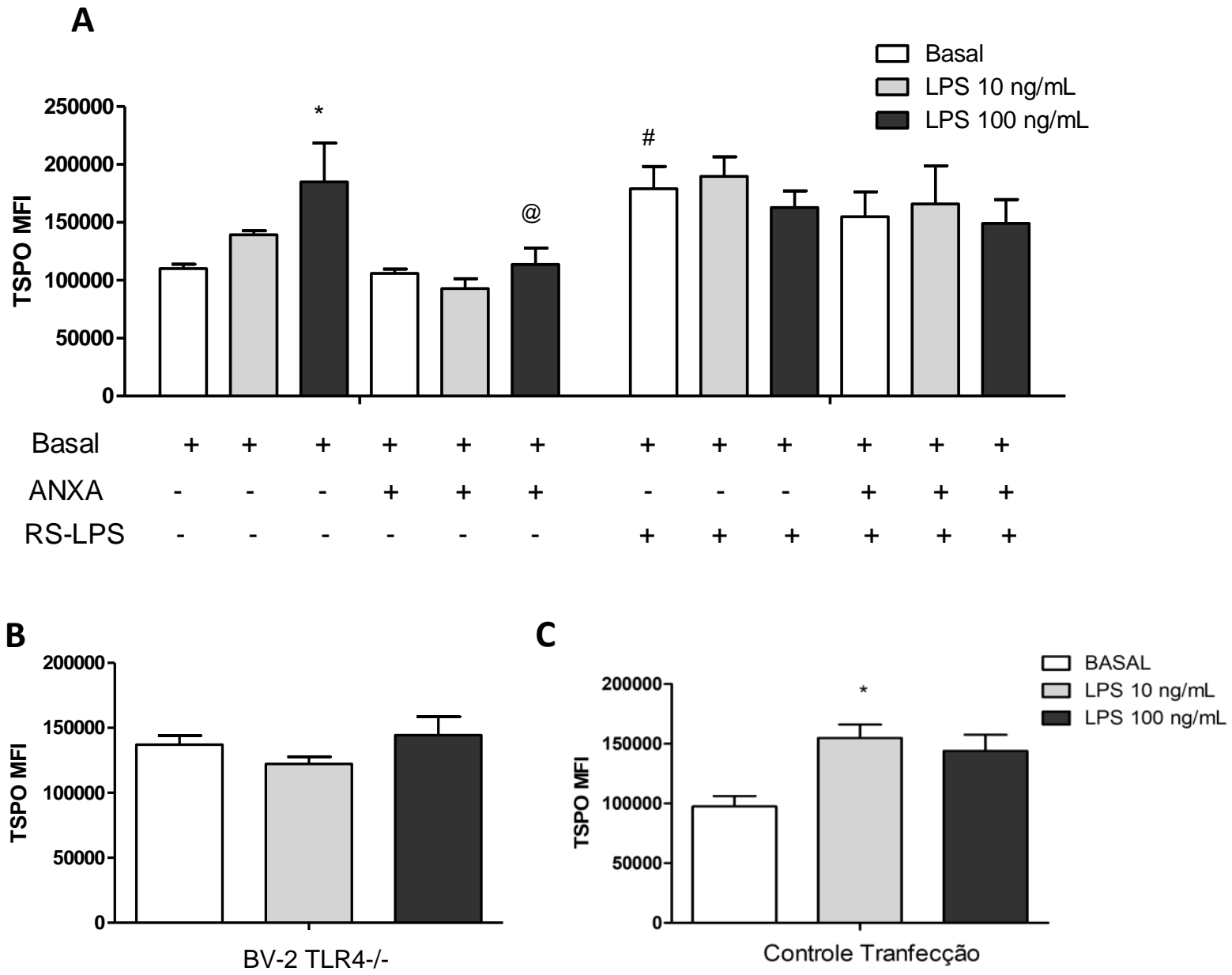

Figura 21: Expressão de TSPO em células BV2 normais (A); tratadas com RS-LPS (B); ou silenciadas para o gene de TLR4 (C) incubadas com LPS por 4 horas. Os dados foram obtidos por citometria de fluxo e representam a média \pm e.p.m de 6 amostras de células em cada grupo. Os resultados foram avaliados por ANOVA de uma via * $p<0,05$ LPS vs basal; @ $p<0,05$ vs LPS $100 \mathrm{ng} / \mathrm{mL}$; \# $\mathrm{p}<0,05$ vs basal BV2 não tratada.

Os resultados obtidos para a expressão do TSPO são inéditos e consistentes com a hipótese de atuação da ANXA1 sobre TSPO via TLR4, uma vez que o bloqueio de TLR4 impediu tanto a variação da expressão de TSPO em resposta ao estímulo do LPS quanto sua redução na presença da ANXA1. O aumento observado nas células tratadas pelo RS-LPS pode sugerir que a ativação do TLR2 também pode provocar aumento na expressão de TSPO, uma vez que o RS-LPS ativa este receptor ao mesmo tempo que bloqueia TLR4. Porém, neste caso, a ANXA1 não foi capaz de reduzir a expressão do receptor. 


\section{7 - Participação de proteínas intermediárias da via do TLR4 na modulação da ANXA1 sobre TSPO}

O LPS possui afinidade pelo receptor TLR4 resultando no recrutamento de moléculas adaptadoras como a MyD88 (KAWAl et al., 1999; LU et al., 2008). A partir da formação do complexo MyD88 ocorre uma série de interações complexas entre proteínas que compõe uma cascata de ativação, culminando na translocação de NFKB para o núcleo da célula. O NFKB é um dos principais fatores de transcrição responsáveis pela síntese de uma diversidade de moléculas infalmatórias (ZHU et al., 2017).

Dados prévios mostram que ANXA1 endógena possui papel homeostático por influenciar a via de MyD88 através da ligação ao FPR2, influenciando de forma ativa na via de sinalização de receptores TLR (BIST et al., 2013).

Baseados nessas informações, nós avaliamos a via intracelular pela qual a ANXA1 exerce seu efeito inibitório sobre a ação inflamatória do LPS em células BV2. De fato, observamos que a incubação com o LPS aumentou a expressão de MyD88 e que o tratamento com ANXA1 reduziu significantemente esta expressão (Figura 22). De forma semelhante, o tratamento com LPS induziu a translocação nuclear do NFKB 1 horas após estímulo com LPS, o que foi revertido pela ação da ANXA1. 
A

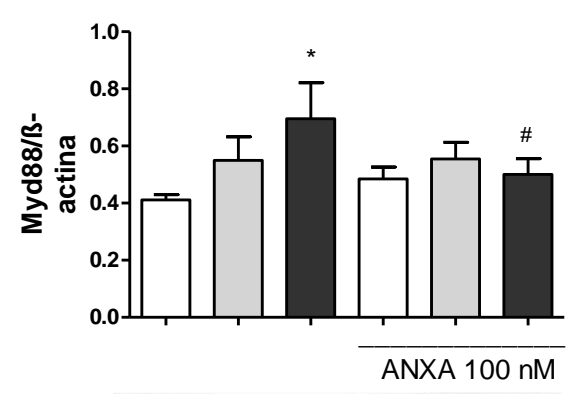

B

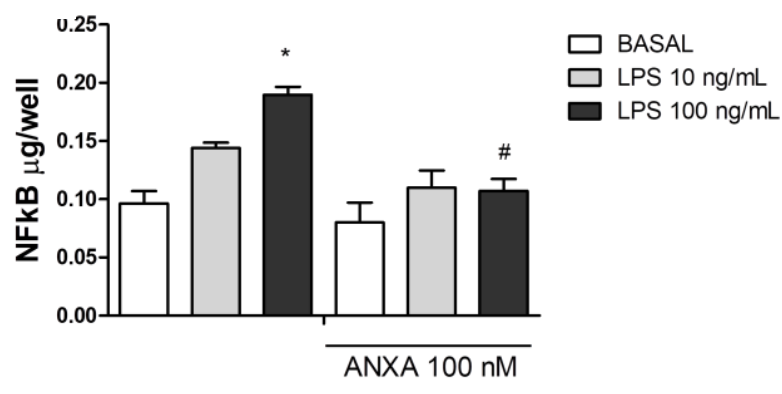

\section{MyD88}

\section{B-actina}

Figura 22: : Expressão de MyD88 (A) e de NF-kB (B) em células tratadas com ANXA1 (100 nM) e LPS (10 e $100 \mathrm{ng} / \mathrm{mL}$ ) por uma hora. Os dados foram obtidos por Western Blotting (A) e ELISA (B). e representam a média \pm e.p.m de 6 amostras de células em cada grupo. Os resultados foram avaliados por ANOVA de uma via * $p<0,05$ vs respectivos basais $\# p<0,05$ vs LPS 100 $\mathrm{ng} / \mathrm{mL}$

Os dados obtidos até aqui mostram claramente que a ANXA1 atua modulando a expressão de proteínas intermediárias da via de TLR4. A fim de confirmar nossa hipótese, nós avaliamos a interferência dessas mesmas proteínas na expressão de TSPO.

Os resultados apresentados na Figura 23 mostram que a inibição de MyD88 ou de NFKB não alteraram a expressão do TSPO em células BV2. E ainda, a incubação com LPS na presença dos inibidores bloqueou a resposta de aumento de sua expressão. Esse resultado corrobora com dados prévios da literatura uma vez que Batarseh e colaboradores (2008) mostraram que a inibição de NFKB não alterou os níveis basais de TSPO. 


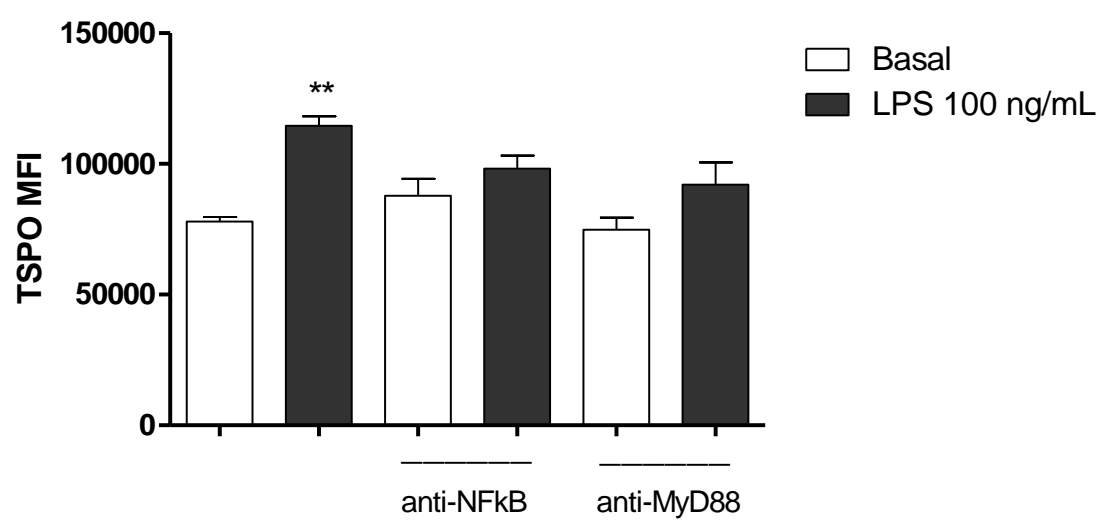

Figura 23: Expressão de TSPO em células BV2 tratadas com anti-NFkB e anti-MyD88 por uma hora. Os dados foram obtidos por citometria de fluxo e representam a média \pm e.p.m de 5 amostras de células em cada grupo. Os resultados foram avaliados por ANOVA de uma via ${ }^{* *} p<$ 0,01 vs respectivo basal

Não há descrições sobre as proteínas intermediárias da via de TLR4 e a expressão ou função de TSPO. Primiani e colaboradores (2014) mostraram que mudanças coordenadas na transcrição gênica e fenótipo inflamatório durante o processo de envelhecimento cerebral em humanos está relacionado a sobrerregulação de genes, chamados de "potencialmente pro-inflamatórios", entre os quais estão os NF-kB1, TRAF6, TLR4, IL1R1 e TSPO.

Nossos dados podem possuir ligação com este estudo, uma vez que é evidente que a expressão de TSPO e a translocação nuclear do NF-KB sofrem um incremento em função de um mesmo estímulo inflamatório.

Associados, os resultados obtidos em nosso trabalho mostram que a expressão de TSPO induzida pelo LPS é mediada pelo TLR4, e que depende da via de sinalização do MyD88/NFkB. Ademais, o efeito inibitório da ANXA1 sobre a expressão de TSPO ocorre pela regulação da mesma via intracelular. 


\section{8 - Participação do receptor FPR2 na modulação da ANXA1 sobre TSPO}

Para avaliar os mecanismos da interação da ANXA1 e TSPO no processo de neuroinflamação, investigamos ainda se os efeitos observados pela incubação das células BV2 com a ANXA1 ocorrem via receptor FPR2. Para tanto, nossa estratégia foi bloquear este receptor utilizando o antagonista WRW4 (HUGHES et al., 2017; SINNIAH et al., 2016).

Nossos resultados mostram que o bloqueio de FPR2 impediu a redução da expressão de TSPO em decorrência da ação da ANXA1. Nota-se que o perfil de expressão basal de TSPO não se alterou em função do bloqueio do receptor. (Figura 24).

A

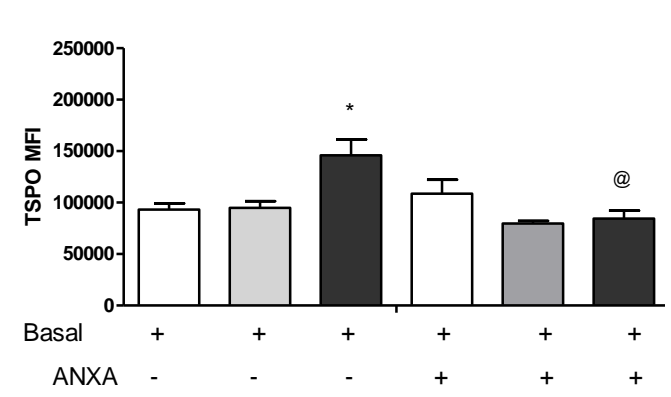

C

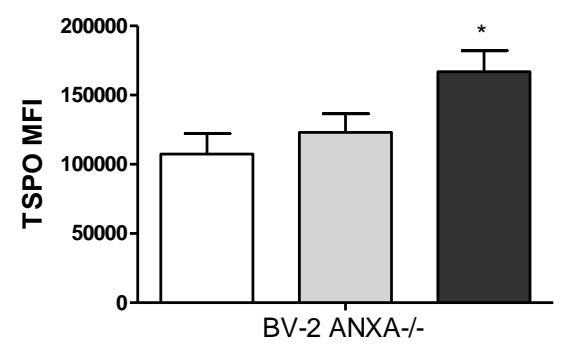

B

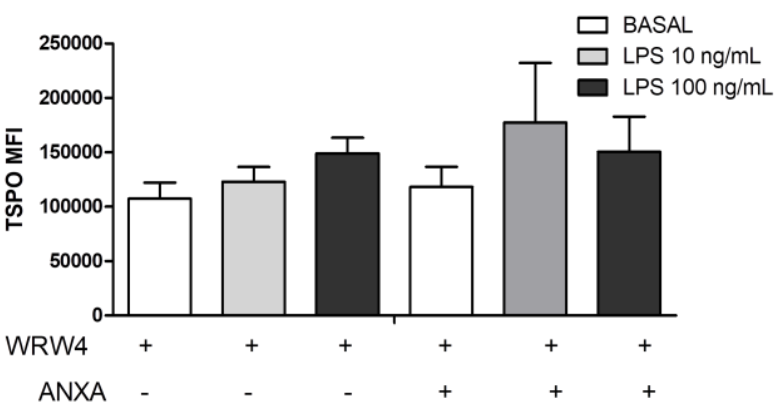

D

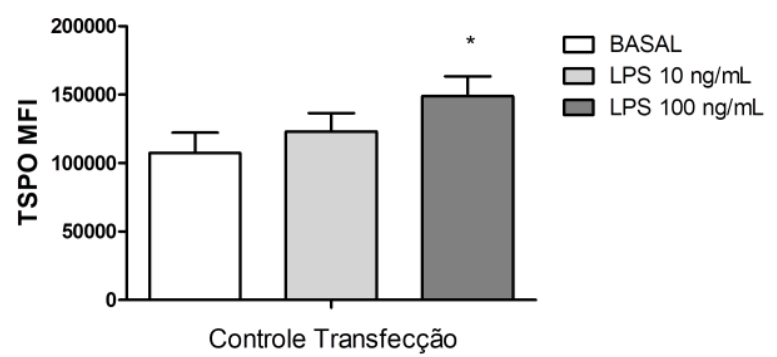

Figura 24: Expressão de TSPO em células BV2 normais (A); tratadas com WRW4 (B); o silenciadas parao gene de TSPO (C) e controle de transfecção (D)incubadas com LPS por 4 horas. Os dados foram obtidos por citometria de fluxo e representam a média \pm e.p.m de 6 amostras de células em cada grupo. Os resultados foram avaliados por ANOVA de uma via. ${ }^{*} p<$ 0,05 vs basal @p $<0,05$ vs LPS $100 \mathrm{ng} / \mathrm{mL}$. 
Os receptores de peptídeos formilados, entre eles o FPR2, pertencem à família de receptores acoplados à proteína G (GPRC) (PERRETTI \& DALLI, 2009; SCHREIBER et al., 1994). Estudos mostram que a proteína ANXA1 age diretamente sobre o receptor FPR2/ALX acoplado a proteína G (PERRETTI et al., 2002; PERRETTI et al., 2001, PERRETTI \& D'ACQUISTO 2009) levando a uma série de respostas celulares incluindo aumento de cálcio intracelular, fosforilação de ERK entre outras ações culminando em um efeito antiinflamatório (SLOWIK et al., 2012; SOLITO et al., 2003).

Em nosso trabalho nós mostramos que ANXA1 possui um papel central na modulação da expressão de TSPO em resposta a estímulo por LPS e que esta modulação se dá pela via de sinalização dos receptores TLR4 e FPR2.

\section{9 - Participação do TSPO na fagocitose de células BV2}

Uma vez que demonstramos o envolvimento da ANXA1 sobre a expressão de TSPO juntamente com a resposta obtida para a proteína de membrana CD36, que está envolvida na resolução da resposta inflamatória e na fagocitose de células apoptóticas (CAO et al., 2016; PARK, 2014; FEBBRAIO et al., 2001), nós avaliamos se o silenciamento de TSPO poderia interferir no processo de fagocitose dessas células. Os dados obtidos mostram que as células silenciadas para o gene de TSPO possuem uma menor habilidade de fagocitar neurônios apoptóticos (Figura 25). A estratégia de Gate utilizada para avaliar os resultados encontra-se no Anexo 3 : 


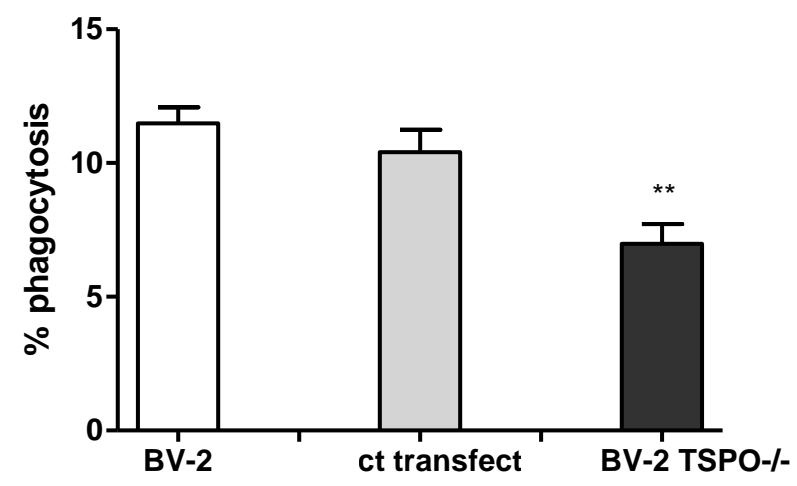

Figura 25: Efeito do TSPO na fagocitose de neurónios apoptóticos por células BV2. Os dados foram obtidos por citometria de fluxo e representam a média \pm e.p.m de 3 amostras de células em cada grupo de células. Os resultados foram avaliados por ANOVA de uma via. ${ }^{* *} p<0,01$ vs BV2.

Os dados aqui obtidos são inéditos de demonstram, que o receptor TSPO tem sua expressão sobrerregulada no processo inflamatório e ainda, que o aumento de sua expressão tem o objetivo de inibir a evolução do processo inflamatório.

O resultado apresentado na Figura 25 expõe uma modulação positiva do receptor sobre a eferocitose. Outros autores já haviam observado a relação entre o TSPO e fagocitose, Karlstertter e colaboradores (2014) utilizaram ligantes de TSPO para mostrar que este receptor possui influência na fagocitose de células de microglia.

Em conjunto, os dados obtidos neste trabalho mostram que a ANXA1 induz a secreção de citocinas antiinflamatórias em células BV2 e que nesta condição, a ANXA1 reduz a expressão de TSPO induzida pelo LPS, via interação com o receptor FPR2, e bloqueando a via de sinalização do TLR4, agindo sobre MyD88 e NFkB. Ademais, os outros dados mostram que o TSPO é um receptor que é expresso na microglia e que ele atua como inibidor do desenvolvimento da inflamação induzida pela via de ativação do LPS contribuindo também com a eferocitose. Assim, nós propusemos a existência de uma relação entre a via de ação da ANXA1 com o TSPO, e que estas vias atuam como inibidores de processos inflamatórios em células BV2. Desta forma, sugerimos que estas podem estar atuantes no controle da neuroinflamação. 
Utilizando os dados obtidos neste projeto e da literatura é possível propor a correlação ANXA1 e LPS na modulação da expressão de TSPO, como segue abaixo (Figura 26).

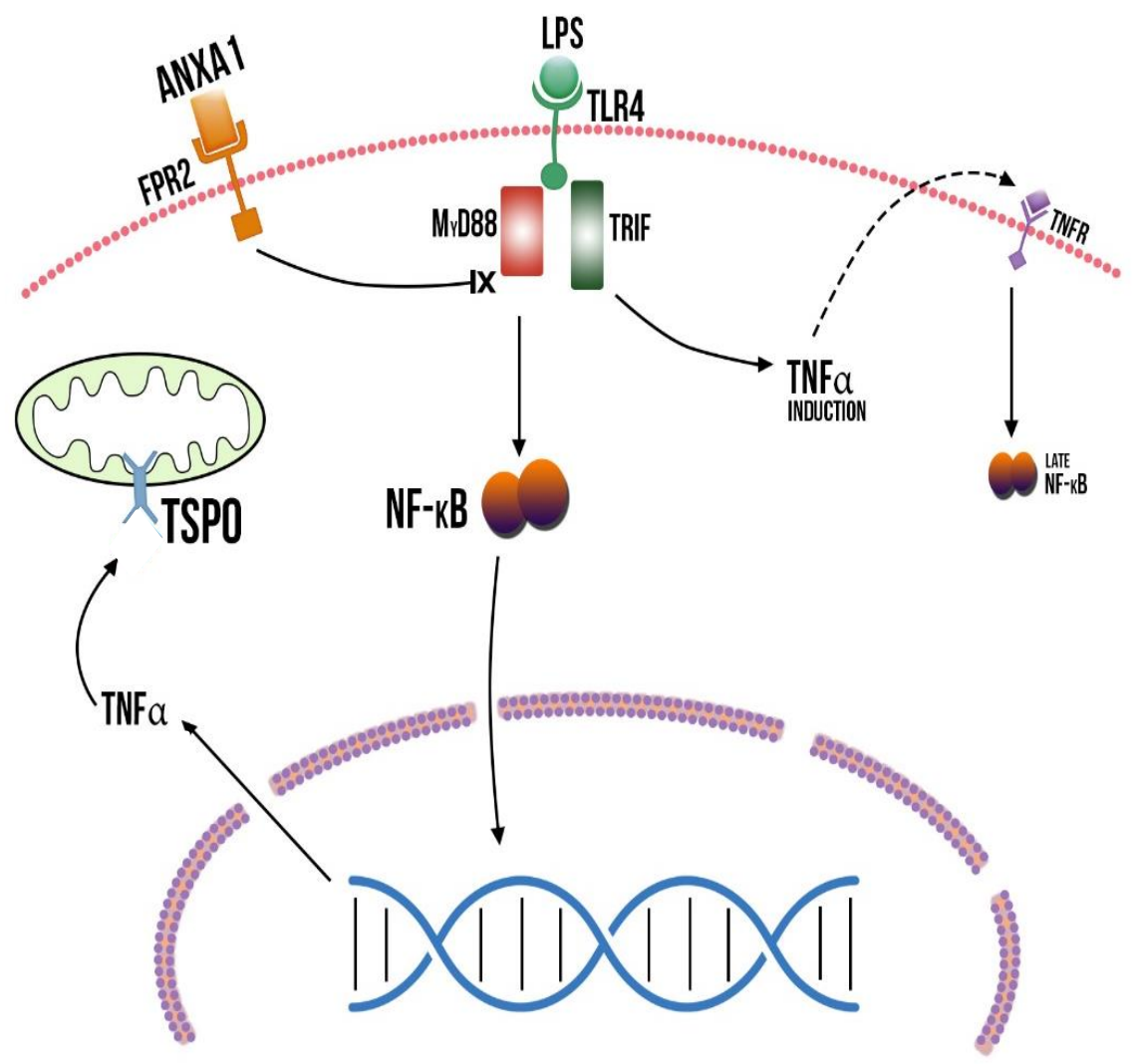

Figura 26: Mecanismo proposto para ação da ANXA1 sobre a expressão de TSPO. A ANXA1 atua sobre o receptor FPR2 e, ao mesmo tempo, bloqueia a via do TLR4 sobre MyD88. Com o bloqueio, há redução de secreção de mediadores inflamatórios como TNFa que reduz a ativação/expressão de TSPO. 


\subsection{Resultados complementares}

\subsubsection{Silenciamento e superexpressão de ANXA1 em células BV2}

A concentração dos plasmídeos recebidos foi inicialmente medida no nanodrop antes do início dos procedimentos para realizar a transfecção. As concentrações obtidas foram, respectivamente:

1 - $\quad \mathrm{pRc} / \mathrm{CMV}-35,2 \mathrm{ng} / \mu \mathrm{L}$ (correspondente ao vetor vazio).

2 - $\quad$ pANXA1 AS $-31,7 \mathrm{ng} / \mu \mathrm{L}$ (correspondente ao plasmídeo contendo a sequência anti senso para a proteína Anexina A1).

3 - $\quad$ pRc/CMV ANXA1 FL - 36,8 ng/ $\mu \mathrm{L}$ (correspondente ao plasmídeo contendo a sequência completa - full leght - para a proteína Anexina A1).

Os plasmídeos foram, então, amplificados em bactérias DH-5a e o DNA plasmidial utilizado nas transfecções foi extraído usando sistema comercial PureLink HiPure Plasmid DNA Purification Kits (Invitrogen - Grand Island - NY, EUA).

A quantificação dos vetores ao final da extração foi de:

2 - pANXA1 AS - 1659,3 ng/ $\mu \mathrm{L}$

$3-\mathrm{pRc} / \mathrm{CMVANXA1} \mathrm{FL}-913,1 \mathrm{ng} / \mu \mathrm{L}$

Após a amplificação e obtenção do plasmídeo puro, as células BV2 puderam ser transfectadas utilizando FuGene HD (Promega Corpad, Madison, USA) conforme as instruções do fabricante. Após concluído procedimento da transfecção, as células foram selecionadas utilizando meio contendo o antibiótico geneticina na concentração de $1,0 \mathrm{mg} / \mathrm{mL}$.

A eficiência na transfecção das células é de extrema importância para prosseguir no delineamento experimental deste trabalho uma vez que a 
interferência da proteína Anexina A1 sobre a expressão (gênica e proteica) de TSPO foi avaliada em condições normais e em condições de silenciamento da Anexina $\mathrm{A} 1$

\subsubsection{Validação da Transfecção}

\subsubsection{Sequenciamento}

A fim de assegurar que a amplificação realizada inicialmente para os plasmídeos foi realizada da forma esperada em relação ao gene cuja expressão foi manipulada foi necessário sequenciá-los e avaliar o pareamento das proteínas. Os primers utilizados foram desenhados com base no mapa do plasmídeo (Figuras 3 e 4) e estão apresentados abaixo:

- Primer T7 FW: 5' CGA AAT TAA TAC GAC TCA CTA TAG GG 3'

- Primer Sp6 Ver: $\quad$ 5' GCT CTA GCA TTT AGG TGA CAC TA 3'

As sequências, $\mathrm{FL}$ e AS, foram alinhadas contra o genoma de referência e foi encontrado $100 \%$ de similaridade e estão descritas abaixo:

Sequência SUPER (ANXA1 FL): full-lenght CDNA para ANXA1 contendo 1040 pb denominado $\mathrm{pRc} / \mathrm{CMV}$ ANXA1 FL

- ATGGCAATGGTATCAGAATTCCTCAAGCAGGCCTGGTTTATTGAAAATGAAG AGCAGGAATATGTTCAAACTGTGAAGTCATCCAAAGGTGGTCCCGGATCAG CGGTGAGCCCCTATCCTACCTTCAATCCATCCTCGGATGTCGCTGCCTTGC ATAAGGCCATAATGGTTAAAGGTGTGGATGAAGCAACCATCATTGACATTCT AACTAAGCGAAACAATGCACAGCGTCAACAGATCAAAGCAGCATATCTCCA GGAAACAGGAAAGCCCCTGGATGAAACACTGAAGAAAGCCCTTACAGGTCA CCTTGAGGAGGTTGTTTTAGCTCTGCTAAAAACTCCAGCGCAATTTGATGCT GATGAACTTCGTGCTGCCATGAAGGGCCTTGGAACTGATGAAGATACTCTA ATTGAGATTTTGGCATCAAGAACTAACAAAGAAATCAGAGACATTAACAGGG TCTACAGAGAGGAACTGAAGAGAGATCTGGCCAAAGACATAACCTCAGACA 
CATCTGGAGATTTTCGGAACGCTTTGCTTTCTCTTGCTAAGGGTGACCGATC TGAGGACTTTGGTGTGAATGAAGACTTGGCTGATTCAGATGCCAGGGCCTT GTATGAAGCAGGAGAAAGGAGAAAGGGGACAGACGTAAACGTGTTCAATAC CATCCTTACCACCAGAAGCTATCCACAACTTCGCAGAGTGTTTCAGAAATAC ACCAAGTACAGTAAGCATGACATGAACAAAGTTCTGGACCTGGAGTTGAAA GGTGACATTGAGAAATGCCTCACAGCTATCG

Sequência ANXA AS: sequência anti-senso contendo 476 pb denominado ANXA1 AS

- ATGGCAATGGTATCAGAATTCCTCAAGCAGGCCTGGTTTATTGAAAATGAAG AGCAGGAATATGTTCAAACTGTGAAGTCATCCAAAGGTGGTCCCGGATCAG CGGTGAGCCCCTATCCTACCTTCAATCCATCCTCGGATGTCGCTGCCTTGC ATAAGGCCATAATGGTTAAAGGTGTGGATGAAGCAACCATCATTGACATTCT AACTAAGCGAAACAATGCACAGCGTCAACAGATCAAAGCAGCATATCTCCA GGAAACAGGAAAGCCCCTGGATGAAACACTGAAGAAAGCCCTTACAGGTCA CCTTGAGGAGGTTGTTTTAGCTCTGCTAAAAACTCCAGCGCAATTTGATGCT GATGAACTTCGTGCTGCCATGAAGGGCCTTGGAACTGATGAAGATACTCTA $\underline{A T T}$

\subsubsection{2 - Caracterização das células após a tranfecção}

Podemos notar que as células, após receberem o plasmídeo, apresentam taxas de crescimento diferenciadas sendo o crescimento das células que receberam o plasmídeo contendo a sequência FL estatisticamente inferior ao crescimento das células BV2 não transfectadas em todos os períodos avaliados, conforme pode ser observado na Figura 27: 


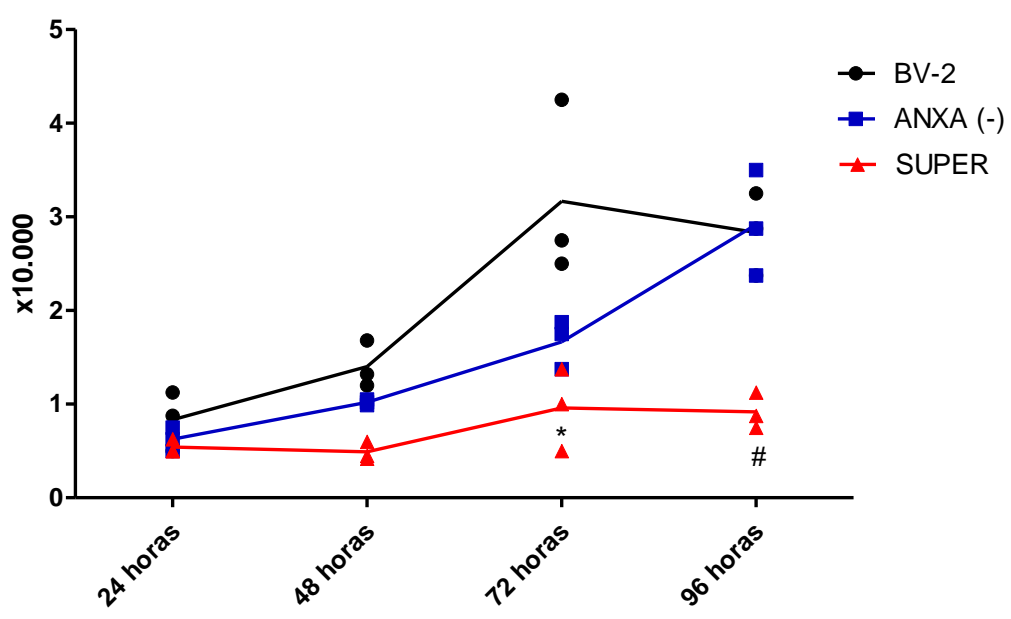

Figura 27: Curva de crescimento comparativa das células que receberam plasmídeo contendo a sequancia anti-senso para ANXA1 (ANXA -) e a sequência full leght (SUPER) após a transfecção. Ensaio realizado utilizando Câmara de Neubauer, $n=3 * p<0,05$ vs BV2 72 horas; \# $p<0,05$ vs BV2 96 horas.

\subsubsection{3 - Níveis de ANXA}

Além disso, após a transfecção, quantificamos a diferença na expressão da proteína ANXA1 pelas técnicas de ELISA e Western Blotting nas células conforme pode ser visto na Figura 28.

A

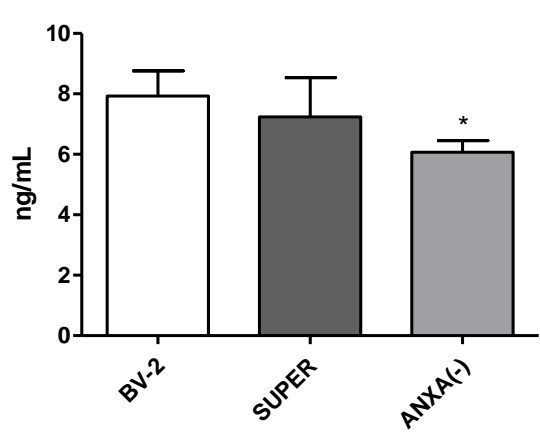

B

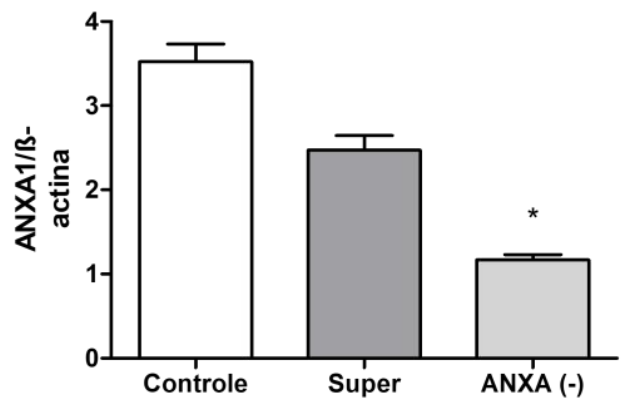

ANXA1 (37kDa)

$\beta$ Actina (42 kDa)

Figura 28: Níveis de ANXA1 intracelular utilizando a técnica de ELISA (A) e Western Blotting (B). Avaliado por ANOVA de uma via $\mathrm{n}=3$.

${ }^{*} p<0,05$ vs $B V 2$ 
Os resultados da validação da transfecção mostram que há uma pequena redução da expressão de ANXA1 nas células BV2 que receberam o plasmídeo contendo a sequência anti-sense para a proteína e ainda, não pudemos observar incremento na produção da Anexina A1 nas células que receberam o plasmídeo contendo a sequência full lenght para ANXA1.

A pequena redução na expressão da ANXA1 nas células ANXA (-) está de acordo com os resultados obtidos por McArthur (2010) no qual foi reportada uma redução de $13,98 \%$. Porém, este mesmo trabalho descreve um incremento na expressão de ANXA1 quando o plasmídeo contendo a sequencia de 1040 pb foi inserida nas células. Os resultados reportados por este trabalho podem ser apreciados na Figura 31:

A

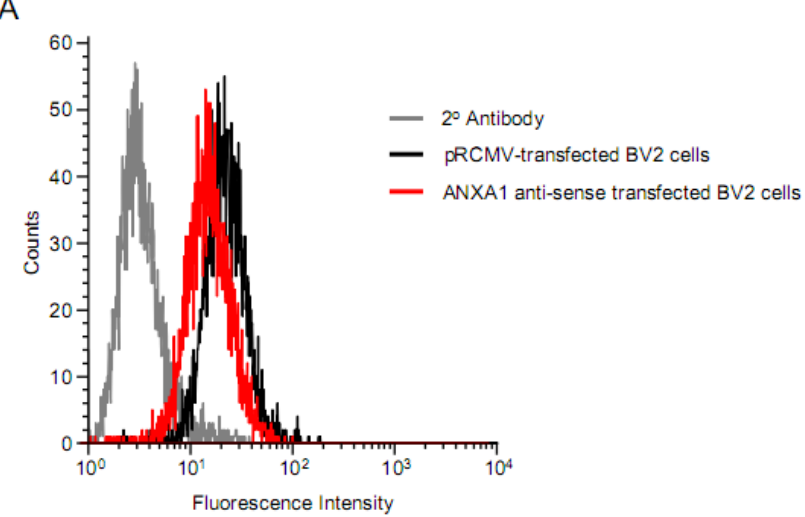

B

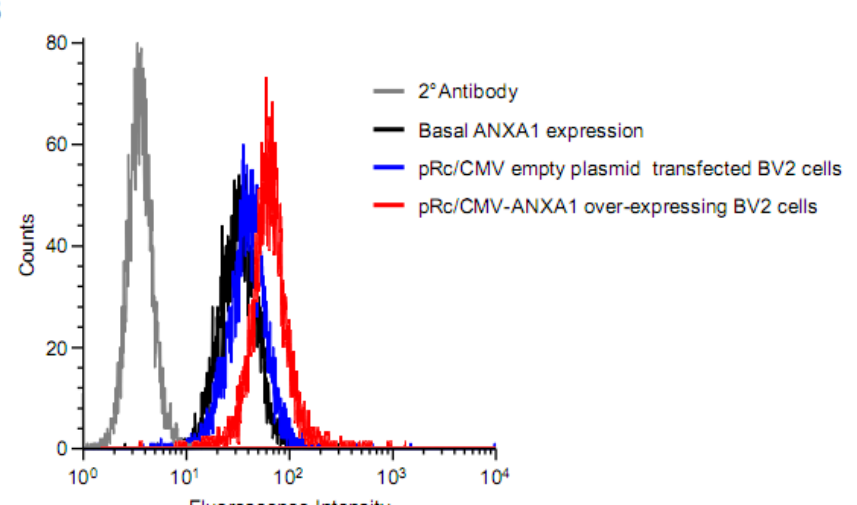

Figura 29: Resultados da caracterização de células BV2 transfectadas utilizando a técnica de citometria de fluxo (FONTE: McArthur et al., 2010). 


\subsubsection{Silenciamento de TSPO e TLR4}

No caso dos plasmídeos utilizados para silenciar a expressão de TSPO e TLR4 que as células apresentam taxas de crescimento semelhantes aos das células BV2 não transfectadas em todos os períodos avaliados, conforme pode ser observado na Figura 32:

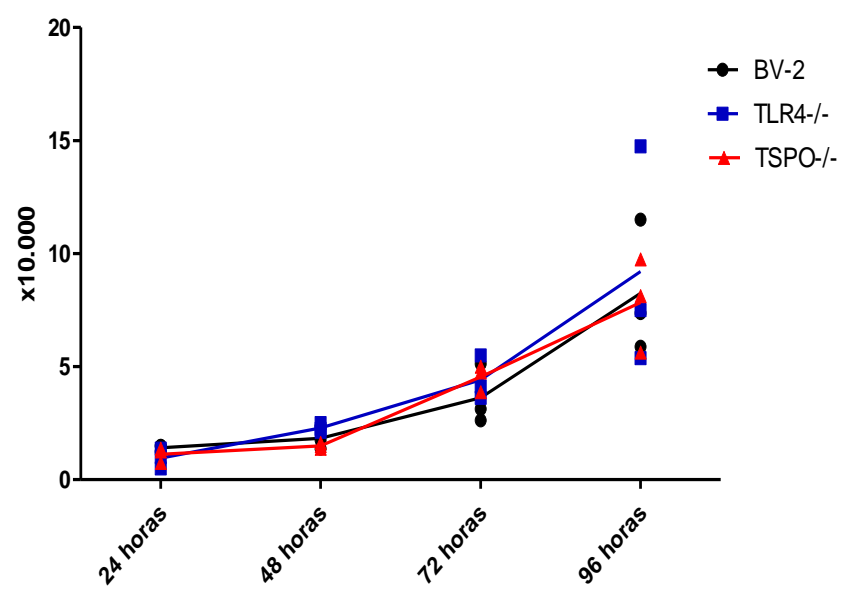

Figura 32: Curva de crescimento comparativa das células que receberam plasmídeo contendo a sequência anti-senso para TLR4 (TLR4-/-) e a sequência anti-senso para TSPO (TSPO-/-) após a transfecção. Ensaio realizado utilizando Câmara de Neubauer, $n=3$.

Além disso, após a transfecção, quantificamos a diferença na expressão das respectivas proteínas pela técnica de citometria de fluxo nas células conforme pode ser visto na Figura 31. Podemos observar $40 \%$ de redução na expressão de TLR4 (Figura 31 a) e 55\% de redução para TSPO (Figura 31 b): 
A

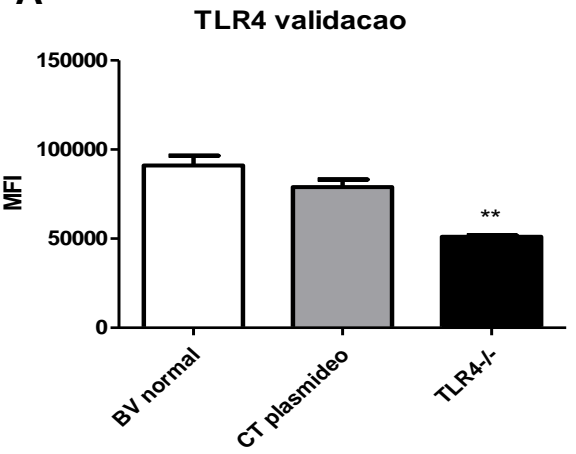

B

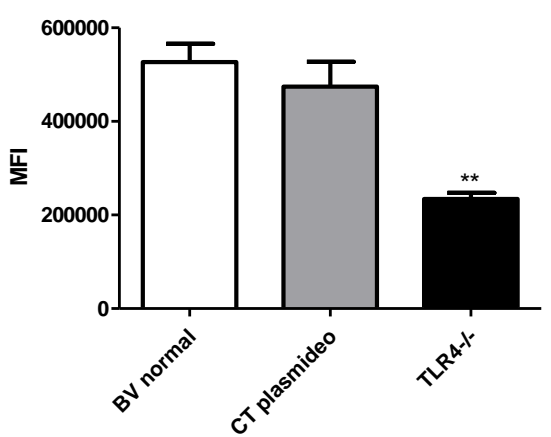

Figura 33: Níveis de TLR4 (A) e TSPO (B) intracelular utilizando a técnica de citometria de fluxo $n=3 .{ }^{* *} p<0,01$ vs BV2 


\section{5 - CONCLUSÕES}

Os resultados obtidos neste trabalho permitem concluir que:

1) A ANXA1 exógena modula negativamente a expressão de TSPO por células BV2 estimuladas pelo LPS;

2) A ANXA1 exógena induz perfil de secreção de citocinas características de perfil antiinflamatório em células BV2 estimuladas pelo LPS;

3) A expressão de TSPO pelo LPS é dependente da via do receptor TLR4 e da ativação das vias MyD88 e NFkappa B;

4) A ANXA1 bloqueia a expressão de TSPO por ligar-se ao FPR2 e inibir a expressão de MyD88 e a translocação de NFKB;

5) O TSPO modula negativamente a secreção do TNF- $\alpha$ e a expressão de CD36 ao mesmo tempo que modula positivamente a fagocitose de neurônios apoptóticos pela célula BV2. 


\section{6 - REFERÊNCIAS BIBLIOGRÁFICAS}

ABED, A.;Minaiyan, M.; Safaei, A.; Taheri, D. Effect of Diazepam on Severity of Acute Pancreatitis: Possible Involvement of Peripheral Benzodiazepine Receptors, ISRN Gastroenterol, 2013

AARUM, J.; SANDBERG, K.; HAEBERLEIN, S.; PERSSON, M. Migration and differentiation of neural precursor cells can be directed by microglia, Proc. Natl. Acad. Sci. USA, v. 100, p. 15983, 2003.

ABBAS; A; JANEWAY, C. JR. Immunology: Improving on Nature in the Twenty-First Century. Cell. v. 100, p. 129-138, 2000.

AKIRA S, TAKEDA K. Toll-like receptor signalling. Nat Rev Immunol 4:499-511 4:499_ $511,2004$.

ALIPRANTIS, A., YANG, R.; MARK, M.; SUGGETT, S.; DEVAUX, B.; RADOLF, J. Cell activation and apoptosis by bacterial lipoproteins through toll-like receptor-2. Science 285:736-9. 1999.

AMANTEA, D.; MICIELI, G.; TASSORELLI, C.; CERTO, M.; MORO, M.; LIZASOAIN, I.; BAGETTA, G. Rational modulation of the innate immune system for neuroprotection in ischemic stroke, Front Neurosci, v. 9, p. 147, 2015.

ARUR, S.; UCHE, U.; REZAUL, K.; FONG, M.; SCRANTON, V.; COWAN, A.; MOHLER, W.; HAN, D. Annexin I is an endogenous ligand that mediates apoptotic cell engulfment. Dev. Cell 4, 587-598, 2003.

BABBIN, B.; LEE, W.; PARKOS, C.; WINFREE, L.; AKYILDIZ, A.; PERRETTI, M.; NUSRAT, A. Annexin I regulates SKCO-15 cell invasion by signaling through formyl peptide receptors. J. Biol. Chem. v. 281, p. 19588-19599, 2006.

BAE, K.; SHIM, H.; BALU, D.; KIM, S.; YU, S. Translocator protein 18 kDa negatively regulates inflammation in microglia, J Neuroimmune Pharmacol. , v. 9(3), P. 424-37, 2014.

BARRIENTOS, R.; HIGGINS, E.; BIEDENKAPP, J.; SPUNGER, D.; WRIGHTHARDESTY, K. Peripheral infection and aging interact to impair hippocampal memory consolidation. Neurobiology of aging, v. 27, p. 723-732, 2006.

BANATI, R.; MIDDLETON. R.; CHAN, R.; HALTY, C.; KAM, W.; QUIN, C.; HOWELL, N.; SZABO, A.; PHAM, T.; DAVIS, E.; LIU, G. Positron emission tomography and functional characterization of a complete PBR/TSPO knockout. Nat Commun, v. 5, p. 5452, 2014.

BATARSEH, A.; PAPADOPOULOS, V. Regulation of Translocator Protein $18 \mathrm{kDa}$ (TSPO) Expression in Health and Disease States, Mol Cell Endocrinol., v. 327(1-2), p. 112, 2010.

BATARSEH, A.; GIATZAKIS, C.; PAPADOPOULOS, V. Phorbol-12-myristate 13-acetate acting through protein kinase $\mathrm{C} \varepsilon$ induces translocator protein $(18-\mathrm{kDa})$ Tspo gene expression, Biochemistry, v. 47(48), p. 12886-12899, 2008. 
BARRIENTOS, R.; HIGGINS, E.; BIEDENKAPP, J.; SPUNGER, D.; WRIGHTHARDESTY, K. Peripheral infection and aging interact to impair hippocampal memory consolidation. Neurobiology of aging, v. 27, p. 723-732, 2006.

BARRIONUEVO, P.; BEIGIER-BOMPADRE, M.; ILARREGUI, J.; TOSCANO, M.; BIANCO, G.; ISTURIZ, M.; RABINOVICH, G. A novel function for galectin-1 at the crossroad of innate and adaptive immunity: galectin-1 regulates monocyte/macrophage physiology through a nonapoptotic ERK-dependent pathway. J. Immunol. v. 178, p. 436445, 2007.

BARRON, A.; GARCIA-SEGURA, L.; CARUSO, D.; JAYARAMA, A.; LEE, J.; MELCANGI, R.; PIKE, C. Ligand for translocator protein reverses pathology in a mouse model of Alzheimer's disease. J Neurosci v. 15(33), p. 8891-8897, 2013.

BARROS, M.; HAUCK, F.; DREYER, J.; KEMPKES, B.; NIEDOBITEK, G. Macrophage Polarisation: an Immunohistochemical Approach for Identifying $\mathrm{M} 1$ and $\mathrm{M} 2$ Macrophages, Plos One, V. 8(11), E:80908, 2013

BARTHOLOME, B. SPIES, C. M.; GABER, T.; SCHUCHMANN, S.; BERKI, T.; KUNKEL, D.; BIENERT, M.; RADBRUCH, A.; BURMESTER, G. R.; LAUSTER, R.; SCHEFFOLD, A.; BUTTGEREIT, F. Membrane glucocorticoid receptors (mGCR) are expressed in normal human peripheral blood mononuclear cells and up-regulated after in vitro stimulation and in patients with rheumatoid arthritis. FASEB J., v. 18, p. 70-80, 2004.

BECKER, C.; O'NEIL, L. Inflammasomes in inflammatory disorders: the role of TLRs and their interactons with NLRs. Semin Immunopathol, 29:239-48, 2007.

BIST, P.; SHU, S.; LEE, H.; ARORA, S.; NAIR, S.; LIM, J.; DAYALAN, J.; GASSER, S.; BISWAS, S.; FAIRHURST, A.; LIM, L. Annexin-A1 regulates TLR-mediated IFN- $\beta$ production through an interaction with TANK-binding kinase 1, J Immunol, v. 191 (8), p. 4375-82, 2013.

BISWAS, S. \& MANTOVANI, A. Macrophage plasticity and interaction with lymphocyte subsets: cancer as a paradigm. Nature Immunol. v. 11, p. 889-896, 2010.

BIZZARRO, V; PETRELLA, A.; PARENTE, L. Annexin A1: novel roles in skeletal muscle biology. J Cell Physiol, v. 227(8), p. 3007-15, 2012.

BLAUSIUS, A., BEUTLER, B. Intracellular toll-like receptors. Immunity 32:305-15, 2010.

BRADEN, S.; POST, J.; HENSLEY, K. A comparative review of cell culture systems for the study of microglial biology in Alzheimer's disease, Journal of Neuroinflammation, v.9, p.115, 2012.

BRENER, Z. Terapêutica Experimental na Doença de Chagas. In: BRENER, Z.; ANDRADE, Z. A.; BARRAL-NETO, M. (Orgs). Trypanosoma cruzi e Doença de Chagas. 2 ed. Rio de Janeiro: Guanabara Koogan, Cap 18, p.379-388, 2000.

BRUUNSGAARD, H.; ANDERSEN-RANBERG, K.; JEUNE, B.; PEDERSEN, A.; SKINKOJ, $\mathrm{P}$. A high plasma concentration of TNF-alpha is associated with dementia in centenarians. J Gerontol A Biol Sci Med Sci 54: M357-364, 1999. 
BESSLER, H.; CASPI, B.; GAVISH, M.; REHAVI, M.; WEIZMAN, A. Significant inhibition of spontaneous IgA secretion by selective peripheral-type benzodiazepine receptor ligands. Clin Neuropharmacol, v. 20(3), p. 215-23, 1997.

CABRAL, G. A. Lipids as bioeffectors in the immune system. Life Science., v. 77(14), p. 1699-1710, 2005.

CAO, D.; LUO, J.; CHEN, D.; XU, D.; SHI, H.; JING, X.; ZANG, W. CD36 regulates lipopolysaccharide-induced signaling pathways and mediates the internalization of Escherichia coli in cooperation with TLR4 in goat mammary gland epithelial cells, Sci Rep. 2016; 6: 23132.

CAVALCANTI, D. M. H.; LOTUFO, C. M. C.; BORELLI, P.; TAVASSI, A. M. C.; PEREIRA, A. L. M.; MARKUS, R. P.; FARSKY, S. H. P. Adrenal deficiency alters mechanisms of neutrophil mobilization. Mol. Cell. Endocrinol., v. 249, p. 32-39, 2006.

CAVALCANTI, D. H. M.; LOTUFO, C. M. C.; BORELLI, P.; FERREIRA, Z. S.; MARKUS, R. P.; FARSKY, S. H. P. Endogenous glucocorticoids control neutrophil mobilization from bone marrow to blood and tissues in non-inflammatory conditions. $\mathrm{Br} \mathrm{J}$. Pharmacol., v. 152, p. 1291-1300, 2007.

CERAMI, C.; LACCARIONO, L; PERANI, D. Molecular Imaging of Neuroinflammation in neurodegenerative dementias: Role of in vivo PET imaging, Int J Mol Sci, 18(5), 2017.

CHAVEAU, F. VAN CAMP. N.; HINNEN, F. KASSIOU, M. TAVITIAN, B. Comparative evaluation of the translocator protein radioligands 11C-DPA-713, 18F-DPA-714, and $11 \mathrm{C}-\mathrm{PK} 11195$ in a rat model of acute neuroinflammation. J Nucl Med, v. 50(3), p. 46876, 2009

CHAVEAU, F.; BOUTIN, H.; VAN, C.; MARGUET, F, CASTEL, M. BENAVIDES, J. DOLLE, F; TAVITIAN, B. In vivo imaging of neuroinflammation in the rodent brain with [11C]SSR180575, a novel indoleacetamide radioligand of the translocator protein (18 kDa). Eur J Nucl Med Mol Imaging. 38(3):509-14, 2011.

CHEN, M. K. \& GUILARTE, T. R. Translocator protein 18kDa (TSPO): molecular sensor of brain injury and repair. Pharmacol. Ther. v. 118, p. 1-17 2008.

CHEN, M. KUWABARA, H.; ZHOU, Y.; ADAMS, R.; BRASIC, J. VERINA, T.; KUMAR, A.; WONG, D.; GUILARTE, T. VMAT2 and dopamine neuron loss in a primate model of Parkinson's disease, J Neurochem, v. 105(1), p. 78-90, 2008.

CHEN, W.; HUANG, S.; LIAO, C.; SUNG, C.; CHEN, J.; WEN, Z. The use of the antimicrobial peptide piscidin (PCD) -1 as a novel anti-nociceptive agent, Biomaterials, $v$. 53 , p. $1-11,2015$

CHOA, N.; YANGB, H.; KIMA, J.; KIMA, Y.; SUNG, S. Chemical constituents isolated from Disporum viridescens leaves and their inhibitory effect on nitric oxide production in BV2 microglial cells, Bioorganic \& Medicinal Chemistry Letters, v. 24, p. 5675-5678, 2014

CHHOR, V.; Le CHARPENTIER, T.; LEBON, S.; ORE, M.; CELADOR, I.; JOSSERAND, J.; DEGOS, V.; JACOTOT, E.; HAGBERG, H.; SAVMAN, K.; MALLARD, C.; GRESSENS, P.; FLEISS, B. Characterization of phenotype markers and neuronotoxic 
potential of polarised primary microglia in vitro, Brain Behav Immun. v. 32(100), p. $70-$ 85, 2013.

CHING, A.; KUHNAST, B.; DAMONT, A.; ROEDA, D.; TAVITIAN, B.; DOLLÉ, F. Current paradigm of the $18-\mathrm{kDa}$ translocator protein (TSPO) as a molecular target for PET imaging in neuroinflammation and neurodegenerative diseases, Insights Imaging, V.3(1), p. 111-119, 2012.

CHIANG, N.; SERHAN, C.; DAHLEN, S.; DRAZEN, J.; HAY, D.; ROVATI, G.; SHIMIZU, T.; YOKOMIZO, T.; BRINK, C. The lipoxin receptor ALX: potent ligand-specific and stereoselective actions in vivo. Pharmacol. Rev. v. 58, p. 463-487, 2006.

CHOI, J., IFUKU, M.; NODA, M.; GUILARTE, T.R. Translocator protein (18 $\mathrm{kDa} /$ peripheral benzodiazepine receptor specific ligands induce microglia functions consistent with an activated state. Glia, v. 59(2), p. 219-30, 2011

COSTA, B.; POZZO, E.; MARTINI, C. Translocator protein as a promising target for novel anxiolytics, Curr Top Med Chem., v. 12(4), p. 270-85, 2012.

CÔTÉ, M.; POIRIER, A.; AUBÉ, B.; JOBIN, C.; LACROIX, S.; SOULET, D. Partial depletion of the proinflammatory monocyte population is neuroprotective in the myenteric plexuss but not in the basal ganglia in a MPTP mouse model of Parkinson's disease. Brain Behav. Immun. 46,154-167, 2015.

COVERT, M., LEUNG, T., GASTON, J. \& BALTIMORE, D. Achieving stability of lipopolysaccharide-induced NF-kappaB activation. Science, v. 309, p. 1854-7. 2005.

CUNNINGHAM, A.; MURRAY, C.; O'NEILL, L.; LYNCH, M.; O'CONNOR, J. Interleukin1 beta (IL-1 beta) and tumour necrosis factor (TNF) inhibit long-term potentiation in the rat dentate gyrus in vitro Neuroscience Letters, 203, p. 17-20, 1996.

CUZZOCREA, S.; CHATTERJEE, P.; MAZZON, E.; DUGO, L.; SERRAINO, I.; BRITTI, D.; MAZZULLO, G.; CAPUTI, A.; THIEMERMANN, C. Pyrrolidine dithiocarbamate attenuates the development of acute and chronic inflammation, $\mathrm{Br} \mathrm{J}$ Pharmacol. 135(2): 496-510, 2002.

DALLI, J.; MONTERO-MELENDEZ, T.; McARTHUR, S.; PERRETI, M. Annexin A1 Nterminal derived Peptide ac2-26 exerts chemokinetic effects on human neutrophils. Front. Pharmacol. V. 28, p. 3-28, 2012.

DANTZER, R.; KELLEY, K. Twenty years of research on cytokine-induced sickness behavior. Brain, behavior, and immunity, v. 21, p. 153-160, 2007.

DAVALOS, D.; GRUTZENDLER, J.; YANG, G.; KIM, J.; ZUO, Y.; JUNG, S.; LITTMAN, D.; DUSTIN, M.; GAN, W. ATP mediates rapid microglial response to local brain injury in vivo. Nature Neurosci. v. 8,p. 752-758, 2005.

DEMEESTERE, D.; LIBERT, C.; VANDENBROUCKE, R. Clinical implications of leukocyte infiltration at the choroid plexus in (neuro)inflammatory disorders, Drug Discovery Today, 2015.

DENES, A., FERENCZI, S., HALASZ, J., KORNVEI, Z., KOVACS, K. Role of CX3CR1 (fractalkine receptor) in brain damage and inflammation induced by focal cerebral ischemia in mouse. J. Cereb. Blood Flow Metab. v. 28, p. 1707-1721. 2008. 
DEY, A.; ALLEN, J.; HANKEY-GIBLIN, P. Ontogeny and Polarization of Macrophages in Inflammation: Blood Monocytes Versus Tissue Macrophages, Front Immunol., v. 5, p. 683, 2014.

DIAS, N.; SELCER, K. Steroid sulfatase in the human MG-63 preosteoblastic cell line: Antagonistic regulation by glucocorticoids and NFKB, Molecular and Cellular Endocrinology, vol 420, p.85-96, 2016.

DICKENS, A.; VAINIO, S.; MARJAMAKI, P.; JOHANSSON, J.; LEHTINIEMI, P.; ROKKA, J.; RINNE, J.; SOLIN, O.; HAAPARANTA-SOLIN, M.; JONES, P.; TRIGG, W.; ANTHONY, D.; AIRAS, L. Detection of microglial activation in an acute model of neuroinflammation using PET and radiotracers11C-(R)-PK11195 and 18F-GE-180, J Nucl Med, v. 55(3), p. 466-72, 2014.

DRIESSLER, F.; VENSTROM, K.; SABAT, R.; ASADULLAH, K.; SCHOTTELIUS, A. Molecular mechanisms of interleukin-10-mediated inhibition of NF-KB activity: a role for p50, Clin Exp Immunol., 135(1): 64-73, 2004.

DUPONT, A.; LARGEAU, B.; RIBEIRO, M.; GUILLOTEAUS, D.; TRONEL, C.; ARLICOT, N. Translocator Protein-18 kDa (TSPO) Positron Emission Tomography (PET) Imaging and Its Clinical Impact in Neurodegenerative Diseases, Int. J. Mol. Sci. 18(4), 785, 2017.

DURAFOURT, B. A.; MOORE, C. S.; ZAMMIT, D. A.; JOHNSON, T. A.; ZAGUIA, F.; GUIOT, M. C.; BAR-OR, A.; ANTEL, J. P. Comparison of polarization properties of human adult microglia and blood-derived macrophages. Glia, v. 60(5), p. 717-27, 2012.

DUAN, L.; CHEN, B. Y.; SUN, X. L.; LUO, Z. J.; RAO, Z. R. WANG, J. J.; CHEN, L. W. LPS-induced proNGF synthesis and release in the N9 and BV2 microglial cells: a new pathwayunderling microglial toxicity in neuroinflammation. PloSOne, v. 8(9), 2013.

EBERHARD, D.; BROWN, M.; VANDENBERG, S. Alterations of annexin expression in pathological neuronal and glial reactions. Immunohistochemical localization of annexins I, II (p36 and p11 subunits), IV, and VI in the human hippocampus. Am. J. Pathol. v. 145, p. 640-649, 1994.

ECKENHOFF, R.; LAUDANSKY, K. Anesthesia, surgery, illness and Alzheimer's disease. Progress in neuro-psychopharmacology \& biological psychiatry, v. 47, p. 162166, 2013.

EKDAHL C. Microglial activation - tuning and pruning adult neurogenesis. Front. Pharmacol. , v. 3, p. 41. 2012

FARSKY, S. H. P.; SANNOMIYA, P.; GARCIA-LEME, J. Secreted glucocorticoids regulate leukocyte-endothelial interactions in inflammation. A direct vital microscopic study. J. Leukoc. Biol., v.57(3), p. 379-386, 1995.

FEBBRAIO, M.; HAJJAR, D.; SILVERSTEIN, R. CD36: a class B scavenger receptor involved in angiogenesis, atherosclerosis, inflammation, and lipid metabolism. J Clin Invest. 108(6): 785-791, 2001. 
FERNADES-ALNEMRI, T.; YU, J.; DATTA, P.; WU, J.; ALNEMRI, E. AIM2 activates the inflammasome and cell death in response to cytoplasmic DNA Nature, v. 458, p. 509513, 2009.

FLOWER, R.; ROTHWELL, N. Lipocortin-1: cellular mechanisms and clinical relevance, Trends Pharmacol. Sci. v. 15, p. 71-76, 1994.

FONSECA, A.; MATIAS, D.; GARCIA, C.; AMARAL, R.; GERALDO, L.; FREITAS, C.; LIMA, F. The impact of microglial activation on blood-brain barrier in brain diseases. Front Cell Neurosci, v. 8, p. 362, 2014.

FORTI, L.; VAN RIOE, E.; NJEMINI, R.; COUDYZER, W.; BEYER, I.; DELECLUSE, C.; BAUTMANS, I.; Effects of resistance training at different loads on inflammatory markers in young adults. Eur J Appl Physiol. 117(3):511-519, 2017.

FRANCESCHI, C.; CAPRI, M.; MONTI, D.; GIUNTA, S.; OLIVIERI, F. Inflammaging and anti-inflammaging: a systemic perspective on aging and longevity emerged from studies in humans. Mech Ageing Dev., 128: 92-105, 2007.

FREILICH, R.; WOODBURY, M.; IKEZU, T. Integrated Expression Profiles of mRNA and miRNA in Polarized Primary Murine Microglia, PLoS One, v. 11;8(11), 2013.

FU, H.; YANG, T.; XIAO, W.; FAN, L.; WU, Y.; TERRANDO, N.; WANG, T. Prolonged Neuroinflammation after Lipopolysaccharide Exposure in Aged Rats, PLoS One. v. 9(8), e106331, 2014.

FUMAGALI, S.; PEREGO, C.; PISCHIUTTA, F.; ZANIER, E.; SIMNONI, M. The Ischemic Environment Drives Microglia and Macrophage Function, Front Neurol., v.6, p. $81,2015$.

GEHRMANN, J. Microglia: a sensor to threats in the nervous system? Res. Virol., v. 147, p. 79, 1996.

GAIKWAD, S.; PATEL, D.; AGRAWAL-RAIPUT, R. CD40 Negatively Regulates ATPTLR4-Activated Inflammasome in Microglia. Cell Mol Neurobiol. 37(2):351-359, 2017.

GAVINS, F.; HUGHES, E.; BUSS, N. HOLLOWAY, P.; GETTING, S.BUCKINGHAM, J. Leukocyte recruitment in the brain insepsis: involvement of the annexin 1-FPR2/ALX anti-inflammatory system. FASEB J. v. 26, p. 4977-4989, 2012.

GAVISH, M.; BACHMAN, I.; SHOUKRUN, R.; VEENMAN, L.; WEISINGER, G.; WEIZMAN, A. Enigma of the peripheral benzodiazepine receptor, Pharmacol Rev., v. 51(4), p. 629-50, 1999

GAO, H.; ZHOU, H.; ZHANG, F.; WILSON, B.; KAM, W.; HONG, J. HMGB1 acts on microglia Mac1 to mediate chronic neuroinflammation that drives progressive neurodegeneration. J Neurosci.v. 19;31(3), p. 1081-92, 2011.

GERKE, V.; CREUTZ, C.; MOSS, S. Annexins: linking Ca2+ signalling to membrane dynamics. Nature Rev. Mol. Cell Biol. v. 6, p. 449-461, 2005.

GHADERY, C.; KOSHIMORI, Y.; COAKELEY, S.; HARRIS, M. RUSJAN, P.; KIM, J.; HOULE, S.; STRAFELLA, A. Microglial activation in Parkinson's disease using [18F]FEPPA, J Neuroinflammation, 14: 8, 2017. 
GINHOUX, F.; GRETER, M.; LEBOEUF, M.; NANDI, S.; GOKHAN, S.; MEHLER, M.; CONWAY, S.; G, L.; STANLEY, E.; SAMOKHVALOV, I.; MERAD, M. Fate mapping analysis reveals that adult microglia derive from primitive macrophages. Science 330, 841-845 (2010).

GIRARD, C.; CADEPOND, F.; LACROIX, A. D.; VERLEYE, M.; GILLARDIN, J. M.; BULIEU, E. E.; SCHUMACHER, M.; SCHWEIZER-GROYER, G. Etifoxine improves peripheral nerve regeneration and functional recovery. Proc. Natl Acad. Sci. USA, v. 105, p.20505-20510, 2008.

GIULIAN, D.; BAKER, T. Characterization of ameboid microglia isolated from developing mammalian brain. J. Neurosci., v. 6(8), p. 2163-78, 1986.

GOMEZ, P. E.; SCHULZ, C.; GEISSMANN, F. Development and homeostasis of "resident"myeloid cells: the case of the microglia. Glia 61, 112-120,2013.

GORDON, S.; MARTINEZ, F. Alternative activation of macrophages: Mechanism and functions. Immunity. v. 32, p. 593-604, 2010.

GOULDING, N.; GODOLPHIN, J.; SHARLAND, P.; PEERS, S.; SAMPSON, M.; MADDISON, P.; FLOWER, R. Anti-inflammatory lipocortin 1 production by peripheral blood leucocytes in response to hydrocortisone. Lancet, v. 335, p.1416-1418, 1990.

GRAAUW, M; MILTENBURG, M; SCHMIDT, M.; DIKE, P; WATER, B. Annexin A1 regulates TGF signaling and promotes metastasis formation of basal-like breast cancer cells, Proc Na Acad Sci USA, 107(14), 6340-6345, 2010.

GREEN, S., CAIRNS, B., RAE, J., ERRET-BARONCINI, C., HONGO, J., ERICKSON, R. Induction of gp91-phox, a component of the phagocyte NADPH oxidase, in microglial cells during central nervous system inflammation. J. Cereb. Blood Flow Metab. v. 21, p. 374-384. 2001.

GREGORY, J. L.; HALL, P.; LEECH, M.; MORAND, E. F.; HICKEY, M. J. Independent roles of Macrophage Migration Inhibitory Factor and endogenous, but not exogenous glucocorticoids in regulating leukocyte trafficking. Microcirc., v. 16, p. 735-748, 2009.

GROOT, N.; BURGAS, M. Is membrane homeostasis the missing link between inflammation and neurodegenerative diseases? Cell. Mol. Life Sci., 72:4795-4805, 2015.

GUO, C.; SHUGING, L.; SUN, M. Potential role of Anxa1 in cancer, Future Oncology, v. 9 (11), p. 1773-1793, 2013.

HAN, H. E.; KIM, T. K.; SON, H. J.; PARK, W. J.; HAN, P. L. Activation of Autophagy Pathway Suppresses the Expression of iNOS, IL6 and Cell Death ofLPS-Stimulated Microglia Cells. Biomol Ther (Seoul), v. 21(1), p. 21-8, 2013.

HANISCH, U. \& KETTENMMANN, H. Microglia: active sensor and versatile effector cells in the normal and pathologic brain. Nature Neurosci. v. 10, p. 1387-1394, 2007.

HARBERTS, E.; DATTA, D.; CHEN, S.; WOHLER, J.E.; OH, U.; JACOBSON, S. Translocator protein $18 \mathrm{kDa}$ (TSPO) expression in multiple sclerosis patients. $\mathrm{J}$ Neuroimmune Pharmacol. v. 8(1), p. 51-7, 2013. 
HAYHOE, R.; KAMAL, A.; SOLITO, E.; FLOWER, R.; COOPER, D.; PERRETTI, M. Annexin 1 and its bioactive peptide inhibit neutrophil-endothelium inter- actions under flow: indication of distinct receptor involvement. Blood v. 107, p. 2123-2130, 2006

HE J, LEE J, FEBBRAIO M, XIE W. The emerging roles of fatty acid translocase/CD36 and the aryl hydrocarbon receptor in fatty liver disease. Exp Biol Med, 236(10):1116-21. 2011

HESSE, M.; MODOLELL, M.; La FLAMME, A.; SCHITO M.; FUENTES, J.; CHEEVER, A.; PEARCE, E.; WYNN, T. Differential regulation of nitric oxide synthase-2 and arginase- 1 by type 1/type 2 cytokines in vivo: granulomatous pathology is shaped by the pattern of L-arginine metabolism. J. Immunol. v.167, p. 6533-6544, 2001.

HENKEL, J.; Microglia in ALS: the good, the bad, and the resting, J Neuroimmune Pharmacol., v. 4, p. 389-398, 2009.

HOAREAU, L.; BENCHARIF, K.; RONDEAU, P.; MURUMALLA, R.; RAVANAN, P.; TALLET, F.; DELARUE, P.; CESAI, M.; ROCHE, R.; FESTY, F. Signaling pathways involved in LPS induced TNFalpha production in human adipocytes, J Inflamm (Lond)., v. 7 , p. 1, 2010.

HOEFFEL, G.; GINHOUX, F. Ontogeny of Tissue-resident Macrophages, Front. Immunol., v. 6, p. 486, 2015.

HOSHINO, K.; TAKEUCHI, O.; KAWAI, T.; SANJO, H. OGAWA, T.; TAKEDA, Y. Cutting edge: toll-like receptor 4 (TLR4)-deficient mice are hyporesponsive to lipopolysaccharide: evidence for TLR4 as the Lps gene product. J Immunol 162:374952, 1999.

HUANG, W.; LIN, Y.; TSAI, C.; TSENG, H.; CHEN, C.; QIAN, L.; HONG, J.; LIN, C. Glycogen synthase kinase-3 negatively regulates anti-inflammatory interleukin-10 for lipopolysaccharide-induced iNOS/NO biosynthesis and RANTES production in microglial cells, Immunology, 128, e275-e286, 2008.

HUGHES, E.; BECKER, F; FLOWER, R.; GAVINS, F. Mast Cells Mediate Early Neutrophil Recruitment and Exhibit Anti-Inflammatory Properties via FPR2/ALX. Br J Pharmacol. 2017 in press

HUMPEL, C. Organotypic vibrosections from whole brain adult Alzheimer mice (overexpressing amyloid-precursor-protein with the Swedish-Dutch-lowa mutations) as a model to study clearance of beta-amyloid plaques. Front Aging Neurosci. v. 9, p. 7:47, 2015.

ISSOP, L; OSTUNI, M; LEE, S; LAFORGE, M; PERANZI, G; RUSTIN, P; BENOIST, J; ESTAQUIER, J; PAPADOPOULOS, V; LACAPERE, J. Translocator Protein-Mediated Stabilization of Mitochondrial Architecture during Inflammation Stress in Colonic Cells. PLoS One. 11(4):e0152919, 2016.

JANEWAY, C. Jr. Approaching the asymptote? Evolution and revolution in immunology. Cold Spring Harb Symp Quant Biol. 54(Pt 1):1-13. 1989.

JENSEN, A.; COLLINS, J.; SHIPMAN, E.; GUYRE, P.; PIOLI, P. A Subset of Human Uterine Endometrial Macrophages is Alternatively Activated, Am J Reprod Immunol, v. 68(5), p. 374-386, 2012 
JEONG, Y.H.; KIM, Y.; SONG, H.; CHUNG, Y.S.; PARK, S.B.; KIM, H.S. AntiInflammatory Effects of $\alpha$-Galactosylceramide Analogs in Activated Microglia: Involvement of the p38 MAPK Signaling Pathway, PloSOne, v. 9(2), 2014.

JEONG, J.; CHOI, I.; JO, G.; KIM, G.; KIM, J.; SUH, H.; RYU, C.; KIM, W.; PARK, K.; $\mathrm{CHOI}, \quad \mathrm{Y}$. Anti-Inflammatory Effects of $3-(40 \quad-H y d r o x y l-30 \quad 50$ Dimethoxyphenyl)Propionic Acid, an Active Component of Korean Cabbage Kimchi, in Lipopolysaccharide-Stimulated BV2 Microglia, J Med Food, v. 18 (6), p. 1-8, 2015.

JORDA, E.; JIMENEZ, A.; VERDAQUER, E.; CANUDAS, A.; FOLCH, J.; SUREDA, F.; CAMINS, A.; PALLAS, M. Evidence in favour of a role for peripheral-type benzodiazepine receptor ligands in amplification of neuronal apoptosis, Apoptosis, v. 10, p. 91-104, 2005.

JUNG, S.; SCHWARTZ, M. Non-identical twins - microglia and monocyte-derived macrophages in acute injury and autoimmune inflammation. Front. Immunol. v. 3, p. 89. 2012.

KARLSTETTER, M.; NOTHDURFTER, C.; ASLANIDIS, A.; MOELLER, K.; HORN, F.; SCHOLZ, R.; NEUMANN, H.; WEBER, B.; RUPPRECHT, R.; LANGMANN, T. Translocator protein (18 kDa) (TSPO) is expressed in reactive retinal microglia and modulates microglialinflammation and phagocytosis. J Neuroinflammation, v. 11, p. 3, 2014.

KARMANN, K.; HUGHES, C.; SCHECHNER, J.; FANSLOW, W.; POBER, J.; CD40 on human endothelial cells: inducibility by cytokines and functional regulation of adhesion molecule expression. Proc Natl Acad Sci U S A, v. 92, p. 4342-4346, 1995.

KAWAI, T.; ADACHI, O.; OGAWA, T.; TAKEDA, K.; AKIRA, S. Unresponsiveness of MyD88-deficient mice to endotoxin. Immunity. 11(1):115-22, 1999.

KETTENMANN, H.; HANISCH, U.; NODA, M.; VERKHRATSKY, A. Physiology of microglia. Physiol. Rev. v. 91, p. 461-553, 2011.

KIERDORF, K.; ERNY, D., GOLDMAN, T.; SANDER, V.; SCHULZ, C.; GOMEZ, E.; WIEGHOFER, P.; HEINRICH, A.; RIEMKE, P.; HOLSCHER, C.; MULLER, D.; LUCKOW, B.; BROCKER, T.; DEBOWSKI, K.; FRITZ, G.; OPDENAKKER, G.; DIEFENBACH, A.; BIBER, K.; HEIKENWALDER, M.; GEISSMANN, F.; ROSENBAUER, F.; PRINZ, M. Microglia emerge from erythromyeloid precursors via Pu.1- and Irf8dependent pathways. Nature Neurosci. v. 16, p. 273-280, 2013.

$\mathrm{KIM}, \mathrm{Y}$; $\mathrm{KOH}, \mathrm{H}$.; KIM, D. Down-regulation of IL-6 production by astaxanthin via ERK-, MSK-, and NF-KB-mediated signals in activated microglia. Int Immunopharmacol. v. 10(12), p. 1560-72, 2010.

KIPNIS, J.; AVIDAN, H.; CASPI, R.; SCHWARTZ, M.Dual effect of CD4+CD25+ regulatory T cells in neurodegeneration: a dialogue with microglia, Proc. Natl. Acad. Sci. U S A, v. 101, p. 14663, 2004.

KITAZAWA, M.; ODDO, S.; YAMASAKI, T.; GREEN, K.; LaFERLA, F. Lipopolysaccharide-induced inflammation exacerbates tau pathology by a cyclindependent kinase 5-mediated pathway in a transgenic model of Alzheimer's disease. The Journal of Neuroscience: The Official Journal of the Society for Neuroscience, v. 25, p. 8843-8853, 2005. 
KITAMURA, Y., TAKATA, K., INDEN, M., TSUCHIVA, D., YANAGISAWA, D., NAKATA, J., Intracerebroventricular injection of microglia protects against focal brain ischemia. J. Pharmacol. Sci. v. 94, p. 203-206. 2004.

KNOTT, C.; STERN, G.; WILKIN, G. Inflammatory regulators in Parkinson's disease: iNOS, lipocortin-1, and cyclooxygenases-1 and -2. Mol Cell Neurosci, v. 16(6), p. 72439, 2000.

KRAMER, C.; GENCO, C. Microbiota, Immune Subversion, and Chronic Inflammation. Front Immunol. 13;8:255. 2017.

LACAREPE, J. J. \& PAPADOPOULOS, V. Peripheral-type benzodiazepine receptor: structure and function of a cholesterol-binding protein in steroid and bile acid biosynthesis. Steroids, v. 68, p. 569-585, 2003.

LALANCETTE-HEBERT, M., GOWING, G., SIMARD, A., WENG, Y.; KRIZ, J. Selective ablation of proliferating microglia cells exacerbates ischemic injury in the brain. J. Neurosci. v. 27, p. 2596-2605. 2007.

LAWRENCE, T.; NATOLI, G. Transcriptinal regulation of macrophage polarization enabling diversity with identity. Nat. Rev. Immunol. v. 11, p.750-761, 2011.

LAWSON, L.; PERRY, V.; DRI, P.; GORDON, S. Heterogeneity in the distribution and morphology of microglia in the normal adult mouse brain. Neuroscience 39, 151-170, 1990.

LAZZARINI, R.; SAKAI, M.; COSTA-PINTO, F. A.; PALERMO-NETO, J. Diazepam decreases leukocyte-endothelium interactions in situ. Immunopharmacol Immunotoxicol., v. 32(3), p. 402-409, 2010.

LAN, N. C.; CHEN, J. S.; JOHNSON, D.; GEE, W. Differential effects of 4'chlorodiazepam on expressed human GABA-A receptors, Journal of Neurochemistry, $v$. 02-01, 1995.

LEAVER, K.; REYNOLDS, A.; CHALON, S.; KASSIOU, M. Effects of Translocator Protein (18 kDa) Ligands on Microglial Activation and Neuronal Death in the QuinolinicAcid-Injected Rat Striatum, ACS Chem Neurosci, v. 3(2), p. 114-119, 2012.

LEE, J. W.; CHOI, Y. J.; PARK, J. H.; SIM, J. Y.; KWON, Y. S.; LEE, H. J.; KIM, S. S.; CHUN, W. 3,4,5-Trihydroxycinnamic Acid Inhibits Lipopolysaccharide-Induced Inflammatory Responsethrough the Activation of Nrf2 Pathway in BV2 Microglial Cells. Biomol Ther (Seoul), v. 21(1), p. 60-5, 2013.

LEHNARDT, S.; MASSILLON, L.; FOLLET, P.; JENSEN, F.; RATAN, R.; ROSENBERG, P.; VOLPE, J.; VARTANIAN, T. Activation of innate immunity in the CNS triggers neurodegeneration through a Toll-like receptor 4-dependent pathway, Proc Natl Acad Sci U S A., v. 14:8514-9, 2003.

LI, J.; RAMENADEN, E.; PENG, J.; KOITO, H.; VOLPE, J.; ROSENBERG, P. Tumor necrosis factor alpha mediates lipopolysaccharide-induced microglial toxicity to developing oligodendrocytes when astrocytes are present, J Neurosci, v. 28(20), p. 5321-30, 2008 
LIEW, F.; XU, D.; BRINT, E. O'NEIL, L. Negative regulation of toll-like receptor-mediated immune responses. Nat Rev Immunol 5:446-58, 2005.

LIMA, C.B.; SAKAI, M.; LATORRE, A.O.; MOREAU, R.L.; PALERMO-NETO, J. Effects of different doses and schedules of diazepam treatment on lymphocyte parameters in rats. Int Immunopharmacol., v. 10(11), p. 1335-1343, 2010.

LIMA C. B.; TAMURA, E. K.; MONTERO-MELENDEZ, T.; PALERMO-NETO, J.; PERRETI, M.; MARKUS, R. P.; FARSKY, S. H. P. Actions of translocator protein on neutrophil adhesion and motility induced by G-protein coupled receptor signaling. Biochemical and Biophisical Research Communications, v. 417, p. 918-923, 2012.

LIU, Y.; WALTER, M.; STAGI, D.; CHERNY, M.; LETIEMBRE, W.; SCHULZSCHAEFFER, H.; HEINE, B.; PENKE, H.; NEUMANN; FASSBENDER, K. LPS receptor (CD14): a receptor for phagocytosis of Alzheimer's amyloid peptide. Brain v. 128, p. 1778-1789, 2005.

LIU, Y.; ZHANG, M.; HAO, W.; MIHALJEVIC, I.; LIU, X.; XIE, K.; WALTER, S.; FASSBENDER, K. Matrix metalloproteinase-12 contributes to neuroinflammation in the aged brain. Neurobiol Aging v. 34(4), p.1231-9, 2013.

LIU, G.; MIDDLETON, R.; HATTY, C.; KAM, W.; CHAN, R.; PHAM, T.; HARRISONBROWN, M.; DODSON, E.; VEALE, K.; BANATI, R. The $18 \mathrm{kDa}$ translocator protein, microglia and neuroinflammation. Brain Pathol., v. 24(6), p. 631-53, 2014.

LIU, S.; GAO, Y; YU, X; ZHAO, B; LIU, L.; ZHAO, Y.; LUO, Z.; SHI, J. Annexin-1 Mediates Microglial Activation and Migration via the CK2 Pathway during OxygenGlucose Deprivation/Reperfusion. Int J Mol Sci. 17(10), 2016a

LIU, X.; JONES, G.; CHOY, E.; JONES, S. The biology behind interleukin-6 targeted interventions, Curr Opin Rheumatol. V. 28(2):152-60, $2016 \mathrm{~b}$.

LOMINADZE, G.; POWELL, D.; LUERMAN, G.; LINK, A.; WARD, R.; McLEISH, K. Proteomic analysis of human neutrophil granules. Mol. Cell. Proteomics v. 4, p. 15031521, 2005.

LONG, F.; WANG, Y. X.; LIU, L.; ZHOU, J.; CUI, R. Y.; JIANG, C. L. Rapid nongenomic inhibitory effects of glucocorticoids on phagocytosis and superoxide anion production by macrophages. Steroids, v. 70, p. 55-61, 2005.

LOPEZ-CASTEJON, G.; BROUGH, D.; Understanding the mechanism of IL-1 $\beta$ secretion, Cytokine Growth Factor Rev. v. 22(4), p. 189-195, 2011.

LU, Y.; YEH, W.; OHASHI, P. S. LPS/TLR4 signal transduction pathway, Cytokine, v. 42 (2), p. 145-151, 2008.

LUCAS, S., ROTHWELL, J., GIBSON, R. The role of inflammation in CNS injury and disease, Br. J. Pharmacol., Suppl 1:S232-40, 2006.

LUI, L.; WANG, Y. X.; ZHOU, J.; LONG, F.; SUN, H. W.; LIU, Y. Rapid non-genomic inhibitory effects of glucocorticoids on human neutrophil degranulation. Inflamm. Res., v. 54 , p. 37-41, 2005. 
LYMAN, M.; LLOYD, D. JI, X.; VIZCAYCHIPI, M,, MA, D. Neuroinflammation: the role and consequences, Neurosci Res, v. 79, p. 1-12, 2014.

MA, L; ZHANG, H.; LIU, N.; WANG, P.; MA, Y; MI, W. TSPO ligand PK11195 alleviates neuroinflammation and beta-amyloid generation induces by systemic LPS administration, Brain Res Bull, 121, 192-200, 2016.

MACIAS, M.; MARTIN-MALPARTIDA, P.; MASSAGUE, J. Structural determinants of Smad function in TGF-b signaling, Trends in Biochemical Sciences, 2015

MACHADO, I.; SANTIN, J.; DREWES, C.; GIL, C.; OLIANI, S. PERRETTI, M. FARSKY, $S$. Alterations in the profile of blood neutrophil membrane receptors caused by in vivo adrenocorticotrophic hormone actions. Am J Physiol Endocrinol Metab, v. 307(9), 2014

MACK, C.; VANDERLUGT-CASTANEDA, C.; NEVILLE, K.; MILLER, S. Microglia are activated to become competent antigen presenting and effector cells in the inflammatory environment of the Theiler's virus model of multiple sclerosis, J. Neuroimmunol., V. 144, p. $68,2003$.

MANIO, M.; MATSUMURA, S.; MASUDA, D.; INOUE, K. CD36 is essential for endurance improvement, changes in whole-body metabolism, and efficient PPAR-related transcriptional responses in the muscle with exercise training. Physiol Rep. 5(10). pii: e13282, 2017

MASSOCO, C. PALERMO-NETO, J. Diazepam effects of peritoneal macrophage activity and corticosterone serum levels in Balb/C mice. Life Sci., v 65(20), p. 2157, 1999.

MARTIN, S. \& TRACEY, K. Tumour necrosis factor (TNF) in neuroimmunology, Advances in Neuroimmunology Vol. 2, p. 125-138, 1992.

MARTIN, M.; REHANI, K.; JOPE, R.; MICHALEK, S. Toll-like receptor-mediated cytokine production is differentially regulated by glycogen, Nature Immunology, v.6, 2005.

MARTÍNEZ-ZAMUDIO, R.; CHOI, H. PARP1 enhances inflammatory cytokine expression by alteration of promoter chromatin structure in microglia, Brain Behav, v. 4(4), p. 552-565, 2014.

McARTHUR, S.; CRISTIANE, E.; PATERNO, M.; CHRISTIAN, H.; RONCAROLI, F.; GILLLIES, G. E.; SOLITO, E. Annexin A1: a central player in the anti-inflamatory and neuroprotective role of microglia, J. Immunol., v. 185 (10), p. 6317-28, 2010.

McENERY, M. W.; SNOWMAN, A. M.; TRIFILETTI, R. R.; SNYDER, S. H. Isolation of the mitochondrial benzodiazepine receptor: association with the voltage-dependent anion channel and the adenine nucleotide carrier Proc Natl Acad Sci U S A, v. 89, p. 3170-3174, 1992.

McGEER,P.; YASOJIMA, K.; McGEER, E.Inflammation In Parkinson's disease. Adv. Neurol. 86,83-89, 2001.

MOGI, M. ,HARADA ,M., RIEDERER, P., NARABAYASHI, H., FUJITA, K., NAGATSU, T. Tumor necrosis factor-a (TNF-a) increases both in the brain and in the cerebrospinal fluid from parkinsonian patients. Neurosci.Lett. 165,208-210, 1994 
MICHEAU, O.; TSCHOPP, J. Induction of TNF receptor I-mediated apoptosis via two sequential signaling complexes, Cell, v. 114, p. 181-190, 2003.

MILDER, A.; SCHLEVOGT, B.; KIEDORF, K.; BOTTCHER, C.; ERNY, D.; KUMMER, M.; QUINN, M.; BRUCK, W.; BECHMANN, I.; HENEKA, M.; PRILLER, J.; PRINZ, M. Distinct and non-redundant roles of microglia and myeloid subsets in mouse models of Alzheimer's disease. J. Neurosci. 31, 11159-11171, 2011.

MILLS, C.; KINCAID, K.; ALT, J.; HEILMAN, M., HILL, A. M-1/M-2 macrophages and the Th1/Th2 paradigm, J Immunol , v. 164, p. 6166-73, 2000.

MILLS, C.; LEY, K. M1 and M2 macrophages: the chicken and the egg of immunity. J Innate Immune, v. 6, p. 1716-26.10, 2014.

MILLS, C.; THOMAS, A.; LENZ, L.; MUNDER, M. Macrophage: SHIP of immunity. Front Immunol, v. 5, P. 1-510, 2014.

MIYOSHI, M.; ITO, H.; ARAKAWA, R.; TAKAHASHI, H.; TAKANO, H.; HIGUCHI, M.; OKUMURA, M.; OTSUKA, T.; KODAKA, F.; SEKINE, M.; SASAKI, T.; FUJIE, S.; SEKI, C.; MAEDA, J.; NAKAO, R.; ZHANG, M.; FUKUMURA, T.; MATSUMOTO, M.; SUHARA, T. Quantitative analysis of peripheral benzodiazepine receptor in the human brain using PET with 11C-AC-5216. J. Nucl. Med. v. 50, p.1095-1101, 2009.

MONTEIRO, D.; CARLOS, I.; PINTO, F.. Diazepam, in a single dose, inhibits cellular chemotaxis, macrophage stimulation, and TNF- $\alpha$ activity in LPS-induced acute inflammatory responses in mice. Rev. Bras. Cienc. Farm. , vol.44, n.4, pp. 613-620. 2008

MORAND, E.; HUTCHINSON, P.; HARGREAVES, A.; GOULDING, N.; BOYCE, N.; HOLDSWORTH, S. Detection of intracellular lipocortin 1 in human leukocyte subsets. Clin. Immunol. Immunopathol. v.76, p. 195-202, 1995.

MORGULIS, M.; RODRIGUES, P.; PALERMO-NETO, J. Benzodiazepine receptors and avian macrophage activity: diazepam decreases spreading and phagocytosis. Immunopharmacol Immunotoxicol., v. 21(4), p. 787, 1999.

MOSSER, D.; EDWARDS, J. Exploring the full spectrum of macrophage activation. Nat. Rev. Immunol. v. 8, p. 958-969, 2008.

MULLA, A.; LEROUX, C.; SOLITO, E.; BUCKINGHAM, J. Correlation between the antiinflammatory protein annexin 1 (lipocortin 1) and serum cortisol in subjects with normal and dysregulated adrenal function. J. Clin. Endocrinol. Metab. v. 90, p. 557-562, 2005.

NADKARNI, S.; DALLI, J. HOLLYWOOD, J.; MASON, J. C.; DASGUPTA, B.; PERRETTI, M. An Investigational Analysis Reveals a Potential Role for Neutrophils in Giant-Cell Arteritis Disease Progression, Circ. Res., v.114(2), p. 242-8 2014.

NAGAI, A.; MISHIMA, S.; ISHIDA, Y.; ISHIKURA, H.; HARADA, Y.; KOBAYASHI, S.; KIM, S. Immortalized human microglial cell line: Phenotypic expression, Journal of Neuroscience Research, v. 81, p. 342-348, 2005. 
NAIR, S. ARORA, S.; LEE, L.; LIM, L. The regulation of TNFa production after heat and endotoxin stimulation is dependent on Annexin-A1 and HSP70, Cell Stress and Chaperones, 2015.

NAKAGAWA, Y.; CHIBA, K. Role of Microglial M1/M2 Polarization in Relapse and Remission of Psychiatric Disorders and Diseases, Pharmaceuticals (Basel), v. 7(12), p. 1028-1048, 2014.

NASI, S.; EA, H.; SO, A; BUSSO, N. Revisiting the Role of Interleukin-1 Pathway in Osteoarthritis: Interleukin-1 $\alpha$ and $-1 \beta$, and NLRP3 Inflammasome Are Not Involved in the Pathological Features of the Murine Menisectomy Model of Osteoarthritis, Front Pharmacol., v. 13, p. 282, 2017.

NATHAN, C.; DING, A. Nonresolving inflammation. Cell, v. 140, p. 871-882, 2010.

NELSON, G.; WILDE, G.; SPILLER, D.; KENNEDY, S.; RAY, D.; SULLIVAN, E.; UNITT, J.; WHITE, M. NF-kB signalling is inhibited by glucocorticoid receptor and STAT6 via distinct mechanisms, Journal of Cell Science, v. 116, p. 2495-2503, 2003.

NEUMANN, J., SAUNERZWEIG, S., RONICKE, R., GUNZER, F., DINKEL, K., ULLRICH, O. Microglia cells protect neurons by direct engulfment of invading neutrophil granulocytes: a new mechanism of CNS immune privilege. J. Neurosci. v. 28, p. 59655975. 2008.

NIMMERJAHN, A.; KIRCHHOFF, F. \& Helmchen, F. Resting microglial cells are highly dynamic surveillants of brain parenchyma in vivo. Science, v. 308,p. 1314-1318, 2005.

ORR, C.; ROWE, D.; HALLIDAY, G. An inflammatory review of Parkinson's disease. Prog Neurobiol. v. 68(5), p.325-40, 2002

OOI, Y.; RAMASAMY, R.; RAHMAT, Z.; SUBRAMAIAM, H.; TAN, S.; ABDULLAH, M.; ISRAF, D.; VIDYADARAN S. Bone marrow-derived mesenchymal stem cells modulate BV2 microglia responses to lipopolysaccharide. Int Immunopharmacol., v. 10(12), p. 1532-40, 2010.

OSTUNI, M.; ISSOP, L.; ELBIM, C.; PAPADOPOULOS, V.; LACAREPE, J. Overexpression of Translocator protein TSPO in inflammatory bowel disease: potential diagnostic and treatment value, Inflamm Bowel Dis, v. 16(9), p. 1476-1487, 2010.

OZAKI, M; IWANAMI, A; NAGOSHI, N.; KOHYAMA, J; ITAKURA, G.; IWAI, $\mathrm{H}$; NISHIMURA, S; NISHIMURA, Y; KAWABATA, S; SUGAI, K; ISODA, M; KASHIWAGI, R; TOYAMA, Y; MATSUMOTO, M; OKANO, H; NAKAMURA, M. Evaluation of the immunogenicity of human iPS cell-derived neural stem/progenitor cells in vitro. Stem Cell Res. 19:128-138, 2017.

PAL, G.; SHAIKH, M.; FORSYTH, C.; OUYANG, B.; KESHAVARZIAN, A.; SHANNON, K. Abnormal lipopolysaccharide binding protein as marker of gastrointestinal inflammation in Parkinson disease. Front Neurosci. 1;9:306, 2015.

PAOLI, F; STAELS, B.; CHINETTI-GBAGUIDI, G. Macrophage Phenotypes and Their Modulation in Atherosclerosis, Circulation Journal, v. 78 (8), p. 1775-81, 2014 
PAPADOPOULOS, V.; BARALDI, M.; GUILARTE, T.R.; KNUDSEN, T.B.; LACAPÈRE, J.J.; LINDEMANN, P.; NORENBERG, M.D.; NUTT, D.; WEIZMAN, A.; ZHANG, M.R. Zhang; GAVISH, M. Translocator protein (18 kDa): new nomenclature for the peripheraltype benzodiazepine receptor based on its structure and molecular function, Trends Pharmacol. Sci. v.27, p.402-409, 2006.

PAPADOPOULOS, V.; LIU, J; CULTY, M. Is there a mitochondrial signaling complex facilitating cholesterol import? Mol. Cell Endocrinol. V. 266, p.59-64, 2007.

PAPADOPOULOS, V.; LECANU, L. Translocator protein (18 kDa) TSPO: an emerging therapeutic target in neurotrauma. Exp. Neurol., v. 219(1), p. 53-57, 2009.

PAPADOPOULOS, V. AGHAZADEH, Y.; FAN, J.; CAMPIOLI, E.; ZIRKIN, B.; MIDZAK, A. Translocator protein-mediated pharmacology of cholesterol transport and steroidogenesis. Mol Cell Endocrinol, v. 408, p. 90-98, 2015.

PARAMESWARAN, N.; PATIAL, S. Tumor Necrosis Factor- $\alpha$ Signaling in Macrophages, Crit Rev Eukaryot Gene Expr., v. 20(2), p. 87-103, 2010.

PARK, B.; LEE, J. Recognition of lipopolysaccharide pattern by TLR4 complexes. Exp Mol Med, 45:e66, 2013.

PARK, Y. CD36, a scavenger receptor implicated in atherosclerosis, Exp Mol Med. 46(6): e99 2014.

PARENTE, L.; SOLITO, E. Annexin 1: More than an antiphospholipase protein. Inflamm. Res.; 53:125- -132, 2004.

PEREGO, C., FUMAGALLI, S., and De SIMONI, M. Temporal pattern of expression and colocalization of microglia/macrophage phenotype markers following brain ischemic injury in mice. J. Neuroinflamm. v. 8, p. 174. 2011.

PERRETTI, M., DALLI, J. Exploiting the Annexin A1 pathway for the development of novel anti-inflammatory therapeutics. Br J Pharmacol, v. 158, p. 936-946, 2009.

PERRETTI, M.; CROXTALL, J.; WHELLER, S.; GOULDING, N.; HANNON, R.; FLOWER, R. Mobilizing lipocortin 1 in adherent human leukocytes downregulates their transmigration. Nature Med. v. 22, p. 1259-1262, 1996.

PERRETTI, M.; CHRISTIAN, H.; WHELLER, S.; AIELLO, I.; MUGRIDGE, K.; MORRIS, J.; FLOWER, R.; GOULDING, N. Annexin I is stored within gelatinase granules of human neutrophils and mobilised on the cell surface upon adhesion but not phagocytosis. Cell Biol. Int. v. 24, p. 163-174, 2000.

PERRETTI, M.; CHIANG, N.; FIERRO, I.; MARULLO, S.; GETTING, S.; SOLITO, E.; SERHAN, C. Endogenous lipid- and peptide-derived anti-inflammatory pathways generated with glucocorticoid and aspirin treatment activate the lipoxin A4 receptor. Nature Med. v. 8, p. 1296-1302, 2002.

PERRETTI, M.; D'ACQUISTO, F. Annexin A1 and glucocorticoids as effectors of the resolution of inflammation, Nature Reviews Immunology, v. 9, p. 62-70, 2009. 
PERRETTI, M.; FILIPPO, C.; D'AMICO, M.; DALLI, J. Characterizing the antiinflammatory and tissue protective actions of a novel Annexin A1 peptide. PLoS One. 12(4):e0175786, 2017.

PERRETTI, M.; GAVINS, F. Annexin 1: an endogenous anti-inflammatory protein. News Physiol. Sci. 18: 60-64., 2003.

PERRY, V.; HOLMES, C. Microglial priming in neurodegenerative disease. Nat Rev Neurol. 10(4):217-24, 2014.

PIPITONE, N.; SINHA, M.; THEODORIDIS, E.; GOULDING, N.; HALL, M.; LANCHBURY, J.; CORRIGALL, V.; PANAYI, G.; PITZALIS, C. The glucocorticoid inhibition of LFA-1 and CD2 expression by human mononuclear cells is reversed by IL-2, IL-7 and IL-15. Eur. J. Immunol., v. 31(7), p. 2135-2142, 2001

PONOMAREV, E.; NOVIKOVA, M.; MARESZ, K.; SHRIVER, L.; DITTEL, B. Development of a culture system that supports adult microglial cell proliferation and maintenance in the resting state, Journal of Immunological Methods, v. 300, p. 32-46, 2005.

PORTELA, C.; TIBE, I; LEICK-MAILDONADO, E.; MARTINS, M.; PALERMO-NETO, J. Effects of diazepam and stress on lung inflammatory response in OVA-sensitized rats, Am J Physiol Lung Cell Mol Physiol, v. 282, p. L1289-L1295, 2002.

PRIMIANI, C.; RYAN, V.; RAO, J.; CAM, M.; AHN, K. MODI, H; RAPOPORT, S.; Coordinated gene expression of neuroinflammatory and cell signaling markers in dorsolateral prefrontal cortex during human brain development and aging. PLoS One. 20;9(10):e110972, 2014.

PUPJALIS, D.; GOETSCH, J.; KOTTAS, D.; GERKE, V.; RESCHER, U. annexin A1 released from apoptotic cells act through formyl peptide receptors to dampen inflammatory activation via JAK/STAT/SOSCS signaling, EMBO Mol Med, vol 3, p. 102114, 2011.

PURVES, D.; AUGUSTINE, G.; FITZPATRICK, D. Neuroscience. 2nd edition.Sunderland (MA). Sinauer Associates; 2001.

PRICE, C., WANG, D., MENON, D., GUADAGNO, J., CLEIJ, M., FRYER, T., Intrinsic activated microglia map to the peri-infarct zone in the subacute phase of ischemic stroke. Stroke v. 37, p. 1749-1753. 2006.

PRINZ, M.; PRILLER, J.; SISODIA, S. S.; RANSOHOFF, R. M. Heterogeneity of CNS myeloid cells and their roles in neurodegeneration. Nature Neurosci. vol 14, p. 12271235, 2011.

PRINZ, M. \& PRILLER, J. Microglia and brain macrophages in the molecular age: from origin to neuropsychiatric disease, Nature Reviews Neurosci., vol 15, p. 300-312, 2014.

PROBERT, L. TNF AND ITS RECEPTORS IN THE CNS: THE ESSENTIAL, THE DESIRABLE AND THE DELETERIOUS EFFECTS, Neuroscience, v. 302, p. 2-22, 2015.

PYO, J. H.; JEONG, Y. K.; YEO, S.; LEE, J. H.; JEONG, M. Y.; KIM, S. H.; CHOI, Y. G.; LIM, S. Neuroprotective Effect of trans-Cinnamaldehyde on the 6-Hydroxydopamine- 
Induced Dopaminergic Injury, Biological and Pharmaceutical Bulletin, v. 36 (12), p. 19281935, 2013.

QIU, W.; YE, Z, KHOLODENKO, D,; SEUBERT, P.; SELKOE, D. Degradation of amyloid $\beta$-protein by a metalloprotease secreted by microglia and other neural and non-neural cells. J Biol Chem. 272:6641-6. 1997.

QURESHI, N., B. W.; JARVIS, K. TAKAYAMA. Nontoxic RsDPLA as a potent antagonist of toxic lipopolysaccharide. H. Brade, and S. M. Opal, and S. N. Vogel, and D. C. Morrison, eds. Endotoxin in Health and Disease 687. Marcel Dekker, New York. 1999.

RAETZ, C. R.; WHITFIELD, C. Lipopolysaccharide endotoxins, Annu. Rev. Biochem., v. 71, p. 635-700, 2002.

RAMACHANDRAN, G. Gram-positive and gram-negative bacterial toxins in sepsis: a brief review, Vilulence, v. 5, p. 1; 2013.

RANKINE, E.; HUGHES, P.; BOTHAM, M.; PERRY, V.; FELTON, L. Brain cytokine synthesis induced by an intraparenchymal injection of LPS is reduced in MCP-1-deficient mice prior to leucocyte recruitment, Eur J Neurosci. v. 24(1), p. 77-86, 2006.

REGEN, T.; ROSSUM, D.; SCHEFFEL, J.; KASTRITI, M.; REVELO, N.; PRINZ, M.; BRUCK, W.; HANISCH, U. CD14 and TRIF govern distinct responsiveness and responses in mouse microglial TLR4 challenges by structural variants of LPS

REUS, G.; FRIES, G.; STERTA, L.; PASSOS, I.; BARICHELLO, T.; QUEVEDO, J. The role of inflammation and microglial activation in the pathophysiology of psychiatric disorders. Neuroscience, 2015.

REY, C.; MAUDUIT, C.; NAUREILS, O.; BENAHMED, M.; LOUISOT, P.; GASNIER, F. Upregul ation of mitochondrial peripheral benzodiazepine receptor expression by tumor necrosis factor alpha in testicular leydig cells. Possible involvement in cell survival, Biochem Pharmacol, v. 60, p. 1639-46, 2000

REYNOLDS, N.; SORAGNI, A.; RABE, M.; VERDES, D. LIVERANI, E.; HANDSCHIN, S.; RIEK, R.; SEEGER, S. Mechanism of membrane interaction and disruption by alphasynuclein. J Am Chem Soc, 133(48):19366-19375, 2011.

RIES, M, LOIOLA, R.; SHAH, U.; GENTLEMAN, S.; SOLITO, E; SASTRE, M. The antiinflammatory Annexin $A 1$ induces the clearance and degradation of the amyloid- $\beta$ peptide. J Neuroinflammation. 2;13(1):234, 2016

ROCA, H.; VARSOS, Z.; SUD, S.; CRAIG, M.; YING, C.; PIENTA, K. CCL2 and interleukin- 6 promote survival of human CD11b+ peripheral blood mononuclear cells and induce M2-type macrophage polarization. J. Biol. Chem. v. 284, p. 34342-34354, 2009.

ROSEN, S. D. Ligands for L-selectin: homing, inflammation, and beyond. Annual. Rev. Immunol. v 22, p. 129-56, 2004.

ROSENGARTH, A.; LUECKE, H. A calcium-driven conformational switch of the $\mathrm{N}$-terminal and core domains of annexin A1. J. Mol. Biol. v. 326, p. 1317-1325, 2003.

ROY, A.; FUNG, Y.; LIU, X.; PAHAN, K. Up-regulation of Microglial CD11b Expression by Nitric Oxide, J Biol Chem, v. 281(21), p. 14971-14980, 2006. 
RUBIO-PEREZ, J.; MORILLAS-RUIZ, J. A Review: Inflammatory Process in Alzheimer's Disease, Role of Cytokines, The Scientific World Journal, 2012.

RUPPRECHT, R.; RAMMES, G.; BAGHAI, T.C.; SCHÜLE, C.; NOTHDURFTER, C.; TROXLER, T.; GENTSCH, C.; KALKMAN, H.O.; CHAPERON, F.; UZUNOV, V.; McALLISTER, K.H.; BERTAINA-ANGLADE, V.; La ROCHELLE, C.D.; TUERCK,D.; FLOESSER, A. KIESE, B.; SCHUMACHER, M.; LANDGRAF, R.; HOLSBOER, F.; KUCHER, K. Translocator protein $(18 \mathrm{kD})$ as target for anxiolytics without benzodiazepine-like side effects. Science v. 325, p.490-493, 2009.

RUPPRECHT, R.; PAPADOPOULOS, V.; RAMMES, G.; BAGHAI, T. C.; FAN, J.; AKULA, N.; GROYER, G.; ADAMS, D.; SCHUMACHER, M. Translocator protein (18 $\mathrm{kDa}$ (TSPO) as a therapeutic target for neurological and psychiatric disorders. Nat. Rev. Drug. Discov., v. 9(12), p. 971-988, 2010.

SAKAI, M.; FONSECA, E.; DAGLI, M.; PALERMO-NETO, J. Diazepam effects on Ehrlich tumor growth and macrophage activity in mice. Life Sci, v. 78(16), p. 1777-83, 2006.

SALINA, A.; DIAS, F.; DEJANI, N.; NINO, V.; MEDEIROS, A. CBS33. Polarização de macrófagos M1/M2 pela fagocitose de células apoptóticas, Ver. Ciênc. Farm. Básica Apl., v. 35, supl 1, 2014.

SAURA, J.; TUSELL, J.; SERRATOSA, J. High-yield isolation of murine microglia by mild trypsinization, Glia, v. 44, p. 183-189, 2003.

SCANNELL M; FLANAGAN, M.; GODSON, C.; MADERNA, P. Annexin-1 and peptide derivatives are released by apoptotic cells and stimulate phagocytosis of apoptotic neutrophils by macrophages, J Immunol, 178, 4595, 2007.

SCARF, A.; AUMAN, K.; KASSIOU, M. Is there any correlation between binding and functional effects at the translocator protein (TSPO) (18kDa)? Curr Mol Med., v. 12(4), p. 387-97, 2012

SCARF, A., ITTNER, L. M.; KASSIOU, M. The translocator protein (18kDa): central nernous system disease and drug design. Journal os medical and pharmaceutical chemistry, 2009.

SCARF, A. M.; KASSIOU, M. The translocator protein. J. Nucl. Med., v. 52(6), p. 677680, 2013.

SCHULZ, C.PERDIGUERO, E.; CHORRO, L.; SZABO-ROGERS, H.; CAGNARD, N.; KIEDORF, K.; PRINZ, M.; WU, B.; JACOBSEN, S.; POLLARD, J.; FRAMPTON, J.; LIU, K.; GEISSMANN, F. A lineage of myeloid cells independent of Myb and hematopoietic stem cells. Science v.336,p. 86-90, 2012.

SCHREIBER, R.; PROSSNITZ, E.; COCHRANE, C.; BOKOCH, G. Domains of the human neutrophil $\mathrm{N}$-formyl peptide receptor involved in $\mathrm{G}$ protein coupling. Mapping with receptor-derived peptides. J Biol Chem, v. 269(1), p.326-31, 1994.

da SETTIMO, F.; TALIANI, S.; la MOTTA, C.; MARINI, A.; SALERMO, S.; BELLANDI, M.; NOVELLINO, E.; GRECO, G. COSIMELLI, B.; da POZZO, E.; SIMOLA, N.; MARTINI, C. Anxiolytic-like effects of N, N-dialkyl-2-phenylindol-3-ylglyoxylamides by 
modulation of translocator protein promoting neurosteroid biosynthesis, J. Med. Chem, v. 51, p. 5798-5806, 2008.

SHAFER, L. McNULTY, J. YOUNG, M. Brain activation of monocyte-lineage cells: involvement of interleukin-6. Neuroimmunomodulation, v. 10(5), p. 295, 2003.

SHAKED, I.; PORAT, Z.; GERSNER, R.; KIPNIS, J.; SCHWARTZ, M. Early activation of microglia as antigen-presenting cells correlates with $\mathrm{T}$ cell-mediated protection and repair of the injured central nervous system, J. Neuroimmunol., v. 146, p. 84, 2004.

SHASTRI, A.; BONIFATI, D.; KISHORE, U. Innate Immunity and Neuroinflammation, Mediators of Inflammation, v. 2013, 2013.

SHINSMON, J.; SHI, T.; RAJESH, R.; SHARMILI, V. Mesenchymal stem cells exert antiproliferative effect on lipopolysaccharide-stimulated BV2 microglia by reducing tumour necrosis factor- $\alpha$ levels, Journal of Neuroinflammation, v. 11, p. 149, 2014

SCHILLING, M., BESSELMANN, M., LEONHARD, C., MUELLER, M., RINGELSTEIN, E., KIEFER, R. Microglial activation precedes and predominates over macrophage infiltration in transient focal cerebral ischemia: a study in green fluorescent protein transgenic bone marrow chimeric mice. Exp. Neurol. v. 183, p. 25-33. 2003.

SELVARAJ, V.; STOCCO, D. The changing landscape in translocator protein (TSPO) function, Trends Endocrinol Metab, 2015.

SIEGER, D.; MORITZ, C.; ZIEGENHALS, T.; PRYKHOZHIJ, S. \& PERI, F. Long-range Ca2+ waves transmit brain-damage signals to microglia. Dev. Cell, v. 22, p. 1138-1148, 2012.

SIMERLY, C. R.; MORENO, R.; RAMALHO-SANTOS, J.; HEWITSON, L.; SCHATTEN, G. Confocal imaging of structural molecules in mammalian gametes. In A Laboratory Guide of the Mammalian Embryo (David K. Gardner \& Michelle Lane, editores). Oxford University Press, pp. 165-183, 2003.

SIMONE, M.; TAN, Z. The role of inflammation in the pathogenesis of delirium and dementia in older adults: a review. CNS neuroscience \& therapeutics v. 17, p. 506-513, 2011.

SINNIAH, A.; YAZID, S.; PERRETTI, M.; SOLITO, E.; FLOWER, R. The role of the Annexin-A1/FPR2 system in the regulation of mast cell degranulation provoked by compound 48/80 and in the inhibitory action of nedocromil. Int Immunopharmacol. 32:8795, 2016

SLOWIK, A.; MERRES, J.; ELFEGEN, A.; JANSEN, S.; MOHR, F.; WRUCK, C.; PUFE, T.; BRANDENBURG, L. Involvement of formyl peptide receptors in receptor for advanced glycation end products (RAGE)--andamyloid beta 1-42-induced signal transduction in glial cells. Mol Neurodegener. v. 20, p. 7:55, 2012.

STELLATO, C. Post-transcriptional and nongenomic effects of glucocorticoids. Proc. Am. Thorac. Soc., v. 1 (3), p. 255-263, 2004

SOKAL, R.; ROHLF, F. WH Free Company, New York, USA, 1995 
SOLITO, E.; RAGUENES-NICOL, C.; COUPADE, C.; BISAGNI-FAURE, A.; RUSSEMARIE, F. U937 cells deprived of endogenous annexin 1 demonstrate anincreased PLA2 activity, British Journal of Pharmacology, v. 124, p. 1675-1683, 1998.

SOLITO, E.; KAMAL, A.; RUSSO-MARIE, F.; BUCKINGHAM, J.; MARULLO, S.; PERRETTI, M. A novel calcium-dependent proapoptotic effect of annexin 1 on human neutrophils. FASEB J, v. 17, p. 1544-1546, 2003.

SOLITO, E.; CHRISTIAN, H.; FESTA, M.; MULLA, A.; TIERNEY, T.; FLOWER, R.; BUCKINGHAM, J. Post-translational modification plays an essential role in the translocation of annexin A1 from the cytoplasm to the cell surface. FASEB J. v. 20, p. 1498-1500, 2006.

SOLITO, E.; SASTRE, M. Microglia function in Alzheimer's disease. Front. Pharmacol., v. 10 , p. $3-14 ; 2012$.

SPENCER, B.; MASLIAH, E. Immunotherapy for Alzheimer's disease: past, present and future. Front Aging Neurosci. 6:114. 2014.

STOEBNER, P. E.; CARAYON, P.; PENARIER, G.; FRE'CHIN, N.; BARNE'ON, G.; CASELLAS, P.; CANO, J. P.; MEYNADIER, J.; MEUNIER, L. The expression of peripheral benzodiazepine receptors in human skin: the relationship with epidermal cell differentiation, British Journal of Dermatology, V. 140, p. 1010 - 1016, 1999.

STRUSBAUGH, H.; ROSEN, S. A potential role for annexin 1 as a physiologic mediator of glucocorticoid-induced L-selectin shedding from myeloid cells. J Immunol, v. 166, p. 6294-6300, 2001

SURIDJAN, I.; POLLOCK, B.; VERHOEFF, N.; VOINESKOS, A.; CHOW, T.; RUSJAN, P.; LOUBAUGH, N.; HOULE, S.; MULSANT, B.; MIZRAHI, R. In Vivo imaging of grey and white matter neuroinflammation in Alzheimer's disease: A positron emission tomography study with a novel radioligand, [18F]-FEPPA. Mol. Psychiatry, 20, 15791587, 2015.

TAN, J.; TOWN, T.; PARIS, D.; MORI, T.; SUO, Z.; CRAWFORD, F.; MATTSON, M.; FLAVELL, R.; MULLAN, M. Microglial activation resulting from CD40- CD40L interaction after beta-amyloid stimulation. Science, v. 286, p. 2352-2355. 1999.

TAKEDA, K.; AKIRA, S. TLR signaling pathways. Semin Immunol 16:3-9, 2006.

TERADA, T.; YOKOKURA, M.; YOSHIKAWA, E.; FUTASUBASHI, M.; KONO, S.; KONISHI, T.; MIYAJIMA, H.; HASHIZUME, T.; OUCHI, Y. Extrastriatal spreading of microglial activation in Parkinson's disease: A positron emission tomography study. Ann. Nucl. Med., 30, 579-587, 2016.

TERRANDO, N.; MONACO, C.; MA, D.; FOXWELL, B.; FELDMANN, M. Tumor necrosis factor-alpha triggers a cytokine cascade yielding postoperative cognitive decline. Proceedings of the National Academy of Sciences of the United States of America, v. 107, p. 20518-20522, 2010.

THAL, S.; NEUHAUS, W. The Blood-Brain Barrier as a Target in Traumatic Brain Injury Treatment, Archives of Medical Research, v. 45 (8), p. 698-710, 2014. 
THOMSON, C.; McCOLL, A.; CAVANAGH, J.; GRAHAM, G. Peripheral inflammation is associated with remote global gene expression changes in the brain. $J$ Neuroinflammation, v. 11:73, 2014.

TREMBLAY, M., STEVENS, B., SIERRA, A., WAKE, H., BESSIS, A., NIMMERJAHN, A. The role of microglia in the healthy brain. J. Neurosci. v. 31, p. 16064-16069, 2011.

TROTTIER, M.; NEWSTED, M.; KING, L.; FRAKER, P. Natural glucocorticoids induce expansion of all developmental stages of murine bone marrow granulocytes without inhibiting function. Proc Natl Acad Sci U S A v. 105(6), p.2028-33, 2008.

VASSALLI, P. The pathophysiology of tumor necrosis factors. Annu Rev Immunol, v. 10, p. 411-452, 1992.

VARRONE, A.; OIKONEN, V.; FORSBERG, A.; JOUTSA, J.; TAKANO, A; SOLIN, O; HAAPARANTA-SOLIN, M.; NAG, S.; NAKAO, R.; AL-TAWIL, N.; WELLS L, RABINER, E, VALENCIA, R; SCHULTZE-MOSGAU, M.; THIELE, A.; VOLLMER, S.; DYRKS, T.; LEHMANN L; HEINRICH, T.; HOFFMANN, A.; NORDBERG, A.; HALLDIN, C.; RINNE, J. "Positron emissiontomography imaging of the 18-kDa translocator protein (TSPO) with [18F]FEMPA in Alzheimer's disease patients and control subjects,". Eur J Nucl Med Mol Imaging. 42(3):438-46. 2015.

VENNETI, S.; LOPRESTI, B.; WILEY, C. The peripheral benzodiazepine receptor in microglia: from pathology to imaging, Prog Neurobiol. v. 80(6), p. 308-322, 2006.

VEREMEYKO, T.; SIDDIQUI, S.; SOTNIKOV, I.; YUNG, A.; PONOMAREV, E.; IL-4/IL13-Dependent and Independent Expression of miR-124 and Its Contribution to M2 Phenotype of Monocytic Cells in Normal Conditions and during Allergic Inflammation, PLoS One., v. 16, p. 8(12), 2013.

VONG, L.; D'ACQUISTO, F.; PEDERZOLI-RIBEIL, M.; LAVAGNO, L.; FLOWER, R.; WITKO-SARSAT, V.; PERRETTI, M. Annexin 1 cleavage in activated neutrophils: a pivotal role for proteinase 3. J. Biol. Chem. v. 282, p. 29998-30004, 2007.

de VRIES, H.; BLOM-ROOSEMALEN, M.; van OOSTEN, M.; de BOER, A.; van BERKEL, T.; BREIMER, D.; KUIPER, J. The influence of cytokines on the integrity of the blood-brain barrier in vitro, Journal of Neuroimmunology, v. 64, p. 37-43, 1996.

WALTHER, A.; RIEHEMANN, K.; GERKE, V. A novel ligand of the formyl peptide receptor: annexin I regulates neutrophil extravasation by interacting with the FPR. Mol. Cell v. 5, p. 831-840, 2000.

WANG, M.; WANG, X.; ZHAO, L.; MA, W.; WONG, W. Macroglia-Microglia Interactions via TSPO Signaling Regulates Microglial Activation in the Mouse Retina, J Neurosci, v. 34(10), p. 3793-3806, 2014

WANG, W; ZHANG, L.; ZHANG, X.; XUE, R; LI, L.; ZHAO, W.; FU, Q.; MI, W.;LI, Y. Lentiviral-Mediated Overexpression of the $18 \mathrm{kDa}$ Translocator Protein (TSPO) in the Hippocampal Dentate Gyrus Ameliorates LPS-Induced Cognitive Impairment in Mice, Front Pharmacol. ; 7: 384. 2016.

WANG, W.; TAN, M.; YU, J.; TAN, L. Role of pro-inflammatory cytokines released from microglia in Alzheimer's disease, Ann Transl Med, v. 3(10), p. 136, 2015. 
WEI, X.; WEI, X.; CHEN, F; ZANG, Y.; XIN1, W.; ZHOU, L.; LIU, X. The Upregulation of Translocator Protein (18 kDa) Promotes Recovery from Neuropathic Pain in Rats, The Journal of Neuroscience, v. 33(4), p, 1540-51, 2013.

WEIN, S.; FAUROUX, M.; LAFFITTE, J.; de NADAI, P.; GUAINI, C.; PONS, F.; COMERA, C. Mediation of annexin 1 secretion by a probenecid-sensitive ABC-transporter in rat inflamed mucosa. Biochem. Pharmacol. v. 67, p. 1195-1202, 2004.

WESTMAN, G; BERGLUND, D; WIDEN, J; INGELSSON, M; KORSGREN, O; LANNFELT, L; SEHLIN, D.; LIDEHALL, A; ERIKSSON, B. Increased inflammatory response in cytomegalovirus seropositive patients with Alzheimer's disease. PLoS One. 9(5):e96779, 2014

WOODFIN, A.; VOISIN, M.; NOURSHARGH, S. PECAM-1: a multi-functional molecule in inflammation and vascular biology, Arterioscler. Thromb. Vasc. Biol. v. 27 (12), p. 2514-2523, 2007.

WU, H.; LIU, Y.; LI, H.; CHEN, C.; DOU, Y.; LOU, H.; HO, M.; LI, X.; GAO, Z.; DUAN, S. Analysis of microglial migration by a micropipette assay, Nature Protocols, v. 9(2), 2014.

WYNN, T.; CHAWLA, A.; POLLARD, J. Macrophage biology in development, homeostasis, and disease. Nature, v. 496, p. 445-455, 2013

WYSS-CORAY, T.; MUCKE, L. Inflammation in Neurodegenerative Disese -a Double Edged Sword. Neuron, v. 35, p.419-432, 2002.

YANG, Y.; MORAND, E.; GETTING, S.; PAUL-CLARK, M.; YONA, S.; HANNON, R.; BUCKINGHAM, J.; PERRETTI, M.; FLOWER, R. Modulation of inflammation and response to dexamethasone by Annexin 1 in antigen-induced arthritis. Arthritis Rheum. V. 50, p. 976-984, 2004.

YI, M.; ZHANG, E. KANG, J.; SHIN, Y.; BYUN, J.; OH, S.; SEO, J.; LEE, Y.; KIM, D. Expression of CD200 in alternative activation of microglia following an excitotoxic lesion in the mouse hippocampus, Brain Res, v. 1481, p. 90-6, 2012.

YOUNG, K; HIRST, W.; SOLITO, E.; WILKIN, G. De novo expression of lipocortin-1 in reactive microglia and astrocytes in kainic acid lesioned rat cerebellum. Glia, 26, 333343. 1999.

YOUSEFI, O.; WILHELM, T.; KUHNY, M. KRATZ, F.; HILDENBRAND, B.; HUBE, M. The 1,4-benzodiazepine Ro5-4864 (4-chlorodiazepam) suppresses multiple proinflammatory mast cell effector functions, Cell Commun Signal, v. 11, p. 13, 2013.

ZAVALA, F.; LENFANT, M. Peripheral benzodiazepine enhance the respiratory burst of macrophage-like P388D1 cells stimulated by arachidonic acid. Int. Immunopharmacol., v.9, p. 269-274, 1987.

ZHANG, Q; HENG, Y.; YUAN, Y; CHEN, N. Pathological -synuclein exacerbates the progression of Parkinson's disease through microglial activation. Toxicol. Lett. 265, 3037, 2016a. 
ZHANG, H; MA, L.; YIN, Y; DONG, L; XU, B. Over-expression of TSPO in the hippocampal CA1 area alleviates cognitive dysfunction caused by lipopolysaccharide in mice. Brain Res, 1646, 402-9, 2016b.

ZHAO, Y.; YU, J.; LI, Q.; MA, C.; LU, C.; XIAO, B. TSPO-specificligand Vinpocetine exerts a neuroprotective effect by suppressing microglial inflammation. Neuron Glia Biol v. 7, p. 187-197, 2011.

ZHENG, J.; BOISGARD, R.; SIQUIER-PERNET, K.; DECAUDIN, D.; DOLLÉ, F.; TAVITIAN, B. Differential expression of the $18 \mathrm{kDa}$ translocator protein (TSPO) by neoplastic and inflammatory cells in mouse tumors of breast cancer, Mol. Pharm., v. 8(3), p. 823-832, 2011.

ZHOU, X.; SPITTAU, B.; KRIEGLSTEIN, K. TGF $\beta$ signalling plays an important role in IL4-induced alternative activation of microglia. J Neuroinflammation, v. 9, p. 210, 2012.

ZHU, J.; QIAN, W.; WANG, Y.; GAO, R.; WANG, J.; XIAO, H. Involvement of mitogenactivated protein kinase and NF-KB signaling pathways in perfluorooctane sulfonic acidinduced inflammatory reaction in BV2 microglial cells. J Appl Toxicol, in press 2017

ZHU, Y; CHEN, X.; LIU, Z.; PENG, Y.; QIU, Y. Interleukin-10 Protection against Lipopolysaccharide-Induced Neuro-Inflammation and Neurotoxicity in Ventral Mesencephalic Cultures, Int. J. Mol. Sci., v. 17, p. 25, 2016.

ZIPP, F. AKTAS, O. The brain as a target of inflammation: common pathways link inflammatory and neurodegenerative diseases. Trends Neurosci, v. 29, p. 518-527, 2006.

ZOPPO, G., MILNER, R., MABUCHI, T., HUNG, S., WANG, X., BERG, G. Microglial activation and matrix protease generation during focal cerebral ischemia. Stroke v. 38, p.646-651. 2007. 


\section{7 - ANEXOS}

\section{ANEXO 1 -}

Estratégia de Gate para avaliar a média da intensidade de fluorescência do receptor TSPO

Controle - anticorpo secundário:
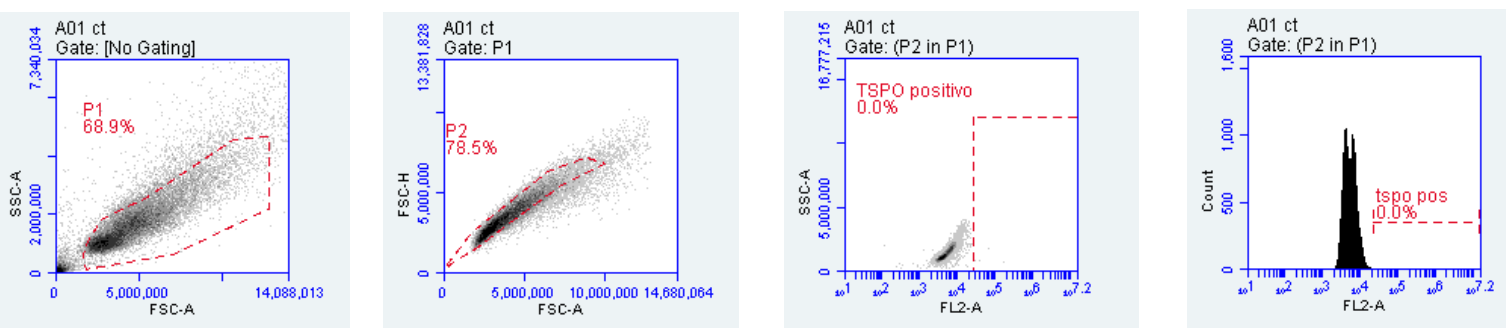

Amostras:
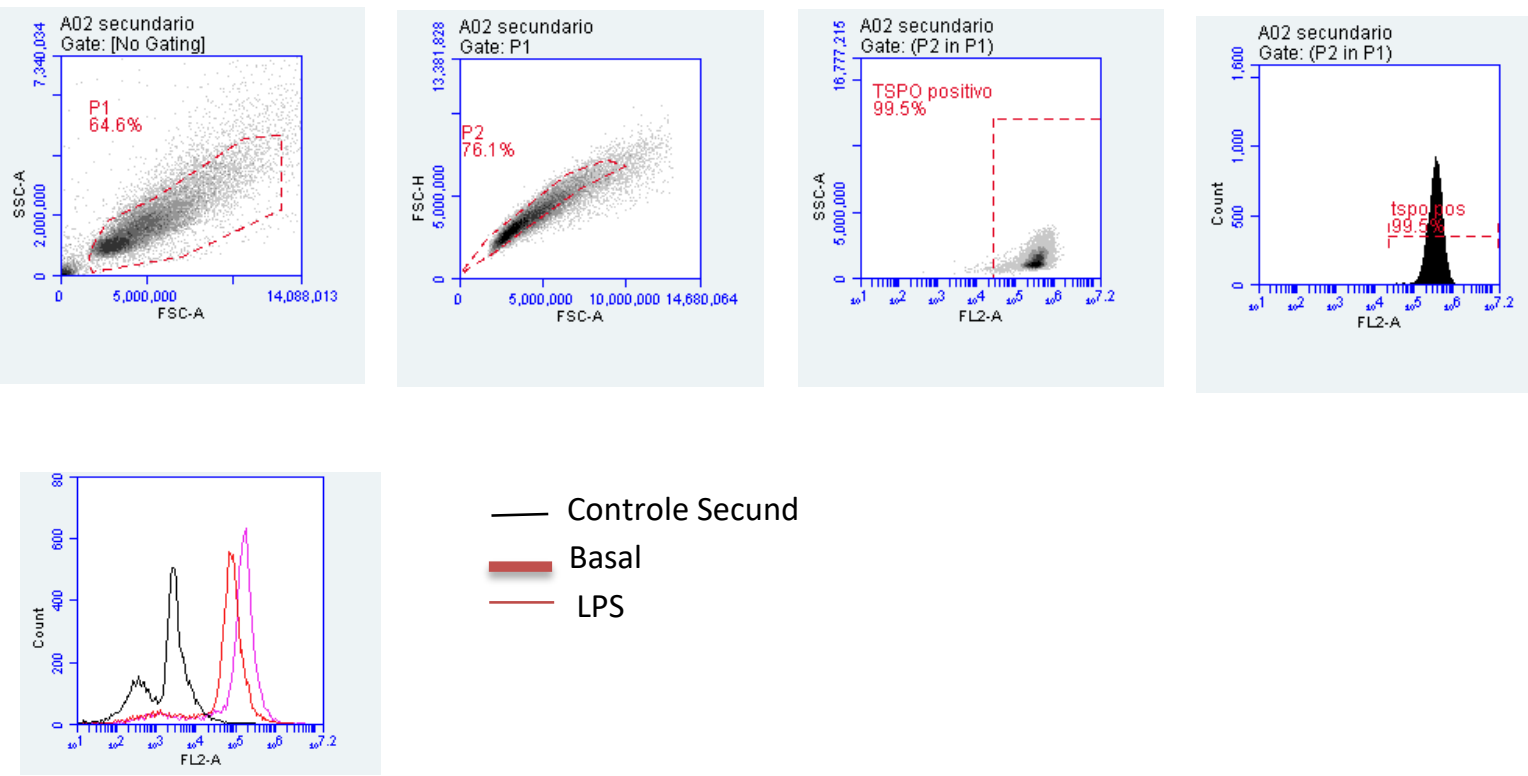

Controle Secund
Basal
LPS 


\section{ANEXO 2 -}

Estratégia de Gate para avaliar a porcentagem de células expressando CD40 e CD36

Controle - anticorpo primário:
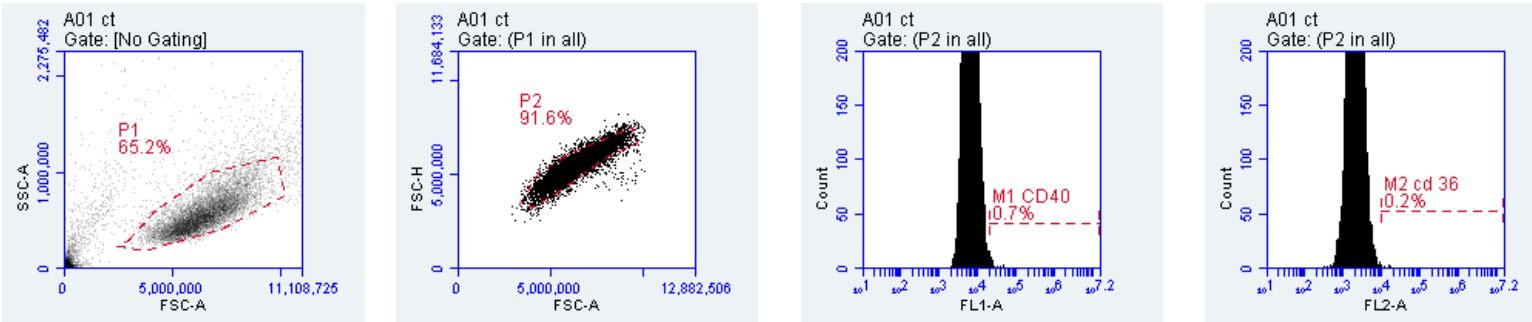

Amostras:
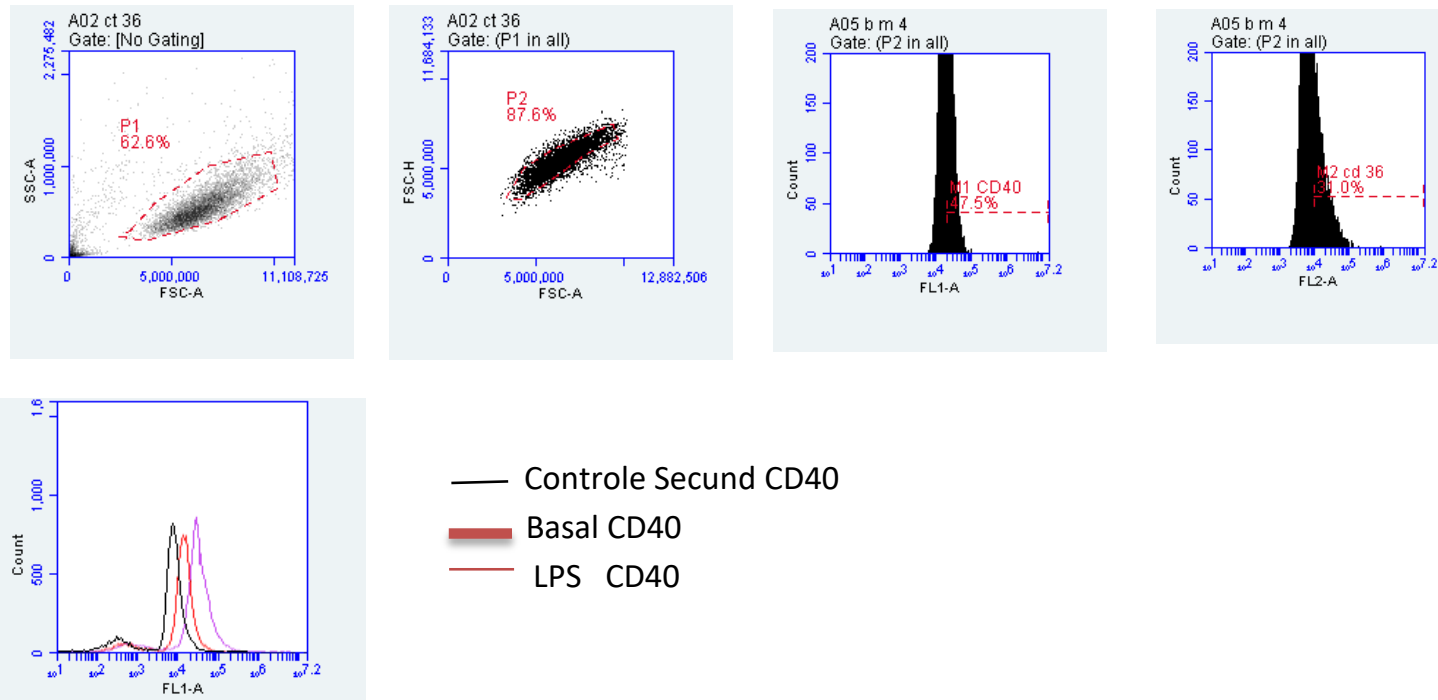

_ Controle Secund CD40

Basal CD40

LPS CD40

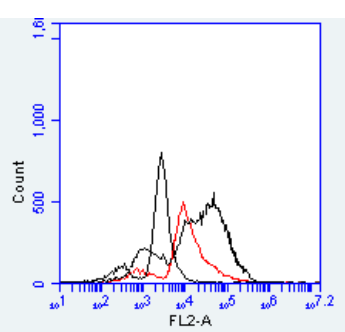

— Controle Secund CD36

Basal CD36

LPS CD36 


\section{ANEXO 3 -}

Estratégia de Gate para avaliar a taxa de fagocitose em células TSPO-/-

Controle:
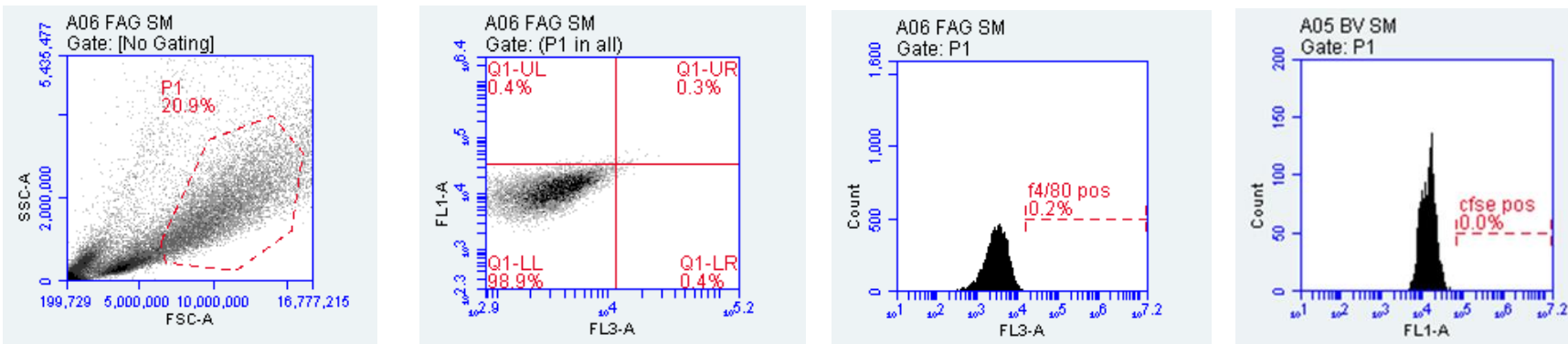

Amostras:
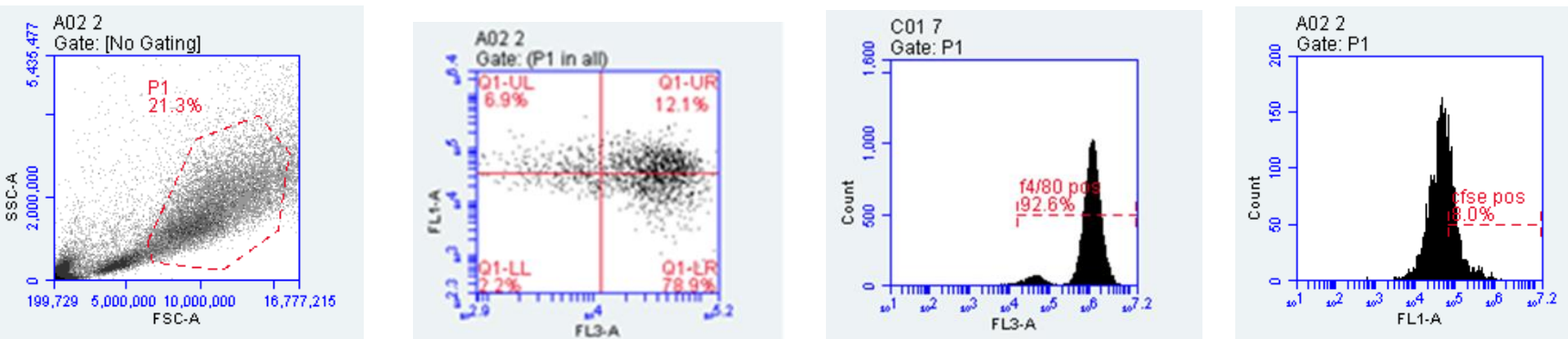